\title{
Entwicklungsgeschichtliche Untersuchungen an zentrischen Diatomeen
}

\author{
V. Bau und Lebenszyklus von Cbaetoceros didymum, mit Beobachtungen \\ über einige andere Arten der Gattung
}

\author{
H. A. v. Stosch, G. Theil \& K. V. Kowallik \\ Botanisches Institut der Universität Marburg, \\ Marburg/Labn, Bundesrepublik Deutschland
}

\begin{abstract}
Ontogenetic investigations on centric diatoms. V. Morphology and life history of Chaetoceros didymum, with observations on some other species of the genus. The marine diatom. Chaetoceros didymum EHRENBERG has been studied with respect to cell morphology, fine structure of the frustule, and life history. Additional observations were made on other Chatetoceros species grown in culture. Co-existence of linear colonies with both intercellular spaces (foramina) and long stiff bristles is mediated by two morphogenetic peculiarities. After cell division the bristles grow out from the apices of the new valves and pass through preformed "bristle openings", two of which occur in each girdle. They cross each other and fuse inseparably, thus bridging the foramina bilaterally. The irreversibility of cell junctions established in this manner results in two types of special "colony-separation-divisions": (1) An equal, but heterovalvate division forming a pair of early dehiscing colony-end-valves; (2) a rare acytokinetic and unequal division. In resting spore formation a heterovalvate division gives rise to a pair of specialized spore-mother-cell hypothecae. Two consecutive acytokineses inside either mother cell follow, the first of which produces the spore epivalvae, the second the spore hypovalvae. In spore germination ustally two consecutive acytokineses exchange the specialized valves of the spore by colony-end-valves, thus giving rise to a one-celled colony. C. didymm is monoecious, though most of the sexualized colonies are either completely male or contain vegetative and female cells. The protoplast of the spermatogonangium is usually divided into 8 naked spermatogonia by 3 steps of diploid mitoses, the first of which may or may not be followed by deposition of a pair of rudimentary valves. The spermatocytes undergo a swelling phase, which forces the parental frustule open; thereafter, 2 steps of meiotic nuclear and cell divisions follow; these form 4 uniflagellate and, normally, monoplastidic male gametes (spermia). In C. eibenii with non-dehiscent parental frustules, the spermia are released via bristle openings. The oogonia contain one functioning and two pycnotic nuclei as a result of meiosis. The spermia, however, may have entered the oogonium via bristle openings, possibly already at zygotene, though nuclear fusion is delayed until the egg has become mature. Thereafter, the zygote leaves the oogonial frustule through one of the bristle openings to which it still remains attached. In its isometric phase the zygote is surrounded by the fertilisation membrane. Its later anisometric growth is supported and probably directed by a system of silica rings, the preperizonium, which, in contrast to the otherwise comparable perizonium of pennate diatoms, forms a common layer with the surrounding scale-bearing fertilisation membrane. Finally, two consecutive acy tokinetic (metagamic) mitoses induce the deposition of the two valves of the "Erstlingszelle" inside the auxospore envelope, which is ruptured during these last events and thus liberates the new enlarged cell.
\end{abstract}




\section{EINLEITUNG}

Die Gattung Chaetoceros ist die erste unter den Centrales gewesen, bei der wahrscheinlich wurde (PERSIDSKr 1929), daß der Auxosporenbildung andere als rein vege-tative Vorgänge vorausgehen. PERsidski kam hier wie später (1935) bei Melosira varians zu der Auffassung, die in der Auxosporen-Mutterzelle stattfindende Meiosis führe zu einer Autogamie von zwei der, wie er glaubte, durch sie produzierten vier Kerne. Für die Melosira-Art (v. STOsCh 1951) wurde inzwischen nachgewiesen, daß es sich in Wirklichkeit - es trift dies auch für Persidskis Material zu - um eine Allogamie gehandelt hatte. Bei einigen anderen Centricae (Gertler 1952, v. Stosch 1954, 1956, v. STOSCH \& DREBes 1964) liegen grundsätzlich ähnliche Verhältnisse vor. Doch bestanden bei Chaetoceros bereits vor PERsidskr Hinweise auf das Vorkommen einer Allogamie durch Beobachtungen Wents (1925, zitiert nach GeITLER 1932, p. 11), auf die wir zurückkommen.

Heute lassen sich viele Chaetoceros-Arten gut kultivieren, außerdem wurden die Methoden der Lebendbeobachtung verbessert. Wir werden daher im folgenden an Laboratoriumskulturen zeigen können, daß Chaetoceros didymum Ehrenberg tatsächlich oogam ist. Die Art ist trotz ihrer geringen Größe gegenüber anderen Centrales - in der Gattung selbst nimmt sie in dieser Hinsicht eine mittlere Stellung ein - nicht ungünstig für die Beobachtung von Kern- und Zellteilung, der Befruchtung im Leben und zahlreicher anderer Vorgänge.

Die Gattung Chaetoceros zeichnet sich in der Mehrzahl ihrer Arten durch das Vorkommen in Zellverbänden aus. Ihre Kolonien unterscheiden sich jedoch von denjenigen der meisten anderen Diatomeen dadurch, daß die an den Apikalenden ihrer Valven entspringenden beiden Borsten mit denjenigen der Nachbarzelle durch Kieselausscheidungen untrennbar verwachsen sind. Diese Kolonien stellen, wie Sснӥтт (1888) bereits schilderte, durch ihre abweichend gestalteten Endzellen auch morphologisch Einheiten höherer Ordnung dar. Das macht besondere Mechanismen der Kolonietrennung notwendig, die ScHüt'T ebenfalls schon beobachtete und über die auch wir berichten werden.

Schließlich ist die Gattung und unsere Art interessant durch das Vorkommen von Dauersporen. Die Bildung dieser Sporen untersuchte wieder als erster SснӥтT und nach ihm mehrere andere Autoren, unter diesen besonders Meunier (1910, 1913); doch war über die cytologischen Vorgänge bei Chaetoceros-Arten, abgesehen von unseren Angaben (v.STOSCH, in ETTL et al. 1967, hier Literatur über Dauersporen, sowie v. STOsCry \& Kowallik 1969) bisher nichts bekannt. Das gleiche gilt für die Dauersporenkeimung, über welche bei Chaetoceros nur wenige ältere Beobachtungen vorliegen (GRAN 1908, Lohmann 1920, Micharlova 1962). Auch diese Vorgänge konnten im Leben verfolgt und cytologisch geklärt werden. Neuerdings wurde aber durch DReBEs (1962) eine vollständige Schilderung des Lebenszyklus von Bacteriastrum byalinum gegeben, die auch die Sporenkeimung einschließt. Darin, wie auch in zahlreichen weiteren entwicklungsgeschichtlichen Abläufen, sind sich Bacteriastrum byalinum und C. didymum ähnlich. Ergänzend zu den Beobachtungen von C. didymum werden solche an einigen anderen Arten der Gattung mitgeteilt. 


\title{
MATERIAL UND METHODIK
}

\author{
Objekte
}

Die meisten der untersuchten Chaetoceros-Arten stammen aus dem Plankton der Nordsee (List und Helgoland)* und wurden in Kulturen gehalten (Tab. 1). Wirklich eingehend beschäftigten wir uns aber nur mit Chatoceros didymum.

$\mathrm{Zu}$ Tabelle 1 ist folgendes zu bemerken: nur C. didymum Klon II und C. gracile Klon I wurden „freiwillig" aufgegeben. C. didymum Klon III, C. spec. und C. costatum konnten je einmal nach Absinken der Zellgrößen durch vegetative Zellvergrößerung regeneriert werden. Diese und die übrigen nicht weitergeführten Stämme gingen zuletzt entweder dadurch ein, daß ihre Vitalität nach Absinken der Zellgröße zu gering wurde, oder weil die aus Auxosporen gezogenen $\mathrm{F}_{1}$-Klone keine sexuellen Nachkommen mehr lieferten und daher schließlich in der gleichen Weise ausstarben, so auch unser Klon III von C. didymum. Es ist eine allgemeine Erfahrung bei allogamen Diatomeen, daß sexuelle Nachkommen-Klone häufig nicht fertil sind. Man muß daher genügend zahlreiche $\mathrm{F}_{1}$-Stämme weiterführen, um einige sexuell weiter fortpflanzungsfähige zu erhalten.

\section{Kulturmethoden}

Chatoceros didymum wurde in Schalen aus Jenaer Geräteglas in der früher (v. STоSCh \& Drebes 1964) angegebenen Nährlösung auf der Grundlage von Nordseewasser aus List/Sylt kultiviert, das mit Nitrat, Phosphat, Kieselsäure, Mangan, Eisen und Athylendiamintetraessigsäure aufgedüngt ist. In diesen Nährlösungen war die Produktion beträchtlich, wurde aber, wie uns schien, durch ein Vitamin begrenzt. Nach Entfernen der natürlichen Vitamine des Seewassers durch Kohlebehandlung zeigte sich tatsächlich, daß ein Wachstum ausblieb und nur nach Zugabe eines Vitamingemisches wieder zu erhalten war. Wirksam ist, wie sich durch weitere Versuche herausstellte, nur Cobalamin. Dieses oder eine Mischung von Vitamin $B_{12}$, Vitamin $B_{1}$ und Biotin wurde bei den weiteren Versuchen der Nährlösung zugesetzt. Nach diesen Zugaben wird in unseren Lösungen Kieselsäure zum wachstumsbegrenzenden Faktor, so daß die $\mathrm{SiO}_{2}-\mathrm{Menge}$ in den weiteren Versuchen erhöht wurde. Die Kulturen standen gewöhnlich im 16-Stunden-Tag bei $15^{\circ} \mathrm{C}$ und wurden mit Leuchtstoffröhren Osram 40 W/32 unter 400 bis 700 R-Lux (vgl. v. STOsCH \& Drebes 1964) beleuchtet. Die Alge läßt sich jedoch noch bei $3^{\circ} \mathrm{C}$ und bis mindestens $21^{\circ} \mathrm{C}$ herauf kultivieren. Tiefe Temperatur $\left(3^{\circ}\right.$ oder $6^{\circ} \mathrm{C}$ ) bei geringer Beleuchtungsstärke (50-100 R-Lux) erlaubt es, die Teilungsrate der Stämme herabzusetzen und diese dadurch länger in der erwünschten Zellbreite zu halten. Auf Angaben über die Kultur der übrigen Arten verzichten wir.

* Nur die Angaben über C. armatum West und C. peruvianum var. gracile SCHRöDER beziehen sich auf Material aus Australien. Ersteres wurde uns von Dr. S. McGrtu freundlichst überlassen und wie die letztere, von v. STOSCF isolierte Art, durch Frl. S. Scribano weiterkultiviert, dann von uns (v. Sтовсн) übernommen. 
Tabelle 1

In unserem Laboratorium kultivierte Chatoceros-Arten. Beobachtet wurden: Dauersporen $=$ $\mathrm{D}$, Dauersporen-Keimung $=\mathrm{DK}$, Auxosporen $=\mathrm{A}$, Spermien $=\mathrm{S}$, Befruchtung $=\mathrm{B}$, Vegetative Zellvergrößerung (vgl. v. Stosch 1965) $=$ V. Bei der Zahl der in Kultur erhaltenen Generationen ist die ursprünglich isolierte Generation mitgezählt.

\begin{tabular}{|c|c|c|c|c|}
\hline Art & Herkunf & Dauer der Kultur & $\begin{array}{l}\text { Genera- } \\
\text { tionen }\end{array}$ & Beobachtet \\
\hline $\begin{array}{l}\text { C. compressum } \\
\text { LAUDER } 1864 \\
\text { Klon I }\end{array}$ & List/Sylt & 15. 6.1954-16. 2.1963 & 4 & $\mathrm{D}, \mathrm{A}$ \\
\hline $\begin{array}{l}\text { C. compressum } \\
\text { Kion II }\end{array}$ & Helgoland & $26.11 .1963-2.7 .1964$ & 1 & $\mathrm{D}, \mathrm{DK}$ \\
\hline $\begin{array}{l}\text { C. costatum } \\
\text { PAvicL. } 1911\end{array}$ & Helgoland & 26. 8.1963-17.12.1966 & 1 & $\mathrm{D}, \mathrm{V}$ \\
\hline $\begin{array}{l}\text { C. didymum } \\
\text { EHRENBERG } 1854 \\
\text { Klon I }\end{array}$ & List & 23. 9.1953-25. 1.1957 & 1 & - \\
\hline $\begin{array}{l}\text { C. didymum } \\
\text { Klon II }\end{array}$ & List & 23. 9.1953-2. 4.1955 & 1 & - \\
\hline $\begin{array}{l}\text { C. didymum } \\
\text { Klon III }\end{array}$ & List & 26. $8.1965-1.2 .1972$ & 4 & $\begin{array}{l}\mathrm{D}, \mathrm{DK}, \mathrm{S}, \mathrm{B}, \\
\mathrm{A}, \mathrm{V}\end{array}$ \\
\hline $\begin{array}{l}\text { C. eibenii } \\
\text { Grunow } 1881 \\
\text { Klon I }\end{array}$ & List & 21. $8.1953-8.8 .1958$ & 2 & $\begin{array}{l}\text { S, B, A (D), } \\
\text { DK }\end{array}$ \\
\hline $\begin{array}{l}\text { C. eibenii } \\
\text { Grunow } 1881 \\
\text { Klon II }\end{array}$ & $\begin{array}{l}\text { Wenningstedt/ } \\
\text { Sylt }\end{array}$ & 16. 9.1970-heute & 2 & $\begin{array}{l}\text { S, B, A (D), } \\
\text { DK }\end{array}$ \\
\hline $\begin{array}{l}\text { C. teres } \\
\text { Cleve } 1896\end{array}$ & List & 30. $5.1955-30.7 .1959$ & 1 & $\mathrm{D}, \mathrm{V}$ \\
\hline $\begin{array}{l}\text { C. gracile } \\
\text { OsTENF. } 1893 \\
\text { Klon I }\end{array}$ & List & 4. 4. $1955-21.6 .1956$ & $?$ & - \\
\hline $\begin{array}{l}\text { C. gracile } \\
\text { OsTENF. } 1893 \\
\text { Klon II }\end{array}$ & List & 4. 4.1955-heute & $?$ & - \\
\hline $\begin{array}{l}\text { Chaetoceros spec. } \\
\text { (Stenocincta) }\end{array}$ & Helgoland & 5. 9.1965-11. 4. 1968 & 1 & $\mathrm{~V}$ \\
\hline $\begin{array}{l}\text { C. protuberans } \\
\text { var. nivalii } \\
\text { nov. var." }\end{array}$ & List & $5.11 .1968-18.12 .1969$ & 1 & $\mathrm{D}, \mathrm{DK}$ \\
\hline $\begin{array}{l}\text { C. armatum } \\
\text { WEST } 1860\end{array}$ & $\begin{array}{l}\text { Port Fairy, } \\
\text { Victoria, } \\
\text { Australien }\end{array}$ & $\begin{array}{l}\text { übernommen: } \\
9.10 .1970 \text {-heute }\end{array}$ & 2 & $S, A$ \\
\hline $\begin{array}{l}\text { C. peruvianum } \\
\text { var. gracile } \\
\text { SCHEÖDER } 1900\end{array}$ & $\begin{array}{l}\text { Port } \\
\text { Philipp Bay } \\
\text { Vic., Australien }\end{array}$ & 13. 4. 1970-heute & 2 & $\mathrm{~S}, \mathrm{~A}$ \\
\hline
\end{tabular}




\section{Mikroskopische Untersuchung}

Die Lebendbeobachtungen konnten nur in einem Falle, der Dauersporenkeimung, direkt in der Kulturschale mit der Tauchimmersion (vgl. v. STOSCH \& DREBEs) durchgeführt werden. Da sich die sperrigen und spezifisch leichten Kolonien in der Kulturschale nicht am Ort halten lassen, mußten alle übrigen Entwicklungsabläufe in einfachen Kammern folgender Herstellung und Anwendung untersucht werden: Auf einen Objektträger wurden in etwa $20 \mathrm{~mm}$ Abstand zwei Glasstreifen oder Glasfäden von. $250 \mu \mathrm{m}$ bzw. $350 \mu \mathrm{m}$ Dicke mit Epoxidharz („Uhu-plus“) gekittet. Die Objektträger wurden danach, ebenso wie die verwendeten Deckgläser, zum Auslaugen in Seewasser aufbewahrt und vor Gebrauch mit destilliertem Wasser gespült und getrocknet. Zwischen die Stïtzen des Objektträgers wurde dann eine passende Menge Kulturflüssigkeit mit den Chaetoceros-Kolonien gebracht und das Deckglas aufgelegt. Das Präparat ist brauchbar, wenn die Flüssigkeit den Deckglasrand an keiner Stelle erreicht, die Tropfen also nicht zu groß waren. Danach wird das Deckglas mit Vaseline umrandet. War die Kultur nicht zu dicht, so führten die Zellen über 24 Stunden oder auch länger alle Lebensprozesse weitgehend normal durch.

Die Beobachtungen wurden meist mit einer auf Gebrauch mit Deckglas korrigierten Wasserimmersion 50/1,0 durchgeführt, die sich durch hohen Arbeitsabstand auszeichnet*. Diese erlaubt es, auch die $350 \mu \mathrm{m}$ tiefe Kammer bis zum Grunde hin auszufocussieren. Unter dem Mikroskop erhält das Präparat durch eine Leuchtstoffröhre von außen so viel Licht wie die Ausgangskultur am Standort. Außerdem wurde das Durchlicht in Objekthöhe auf den gleichen Betrag eingestellt. Das Außenlicht sorgte dafür, daß die nicht unter Beobachtung stehenden Zellen weiter assimilieren können, das Durchlicht entsprechend für die unter Beobachtung stehenden Zellen. Auf diese Weise konnte in einer Beobachtungsserie mehr als eine Kolonie laufend verfolgt werden. Das Filmmaterial (AGFA Copex Ortho) wurde mit einem Blitzgerät (Ukatron UN 60) der Firma Zeiss, Oberkochen, belichtet.

Für cytologische Präparate wurde im allgemeinen in Bouin-Seewasser-Gemisch (15 Teile Pikrinsäure gesättigt in Seewasser, 5 Teile Formol 30\%, 4 Teile Essigsäure $50 \%, 24$ Teile Seewasser) durch Zugießen in die Kulturschale fixiert. Nach einer halben bis mehreren Stunden wurde das fixierte Material in Alkohol überführt und nach meist weiteren 24 Stunden über Zwischenstufen in $50 \%$ Essigsäure gebracht. Letztere wurde durch n $\mathrm{HCl}$ ersetzt, und die Zellen wurden 1 bis 4 Minuten bei $60^{\circ} \mathrm{C}$ hydrolisiert. Die Salzsäure verdrängte man nun durch $50 \%$ Essigsäure, gefolgt von Eisenkarmin-Essigsäure (EKE) und färbte in dieser erst 30 Minuten bei Zimmertemperatur, dann 2 bis 5 Minuten im Wasserbad bei $100^{\circ} \mathrm{C}$. Schließlich wurde über Phenol-Essigsäure und Phenol in Phenol-Caedax eingeschlossen (v. Strosch \& Drebes 1964,

* Wie die früher bereits verwendete Tauchimmersion (v. STOSCH \& DREBEs 1964) verdanken wir auch das hier benutzte Objektiv, eine ebenfalls durch hohen Arbeitsabstand ausgezeichnete Neukonstruktion, den Entgegenkommen der Firma Leitz, Wetzlar. Herrn Dr. H. ClaussEN, Wetzlar, möchren wir auch in diesem Falle sehr herzlich dafür Dank sagen, daß er unserer diesbezüglichen Bitte Gehör schenkte. Beide Objektive sind wegen ihrer schmalen Form besonders für Lebendbeobachtungen geeignet. 
v. Stosch 1952). Alle Operationen nach dem Fixieren bis einschließlich Überführung in Phenol wurden in Mikro-Glasfilternutschen durchgefuhrt.

Für die Untersuchung der Schalenstruktur und der Perizonien wurde das lebende Material mit Jod-Seewasser fixiert, dann in $96 \%$ Alkohol und zurück in Wasser überführt. Die Suspension wurde dann auf dem Deckglas angetrocknet und geglüht, nach dem Glühen kurz in $\mathrm{n} \mathrm{HCl}$ und dann in Wasser gewaschen, nachgeglüht und in Luft eingeschlossen.

Zur Darstellung der isolierten Gürtelbänder wurde ähnlich vorbehandelt, das konzentrierte, in Wasser befindliche Material jedoch durch Erhitzen mit Chromschwefelsäure verascht und mit einer Mikro-Dialysiermethode (v. Sтоsсн 1970) von dem Digestionsgemisch befreit, resuspendiert, auf ein Deckglas angetrocknet und wie die Glühpräparate weiter behandelt. In beiden Fällen ist für die Darstellung dieser äußerst dünnen Kieselelemente Beobachtung im negativen Phasenkontrast (Anoptral Reichert) am besten geeignet. Die durch Dialyse gereinigte Suspension kann natürlich auch zur Beschickung von befilmten elektronenmikroskopischen Objektträgern Verwendung finden. Wir haben im Gegensatz zu RermanN (1960) keine Veränderungen der Feinstruktur durch die Bichromatschwefelsäure-Behandlung feststellen können.

Planktonproben wurden in Phenol-Pleurax eingeschlossen.

Zur Herstellung von Schalenpräparaten für die Elektronenmikroskopie wurde in Methanol-Ameisensäure 3:1 (v. STosca \& Drebes 1964) fixiert, später in Wasser überführt, zum Auseinandertreiben der Schalen mit konzentrierter, wäßriger Chloralhydratlösung behandelt, nach Auswaschen mit Pankreatin 2,5\% in Puffer $(2 \%$ $\left.\mathrm{Na}_{2} \mathrm{HPO}_{4} \cdot 2 \mathrm{H}_{2} \mathrm{O}+0,2 \% \mathrm{KH}_{2} \mathrm{PO}_{4}, \mathrm{pH} 7,6\right)$ ungefähr 12 Stunden bei $36^{\circ} \mathrm{C}$ skelettiert [Pankreatinverdauung siehe v. STOSCH (1952), für Diatomeen zuerst von REIMANN (1960) angewendet]. Nach mehrmaligem Waschen wurden die Präparate auf kohlebefilmte Netzobjektträger gebracht und getrodknet. Untersuchung im Elektronenmikroskop Siemens Elmiskop IA.

\section{ERGEBNISSE}

\section{Der Bau der Zelle und ihrer Kieselschale}

Von der Gürtelseite und in Richtung der Transapikalachse gesehen hat die ruhende Zelle von Chaetoceros didymum annähernd die Gestalt eines Rechtecks. Bei den im Größenzyklus des Klones breiten Zellen (bis $36,5 \mu \mathrm{m}$ ) verläuft die längere Seite des Rechtsecks quer zur Längsrichtung der Zelle bzw. der Kolonie (Abb. 1); bei schmäleren Zellen sind beide Seiten etwa gleichlang (Abb. $5 \mathrm{k}$ ), und bei extrem schmalen Zellen (bis $7,3 \mu \mathrm{m})$ ist die apikale Seite des Rechtecks die kürzere. Die Ecken des Rechtecks sind in der Längsrichtung der Kolonie vorgezogen und laufen in die langen hohlen Kieselborsten aus. Je zwei korrespondierende Borsten der Schalen zweier benachbarter Zellen, d. h. von Schalen, die ontogenetisch nach der gleichen Zellteilung entstanden sind, treffen und überkreuzen sich und sind an der Kontaktstelle durch gemeinsam ausgeschiedene Kieselsäure fest miteinander verwachsen. Jenseits eines Treffpunktes wendet sich die Borste der einen Schale in eine zur Apikalebene etwa senkrechte Richtung, die 


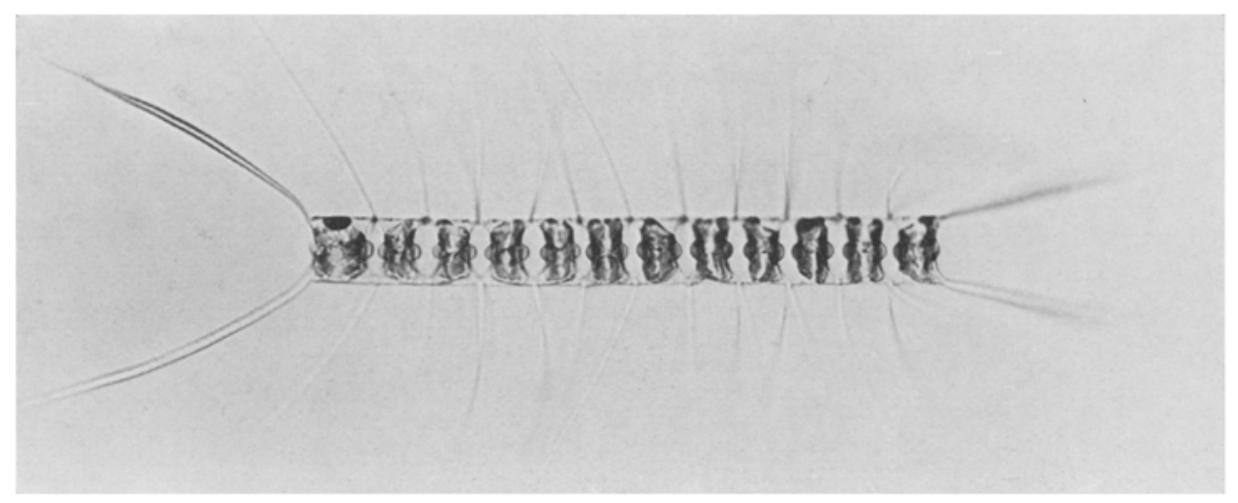

Abb. 1: Chaetoceros didymum. Kolonie ohne intrakoloniale Sonderborsten; $(300: 1)$

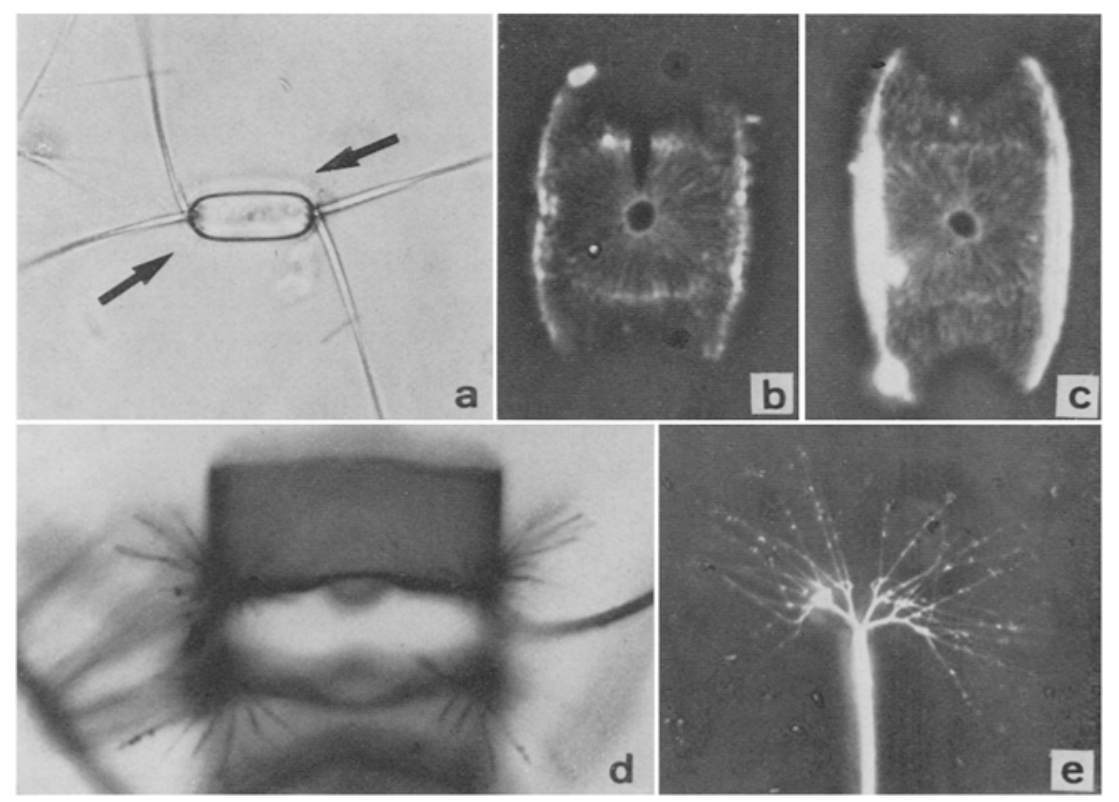

Abb. 2: Chaetoceros didymum. (a) Valvaransicht von Zellenpaar einer Kolonie mittlerer Breite; "Achselfächer" erkennbar (Pfeile); $(500: 1)$. (b) und (c) Skelett unfertig ausgebildeter Valven, Anoptralkontrast; (2000:1). (d) Seitenansicht eines Thekenpaares mit EKE überfärbt; Kieselfäden der Achselfächer strahlen von den Borstenachseln aus. (e) Einzelner Achselfächer an Borstenbasis, Anoptralkontrast. (d) und (e) $(1000: 1)$

der Schwesterschale schließt mit der gleichen Ebene einen Winkel von ungefähr $15^{\circ}$ ein (Abb. 2a). Grundsätzlich verläuft dabei die eine der Borsten der einen Theka über der Apikalebene, die andere Borste unterhalb der Apikalebene. Die Richtung der entsprechenden Borsten der Schwestertheka (Nachbarzelle) und der zweiten Theka der gleichen Zelle ist dann alternierend. Von den vier Borsten einer Zelle ist meist das eine Paar steil zur Apikalebene, das andere Paar flach zur Apikalebene geneigt. Gelegent- 
lich können aber auch alle vier Borsten den gleichen Winkel zur Apikalebene einschlieBen (vgl. die Abbildungen bei Hustedt 1930). Dieses Verhalten zeigen regelmäßig die Endborsten der Kolonie. Diese bilden zusammen eine schmale Parabelfigur, deren Ebene um etwa $30^{\circ}$ zur Apikalebene gedreht ist; am entgegengesetzten Kolonieende hat dieser Winkel negatives Vorzeichen (Abb. 1). Die einem Kolonieende nahen Borsten gewöhnlicher Koloniezellen sind häufig zu diesen Enden hin übergekrümmt.

Durch die Borstenbasen bekommen die interzellulären "Fenster" zwischen zwei Zellen die Gestalt eines liegenden Doppelspitzbogens, der jedoch bei C. didymum modifiziert ist durch die von beiden Valvenmitten aus vorgestülpten halbkugelig-kegeligen Protuberanzen, in denen die Pyrenoide der ruhenden Zelle liegen. Der Valvendiskus trägt also die beiden Borsten, und die Protuberanz und biegt pleurawärts in einen kurzen zylindrischen Mantel um (Abb. 3c), an dessen freien Rand dann das erste einer Anzahl von $Z$ wischenbändern ansetzt. Auf die Zwischenbänder folgt schließlich das einzige Gürtelband. Mantel und Gürțel haben bei breiten Zellen lang-ovalen (Abb. 2a), bei schmalen Zellen kurz-ovalen Querschnitt (Abb. 3f). Vom Übergang zwischen Diskus und Mantel erhebt sich distal ein schmaler Saum, der bei Kolonie-Endvalven in eine Anzahl von Kieselfilamenten (im weiteren als "Filamente" bezeichnet) ausläuft (Abb. $3 a, c, f ; A b b .13 a)$. Weitere Filamente stehen spärlich auf dem Valvendiskus und gehäuft auf der Protuberanz. Die Scheitel der Protuberanzen sind von einem spaltförmigen Porus durchbrochen (Abb. 3f), der jedoch, ebenso wie die Filamente, allen inneren Valven der Kolonie fehlt (Abb. 3e). Die Borsten der Endschalen (im folgenden kurz „Endborsten“ genannt) unterscheiden sich von den Borsten der Kolonieschalen sowohl hinsichtlich ihrer Form als auch ihrer Dicke (Abb. 1, 3a); weitere Feinbaumerkmale zeigt Abbildung 3. Doch ist noch auf merkwürdige Kieselsäure-Anhangsgebilde beider Borstenarten einzugehen, die durch GRAN (1897) entdeckt und durch MaNGIN (1908, 1912) näher beschrieben wurden; MANGrN sah auch als erster die Filamente. An die Außenseite der Borste setzt dort, wo sie oberhalb ihrer Basis eine zylindrische Form angenommen hat, ein proximalwärts gerichteter Fächer aus sehr feinen Kieselsäurefäden an (Abb. $3 a-d)$. Da diese Systeme in den Borstenachseln liegen, werden sie im folgenden als „Achselfächer" bezeichnet. Das Gesamtsystem spaltet sich durch eine erste Dichotomie dicht über der Ansatzstelle in zwei Halbfächer auf, die sich sogleich noch einmal spalten und dann durch weitere Dichotomien verzweigen (Abb. 2e). Außerdem können an der Basis des Fächers noch kurze "Adventiväste“ hinzutreten (Abb. 3d). Jeder Halbfächer legt sich mit einigen seiner Aste der Oberfläche des Mantels im Umkreis der Borstenbasen an und strahlt mit den übrigen in den Raum aus (Abb. 2a, d). Neben der Kieselsäure scheinen nach dem färberischen Verhalten auch saure Kohlenhydrate im Material der Achselfächer vorhanden zu sein. Das ist wohl der Grund dafür, daß die Fäden in späteren Arbeiten (Gran 1908, Mangin 1912, Meunier 1913) als aus Schleim bestehend angesehen werden. Hendey, Cushing \& Ripley (1954) halten die Fächer merkwürdigerweise für Teile des Schalengürtels.

Kürzlich wurden beide Sorten von Kieselsäureanhängseln (Filamente und Achselfächer) bei C. didymum von BLAsco (1970) elektronenmikroskopisch abgebildet. Allerdings wird offenbar angenommen, daß sowohl Filamente als auch Spaltporus allen Zellen zukommen; wir finden jedoch beide Strukturen nur an Endvalven.

Die Entstehung der Fächer und ebenso der Filamente an den Endschalen ist unge- 


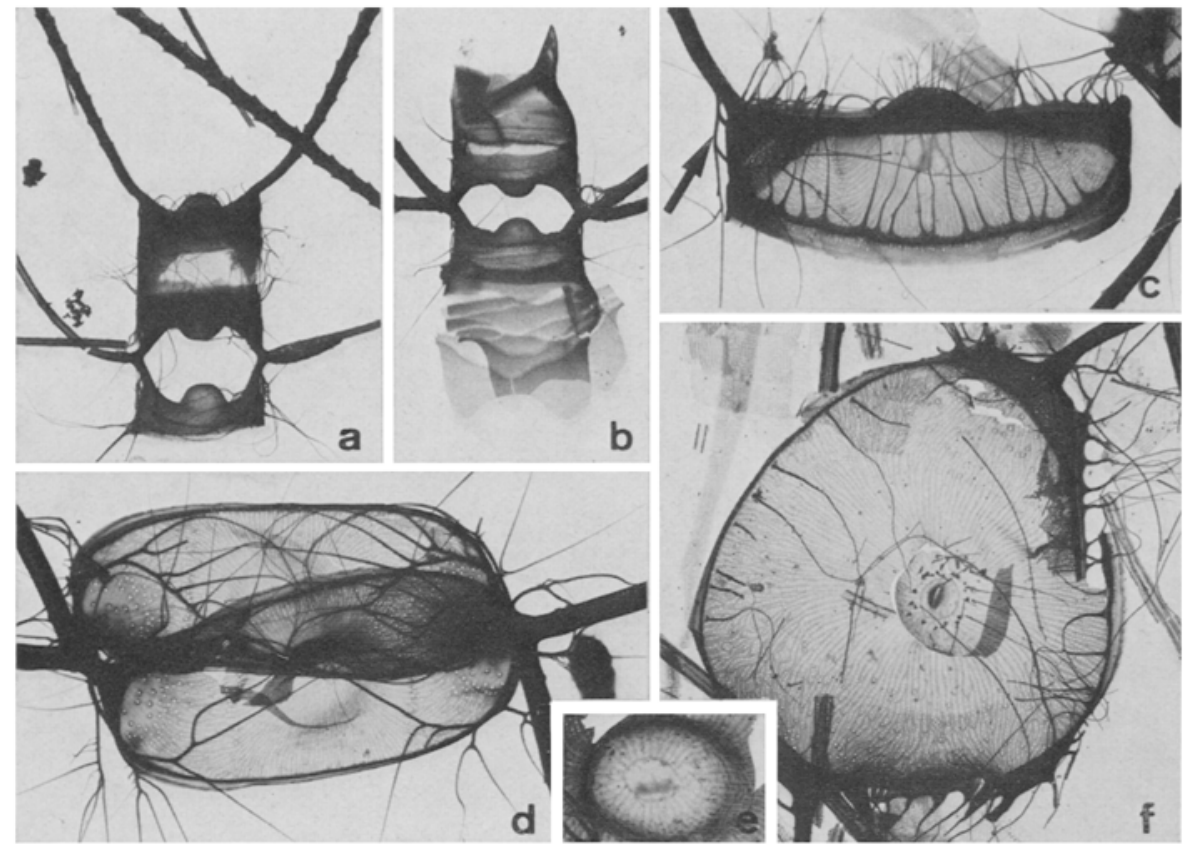

Abb. 3: Chatoceros didymum, elektronenmikroskopische Aufnahmen. (a) Kolonieende mit Kieselfilamenten an der Endschale, nicht an den beiden Innenschalen; Achselfächer (siehe auch [c] und [f]) ragen seitlich über Gürtelumriß hinaus; (ca. 1000:1). (b) Sonderborstenpaar dicker und stärker zum Kolonieende hin übergekrümmt als die normalen Kolonie-Innenborsten in (a); unten Gürtelband durch Borstenbuchten links und rechts ausgerandet; (ca. 1000:1). (c) Endvalve mit Filamenten auf dem Diskus, besonders aber am Diskusrand und auf der Protuberanz; links Achselfächer (Pfeil); (ca. 2500:1). (d) Paar von Kolonie-Innenvalven, Kieselfäden der Achselfächer haben sich über die Schalen gelegt; (ca. 2500:1). (e) Protuberanz einer Kolonie-Innenschale; der in der Schalenanlage (Abb. 2b, c) vorhandene Porus hat sich geschlossen; (ca. $4000: 1$ ). (f) Endvalve in der Aufsicht; schlitzförmiger Porus in Protuberanz; Valvenrand mit Kieselfilamenten; (ca. 2500:1)
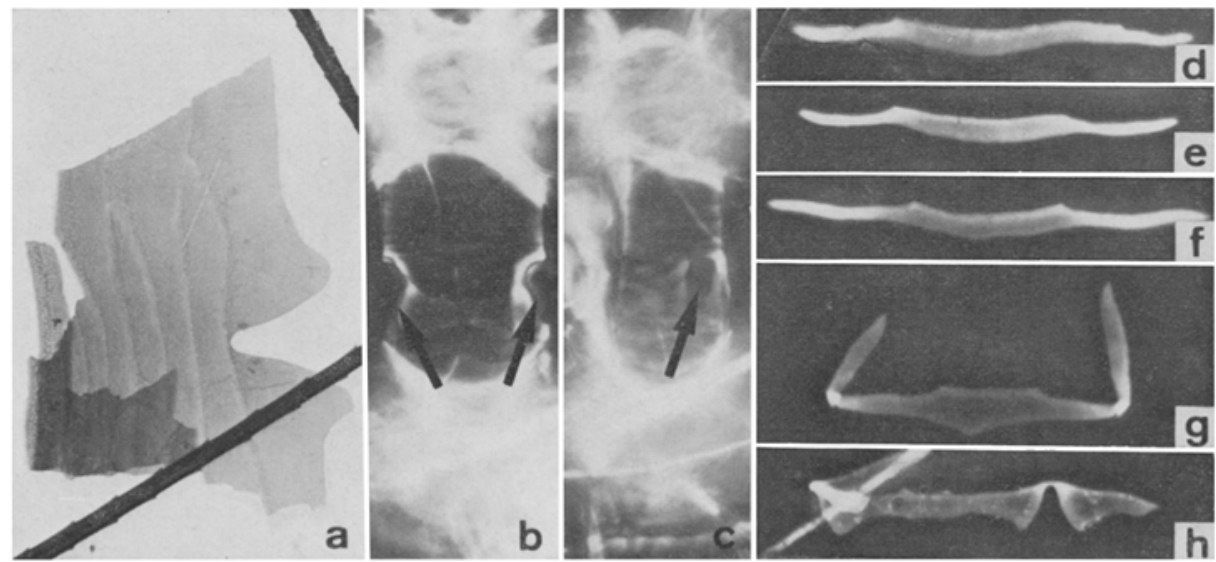

Abb. 4 
klärt. An den freien Enden wird bei beiden eine feine Durchbohrung sichtbar. Die Kieselsäurefilamente sind daher möglicherweise wie die Borstenbildungen anderer zentrischer Diatomeen und die groben Borsten von Chaetoceros selbst als Ausscheidung einer Plasmaseele zu deuten. Allerdings läge der Durchmesser der plasmatischen Matrix dann in der Größenordnung von $10 \mathrm{~nm}$.

Dem C. didymum gestaltlich ähnlichen C. protuberans fehlen Achselfächer und besondere Endschalenfilamente ebenso, wie anscheinend den anderen ChaetocerosArten. Nur bei dem ökologisch und strukturell merkwürdigen C. armatum kommen Kieselsäurefäden im basalen Teil der Borsten vor (LEWIN \& NORRIs 1970); nach Eigenbeobachtungen treten hier auch Endschalenfilamente auf.

Die Pleura (Abb. 4) setzt sich aus einer Anzahl gegen die Apikalebene alternierender, also zweizeilig gestellter Hufeisenbänder zusammen, deren Breite an der Valva. gering, zum offenen Ende der Theka hin größer ist. Die Bänder schließen auf der breiten Gürtelseite, im Gegensatz zu biradiaten Biddulphia-Arten, bei denen der Schluß auf der Schmalseite erfolgt. Jedes Band besitzt in seiner Mitte eine valvenwärts gerichtete Lasche und dieser gegenüber eine leichte Ausbuchtung, die zusammen die Lücken zwischen den Enden des vorhergehenden bzw. nächstfolgenden Bandes schließen. Diese Lücken und damit die Laschen und Ausbuchtungen erstrecken sich bei den ältesten valvennahen Bändern (Abb. 4d) fast über den gesamten flachen Teil der Pleura (die Bänder sind dabei selbst entsprechend kurz) und werden bei den nächsten $Z$ wischenbändern schmäler (Abb. 4a, 4d-g). Die Enden des anschließenden einzigen Gürtelbandes stoßen ohne Zwischenraum aufeinander und werden distal durch die zugespitzte abvalvare Auswölbung des davor liegenden letzten Zwischenbandes (Abb. $4 \mathrm{~g}$ ) abgedeckt. Dieses. Gürtelband besitzt nur eine schmale Lasche und keine Ausbuchtung (Abb. 4h) und nimmt nun in seiner Ausgestaltung in eigentümlicher Weise auf die weit über die Gürtelkontur herausragenden Borsten Rücksicht. Es ist auf den beiden schmalen Seiten des. Gürtels, d. h. unter den Apikalenden und damit den Borsten äußerst tief eingeschnitten (Abb. $4 \mathrm{a}, \mathrm{h}$ ). Beiderseits dieser Borste $\mathrm{n} \mathrm{bu} \mathrm{cht}$ (bristle indentation) springt das Band in breiten Lappen vor, um darauf wieder etwas schmäler zu werden, so daß auf Ober- und Unterseite der Zelle eine zweite breite, aber seichte Einbuchtung gebildet wird. Weichen die Theken der Zelle vor der Zellteilung auseinander, so wird am Ort der präsumptiven Borsten zuerst beiderseits je eine von den Borstenbuchten ausgesparte Offnung an der Schmalseite der Schalen frei (Abb. 4b, c), während die übrigen Teile des Gürtels noch übereinandergreifen. Diese Ơffnungen ermöglichen den nach der Zellteilung auswachsenden Borsten den Durchtritt, ohne daß der Koloniezusammenhang verlorengeht. Sie stellen also Konstruktionselemente der Zellen dar, die das Heraustreten der Borsten über die Flächen der Pleura hinaus ermöglichen und hier als „B orstenpforten“ (bristle openings) bezeichnet werden. Die Borstenpforten scheinen bei Chatoceros bisher übersehen worden zu sein und dürften den koloniebildenden

Abb. 4: Chaetoceros didymum. (a) Gürtelbruchstück elektronenmikroskopisch; Borstenbucht im Gürtelband, während nach links die Zwischenbänder folgen; man erkennt, daß diese valvenwärts kürzer werden; (ca. 5000:1). (b) Borstenpforten (Pfeile) im Profil (breite Gürtelansicht) und in (c) Schrägansicht, so daß Offfnung (Pfeil) erkennbar. (d)-(h) Isolierte Bänder des Gürtels in abvalvarer Folge und gleichartiger Orientierung: (d)-(g) Zwischenbänder, (h) Gürtelband mit Borstenbuchten. (b)-(h) Anoptralkontrast; (1000:1) 
Arten der Gattung (mit einer Ausnahme)* zukommen. Direkt nachgewiesen wurden Borstenbuchten noch bei C. protuberans var. nivalii, C. compressum, C. costatum, C. laciniosum SCHÜTT und bei C. eibenii.

Neben ihrer vegetativen Aufgabe führen die Borstenpforten auch generative Funktionen aus. So dienen sie bei $C$. didymum und wohl auch bei anderen Arten dem Oogonium als Eintrittsstelle für die Spermien und später als Austrittsöffnung für die junge Zygote, was noch zu schildern ist. Bei C. eibenii fungieren sie außerdem als Austrittsöffnungen für die aus den Spermatogonangien freiwerdenden Spermien, nicht jedoch bei C. didymum, wo sich die Spermatogonangien öffnen (vgl. p. 415).

Auf den elektronenmikroskopischen Aufnahmen sowie im Phasenkontrast (besonders Abb. 4a, d-h) erkennt man, daß die um die Schmalseite herumbiegenden Teile der Gürtel- bzw. Zwischenbänder in ersten Falle dunkler, im zweiten Falle heller erscheinen. Das bedeutet größere Dicke des Gürtels an der Schmalseite der Zelle, und dies ist ein Grund - vielleicht nicht der einzige - dafür, daß die Zellen während der Zellverkleinerung im Laufe der Zellteilungen weit mehr an Breite als an Dicke abnehmen.

Kurz hingewiesen sei darauf, daß eine Anzahl von Chaetoceros-Arten, unter diesen vor allem diejenigen der Sektion Pbaeoceros, eine Gürtelkonstruktion besitzen, die aus alternierenden, sich auf den breiten Gürtelseiten in je einer Zickzacklinie treffenden Halbringen besteht. Das Gürtelband jedoch ist bei dem untersuchten C. eibenii (immer?) einteilig, aber offen, wobei sich die Enden seitlich von der Mitte der breiten Gürtelseiten, d. h. nahe der einen der beiden Borstenbuchten, verschränken.

Eine der höheren Borstenzahl entsprechende Vielzahl von Austrittsöffnungen beschreibt Drebes (1972) für Bacteriastrum byalinum. Diese ermöglichen auch hier vermutlich das Eindringen der Spermien und mit Sicherheit das Austreten der Zygote.

In Zellen der späten Interphase (vg1. p. 398) fallen die beiden polar gelegenen Plastiden auf (Abb. 5), die aus zwei großen, der Zellober- bzw. -unterseite angepreßten Lappen zusammengesetzt sind (siehe auch GeITLER 1967), wobei die entsprechenden Buchten auf den Zellflanken liegen und deshalb in breiter. Gürtelansicht nicht erkannt werden können. Der freie Rand der Plastidenhälften kann selbst mehr oder weniger stark gelappt sein. Im Zentrum der Plastide liegt ein groß̉es Pyrenoid, das den Innenraum der Protuberanz ausfüllt. In stärker gefärbten Karminessigsäure-Präparaten läßt das Pyrenoid eine grobe Lamellierung erkennen.

Der Kern findet sich während der mittleren Interphase im oberen und unteren Wandbelag der breiten Seite der Pleura. Er besitzt einen relativ großen Nukleolus und ist von einem Mantel von einfachen Dictyosomen (also nicht Doppelplättchen) umgeben, der im Leben leicht zu erkennen ist (Abb. 5a).

* Chatoceros armatum, das auch in der Struktur der Borsten innerhalb der Gattung ungewöhnlich ist (LEWIN \& NorRrs 1970) besitzt keine Borstenpforten. Die auswachsenden Borsten werden bei ihrer Bildung in den ringförmigen Interzellularraum zwischen den Tochterzellen hineingeschoben und liegen nach Fertigstellung um die Mittelteile der beiden aneinanderstoßenden Diskusflächen herumgewickelt. Erst wenn sich die Gürtel der Mutterzelle auseinanderschieben, strecken sie sich durch den entstehenden Ringspalt nach außen aus. Auch Spermienentstehung und Auxosporenentwicklung sind völlig verschieden von dem, was man in der Gattung Chaetoceros findet. C. armatum gehört daher in eine eigene Gattung, die Psendochaetoceros heißen könnte, und diese vermutlich in eine eigene Familie. Wir werden hier nicht auf diese Spezies eingehen und ihre Behandlung einer späteren Veröffentlichung vorbehalten. 


\section{Zellteilung und Zellzyklus}

Verfolgt man die Längenänderungen einer Zelle von Chaetoceros didymum im Teilungszyklus, so bleibt die nach Beginn der Borstenbildung in der vorhergehenden Teilung erreichte Länge während der Dauer etwa eines drittel bis eines halben Zellzyklus, bei schwacher Beleuchtung wohl auch länger erhalten. Danach beginnt die Streckung, die zur Mitose hin beschleunigt abläuft und erst in der späten Prophase zum Stillstand kommt (Abb. 5). Der meist in der Mitte des oberen oder unteren Wandbelags (Abb. 5a, b) an der breiten Pleuraseite liegende Kern schwillt nun an, wobei der Nukleolus verschwindet. Mit der Auflösung der Kernhülle* zerstreuen sich auch die Dictyosomen (Abb. 5b). Während der Metakinese und Metaphase (Abb. 5c) ist der Kern dann im Leben schwer zu erkennen, um in der Anaphase in einer breiten Rechteck-, dann Hantelfigur (Abb. 5d, e) wieder deutlich zu werden. Die Spindel streckt sich nun ziemlich rasch, wie die Zeitangaben an den Abbildungen zeigen. Sie ist durch ihre gegenüber dem Plasma höhere Lichtbrechung leicht zu sehen (Abb. 5e) und steht parallel zur Längsachse der Zelle oder im Winkel bis etwa $30^{\circ}$ gegen diese geneigt. Sobald die Spindel fast ihre maximale Länge erreicht hat - der Kernzustand dürfte dann der Telophase entsprechen - beginnt die Cytokinese-Furche gleichmäßig von beiden Zellflanken her keilförmig in den Protoplasten einzuschneiden. Sie vertieft sich rasch, wobei ihre Flanken konvex gegen das Plasma ausgewölbt werden (Abb. $5 \mathrm{f}, \mathrm{g}$ ), was besonders deutlich an breiten Zellen zu sehen ist (Abb. 7a). Entsprechende Einfurchungen des Plasmas an Ober- und Unterseite der Zelle sind in der schmalen Pleuralansicht zu erkennen (Abb. 6c, d). Wenige Minuten nach Beginn der Furchung ist der Protoplast durchgeschnürt; die Menisken der Tochterzellen sind dann nur noch durch den Mittelteil der Mitosespindel verbunden. Dieser liegt gewöhnlich etwas neben der Mitte des Furchungsspaltes, während die Kerne nach der entgegengesetzten Seite verschoben sind (Abb. 5h). Da die Spindel an den Tochterkernen verankert bleibt, biegt sie sich schließlich bogenförmig durch (vgl. auch $A \mathrm{bb} .15 \mathrm{c}$ ). In der schmalen Gürtelansicht ( $\mathrm{Abb} .6 \mathrm{~d}$, e) ist die Furche an der vom Kern abgewandten Seite stärker vorgeschoben, so daß auch in dieser Ansicht eine nach der entgegengesetzten Richtung gekrümmte Spindelprojektion erscheint. Die wirkliche Krümmungsebene der Spindel schließt also einen Winkel von etwa $45^{\circ}$ mit der Apikalebene ein. Die Menisken der Tochterzellen sind in diesem Zeitpunkt ziemlich weit auseinandergewichen und erscheinen in breiter Gürtelansicht fast gerade (Abb. $5 \mathrm{~h}$ ), in schmaler Gürtelansicht jedoch stark gewölbt (Abb. 6d, e). Der Teilungsspalt ist dadurch rechteckig geworden. Die Spindel bricht darauf in ihrer Mitte, wie früher für Stephanopyxis geschildert (v. Stosch \& Drebes 1964), und die Enden der Halbspindeln werden rasch resorbiert. In günstigen Fällen (Abb. $7 \mathrm{~b}$, c) kann man beobachten, daß sich. Dictyosomen entlang der neuen Zellflächen verteilt haben. Sie verbleiben hier bis zum Beginn der Borstenbildung, was mit ihrer vermuteten Funktion, Wandmaterial-Vorstufen zu liefern, im Einklang wäre. Ähnliche Ancrdnungen in der Nähe entstehender Schalen einer pennaten Diatomee demonstrieren Coombs et al. (1968a, 1968b).

Wenige Minuten nach Durchbrechen der Spindel beginnt dann über den Kernen

$*=$ Kernmembran der Lichtmikroskopiker. 

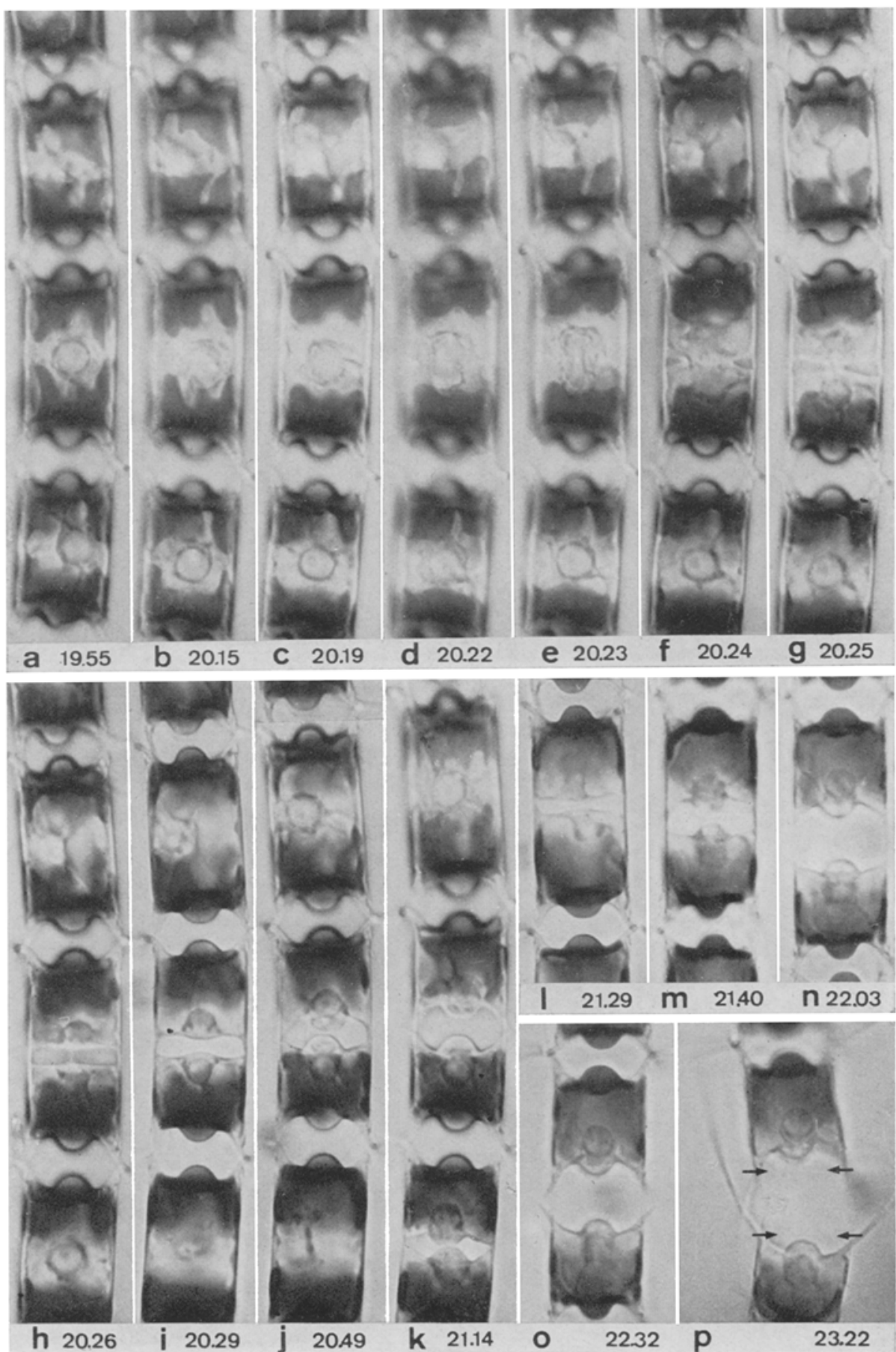

Abb. 5 
die Aufwölbung der Protuberanzen (Abb. 5i, j). Wie man an Fällen mit nicht opponierten Kernen erkennt, wird die Lage der letzteren offenbar durch den Kernort bestimmt (Abb. $7 b, c)$. Der Kern schmiegt sich zunächst ziemlich fest und nur durch eine dünne Plasmalage von der Oberfläche getrennt in die Protuberanz ein (Abb. 5i), weicht aber nach deren Fertigstellung etwas weiter in Richtung Zellmitte zurück (Abb. 5j, k). Bereits zu Beginn der Ausformung der Protuberanzen schieben sich an den Flanken der Furchungsfigur die Zelloberflächen aufeinander zu (Abb. 5i, j), so daß das anfangs rechteckige Fenster nun seine endgültige bikonvexe Gestalt erhält. In den so begrenzten Raum ragen die beiden etwa halbkugeligen Protuberanzen herein, die sich in dem abgebildeten Beispiel (Abb. 5j) fast berühren. An der Lage der Protuberanzen wird besonders deutlich, daß die beiden Schwesterzellen nunmehr etwas auseinanderweichen. Ist dieser Prozeß beendet, so treten aus den Borstenpforten die Borsten aus (Abb. 5k).

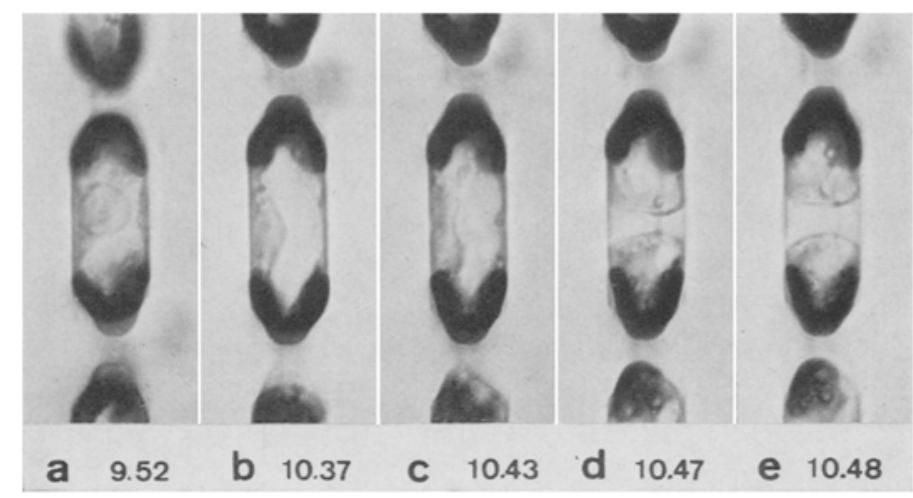

Abb. 6: Chaetoceros didymum, schmale Gürtelansicht. Erste Teilung im Spermatogon, demonstriert Furche und Spindel. Mit Zeitangaben. Weitere Erklärung im Text; $(1000: 1)$

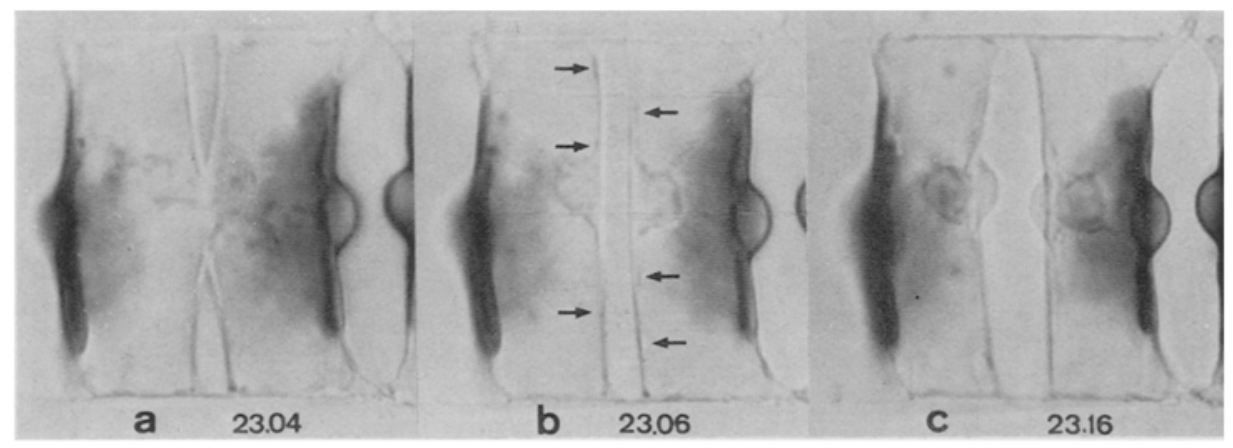

Abb. 7: Chaetoceros didymum. Furchung einer Zelle maximaler Breite. Dictyosomen verteilen sich entlang der Furchungsfläche (Pfeile). Mit Zeitangaben; (1000:1)

Abb. 5: Chaetoceros didymum, breite Gürtelansicht. (a)-(k) Zellteilung: mittlere Zelle teilt sich unter Bildung von Kolonie-Innenschalen; ebenso (i)-(k) untere Zelle. (l)-(p) Trennteilung: obere Zelle der Abb. (a)-(k) teilt sich unter Bildung von Kolonie-Endschalen. In (p) Kieselfilamente auf neugebildeten Endschalen (Pfeile). Dauerbeobachtungen mit Zeitangabe. Weitere Erklärung im Text; $(1000: 1)$ 
Das Auseinanderweichen der Tochterschalen beruht auf einer Streckung der Mutterzelle und steht wahrscheinlich mit der Borstenbildung in unmittelbarem Zusammenhang: Die auswachsenden Borsten selbst schieben sich gegeneinander und drücken dadurch die Theken der Mutterzellen auseinander. Dafür spricht, daß bei Ausbleiben der Borstenbildung (Abb. 8) auch die Streckung ausfällt. Vermutlich öffnet erst diese Strekkung die Borstenpforten so weit, daß die Borsten durch sie über die Zellkontur hinauswachsen können. Dicht außerhalb der Borstenpforten (Abb. 5k) überkreuzen sich die Borstenpaare. Dabei tritt deren paarweises Verwachsen ein, was aber im Leben nicht erkennbar ist; doch bleiben benachbarte Borstenpaare selbst nach Säurebehandlung an ihren verwachsenen Stellen miteinander verbunden. Die Borsten wachsen danach mit den oben besprochenen Richtungsänderungen rasch weiter; nach etwa 11 Minuten haben sie bereits die halbe Länge des Zelldurchmessers erreicht. Bis zur Fertigstellung vom ersten Erscheinen an vergehen jedoch etwa 11/2 Stunden. An der wachsenden Borste beobachtet man ein vorauseilendes dünnes Ende, das sich vor allem an den Hypovalven der Dauersporen-Mutterzellen demonstrieren läßt (Abb. 12c). Diese Verjüngung stellt offenbar die plasmatische Matrix dar, die etwas weiter hinten ziemlich abrupt in die viel breitere Kieselsäurehülle der Borste übergeht (vgl. auch Iyengar \& SubraimanYAN 1944).

Der gesamte Zellzyklus von Teilung zu Teilung wurde nur an drei Zellen verfolgt. Er dauerte unter den herrschenden Bedingungen 8 Std. 50 Min., 9 Std. und 9 Std. 5 Min. Jede Tochterzelle enthält zunächst nur eine Plastide, die auch nach Beendigung der Borstenbildung noch am gleichen Ort liegt, an dem sie aus der Mutterzelle übernommen wurde. Kurz vor Ablauf der ersten Interphasenhälfte (4 Std., bzw. 4 Std. 10 Min. nach dem Auftreten der Furche) beginnt die Verlagerung der Tochterplastiden in

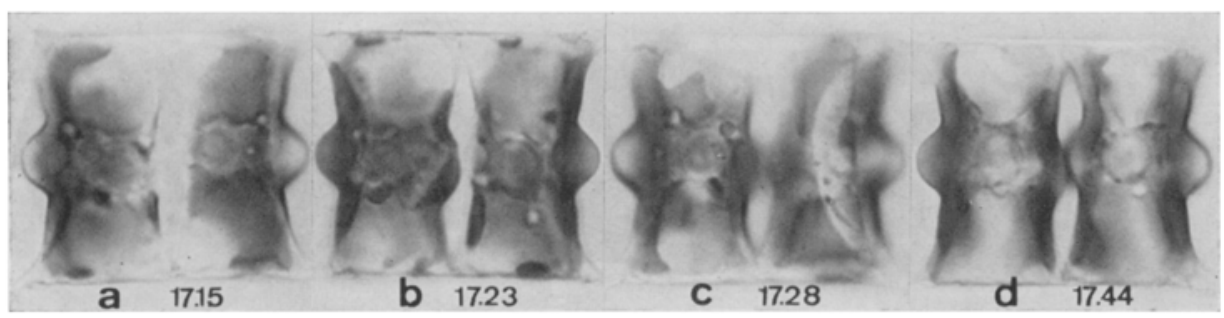

Abb. 8: Chaetoceros didymum. Plastidenteilung und -umlagerung in der Interphase. Mit Zeitangaben. Weitere Erklärung im Text; (1000:1)

Richtung der Hypovalven. Die Teilung der Plastide erfolgt in der Apikalebene (der Bildebene der Abb. 8) und kann daher selbst gewöhnlich nicht beobachtet werden. Der Spalt geht dann durch die schmale Brücke in der zweilappigen Plastide, in welcher das Pyrenoid liegt. In letzterem verläuft er aber manchmal gegen die Apikalebene in der Weise geneigt, daß er auch bei einer Zellorientierung wie in Abbildung 8 sichtbar wird. Die Umlagerung der Plastiden vollzieht sich in etwa 25 Minuten. In Abbildung 8b und c schiebt sich die Plastide der linken Zelle an deren Oberseite, die der rechten Zelle, bei der dieser Vorgang besonders klar zu erkennen ist, an deren Unterseite in Richtung auf die jeweilige Hypovalva zu. Der Kerne liegen jeweils auf derjenigen Zellseite, die 
der Wanderplastide gegenüberliegt, so daß sich Kerne und Plastiden nicht stören. In anderen Zellen wurde auch Wanderung beider Plastiden eines Zellpaares auf der gleichen Seite gesehen. In Abbildung 8d haben die Pyrenoide der Wanderplastiden die Protuberanzen der Hypovalva erreicht, und die Umlagerung ist im wesentlichen abgeschlossen.

Der hier geschilderte Zellzyklus spielte sich während der Lichtphase ab. Interferiert das Eintreten der Dunkelphase, so treten Verzögerungen hinzu, die aber nicht genauer untersucht wurden.

Zur Entwicklung der Valven nach der Zellteilung seien noch einige Beobachtungen angeführt. Kieselskelette sehr junger Valven wurden in Trockenpräparaten feucht veraschten Materials gefunden. Die frühesten, deutlich erkennbaren Stadien bestehen nur aus der Protuberanz, die zu diesem Zeitpunkt einen relativ großen zentralen Porus besitzt. Von den Porusrändern strahlen die Kieselstrukturen radial und zentrifugal aus. Die in Abbildung 2 gezeigten Valven sind bereits etwas weiter entwickelt. In $\mathrm{Ab}-$ bildung $2 b$ ist außer der Protuberanz bereits ein Teil des Diskusrandes und der Diskusfläche zu erkennen. Zeitlich läuft die Bildung des Diskusrandes derjenigen der Diskusfläche voraus, so daß vor den Apices, an denen später die Borsten entstehen, zunächst ein etwa kreisförmiges unverkieseltes Feld ausgespart bleibt. Die Schalenbildung schreitet also nicht wie bei Stephanopyxis (ReImanN 1960) gleichmäßig zentrifugal vor. Außerdem ist der Porus später bei den Endschalen stark verengt, bei den übrigen Schalen ganz geschlossen, so daß hier noch ein geringes zentripetales Wachstum der Valva erfolgt. Der ursprüngliche Rand des Porus markiert sich aber auch bei den fertiggestellten Schalen (Abb. 3e, f).

\section{Kolonien und Kolonieteilungen}

Durch die paarweise Verwachsung ihrer Borsten und damit ihrer Schalen und durch die besondere Ausbildung der Endborsten stellen sich die Kolonien von Chaetoceros, wie auch diejenigen des verwandten Bacteriastrum, als Organisation iberzellulärer Individualität dar.

Neben den Endborsten finden sich auch im Inneren der Kolonien vielfach (aber nicht immer, siehe Abb. 1) Valvenpaare mit verstärkten, zu einem Kolonieende hin parabelförmig gekrümmten Borsten (Abb. 3b und Abb. 18a); jedoch ist die Parabelfigur breiter als jene der Endborsten. Dieses wurde bereits von MEunier (1913) gesehen. Wir haben den Eindruck, daß die interkalaren Spezialborsten nach der Teilung einer Endzelle an beiden newen Tochtervalven enstehen - möglicherweise, weil eine in der Endzelle herrschende Tendenz zur Bildung stärkerer Borsten noch anhält - und durch weitere Zellteilungen in das Innere der Kolonie verschoben werden. Ob das richtig ist, könnte nur langdauernde Lebendbeobachtung von Einzelkolonien zeigen. Ahnliche, durch stärkere Borstenpaare heterovalvate Zellen sind aus der Section Dichaeta der Gattung Chatoceros und außerdem bei C. compressum bekannt.

Die Teilung einer Mutterkolonie in zwei Tochterkolonien kann durch zwei verschiedene Mechanismen vermittelt werden: (1) durch äquale, aber heterovalvate Trennteilungen, die, zuerst von ScHüTt (1888) beschrieben, zur Ausbildung von Endvalven 
beiderseits der Trennstelle führen; (2) durch einen Mechanismus, der bisher nur von C. didymum bekannt ist (v. Sтоsch \& Kowallik 1969). Im letzteren Fall liefert eine acytokinetische Mitose nach Art einer Häutung nur an der einen Tochterkolonie eine Endschale, läßt an der anderen aber eine entleerte Theka, die Epitheka der Mutterzelle, zurück.

Die äquale Trennteilung konnte häufig im Leben gesehen werden. Eine durchlaufende Beobachtungsserie ist in Abbildung 5 wiedergegeben (in a-k die obere Zelle, diese dann allein in 1-p). Nach Streckung und Einleitung der Mitose verläuft die Furchung (Abb. 5l) normal. Auch nach der Entstehung der Protuberanz ist die Trennteilung noch nicht von einer gewöhnlichen Zellteilung zu unterscheiden (Abb. $5 \mathrm{~m}$ ). Danach aber weichen die Tochterzellen im Laufe weniger Minuten auseinander (Abb. 5n). Dabei werden die Theken der Mutterzellen voneinander geschoben und schließlich getrennt, worauf sich die Tochterkolonien häufig sogleich gegeneinander verlagern. Dieses geschieht jedoch im gegebenen Beispiel erst später (Abb. 5p). Obgleich zwischen Abbildung $5 \mathrm{~m}$ und n 23 Minuten liegen, haben wir beobachtet, daß das Auseinanderweichen selbst weniger als 3 Minuten dauert. Die Ursache für das Auseinandergleiten der Gürtel scheint im Auswachsen der auf p. 391 beschriebenen Kieselfilamente an den Disci der neugebildeten Endvalven zu liegen, wodurch letztere schließlich auseinandergeschoben werden. Die unter den Beobachtungsbedingungen nicht leicht erkennbaren Filamente (Abb. 5p) werden daher erst im Zeitpunkt des Auseinanderweichens sichtbar. Für eine Mitwirkung von Gallertausscheidungen in den Interzellularraum zwischen den Endschalen bestehen keine Anhaltspunkte, obwohl das Vorhandensein eines Porus in den Protuberanzen nur dieser Schalen suggestiv für die Ausscheidung von Gallerte sein würde*. Das Auseinanderweichen der Endschalen ist nicht mit dem zwar ähnlichen, im Ausmaß jedoch geringeren Vorgang nach der normalen Zellteilung zu verwechseln (Abb. 5i-k), welcher durch das Auswachsen der Borsten verursacht wird. Die Borsten entstehen auch in einem wesentlich späteren Entwicklungsstadium der Zelle als die in der Trennteilung wirksamen Filamente. Im abgebildeten Beispiel wurden die Borsten 12 Minuten nach dem Auseinandergleiten (Abb. 5o) erkennbar, in einem anderen Fall nach 10 Minuten. Abbildung 5 p zeigt, daß die neuen Endborsten nunmehr die auf p. 391 beschriebene Form angenommen haben. Die Wachstumsgeschwindigkeit der Borsten betrug in diesem Fall etwa $31 \mu \mathrm{m}$ pro Stunde. Ein Verwachsen der Endborsten wird dadurch verhindert, daß die einander gegenüberliegenden Paare in um $60^{\circ}$ gegeneinander verdrehten Ebenen vorgetrieben werden und sich daher nicht berïhren. Kolonieteilungen können gelegentlich gehäuft auftreten und sich sogar in zwei benachbarten Zellen ereignen. Derart entstand z. B. aus einer ursprünglichen siebenzelligen Kolonie eine dreizellige, eine zweizellige und eine vierzellige Kolonie.

Die Frage, ob die spezielle Gestalt der Endborsten bereits primär mit der Umstimmung der Zelle zur Endschalenbildung, welche ihrerseits die Trennung verursacht, gegeben ist oder sekundär durch Ausfallen der Verwachsung der sich gegenüberstehenden Borsten induziert wird, kann endgültig nur experimentell entschieden werden. Für die

* Bei anderen koloniebildenden Chaetoceros-Arten fehlen die Filamente; dagegen ist, soweit bekannt (siehe auch Hargraves 1972), immer ein Endschalen-Porus vorhanden, so daß bei diesen vermutlich Gallerte die Trennung besorgt. 
erstere Annahme spricht im Augenblick das Argument, daß zufällig einseitig nicht verwachsene intrakoloniale Borstenpaare keinen Endborstencharakter annehmen.

Die zweite Art der Trennteilung beruht auf einer acytokinetischen Häutung. Sie ist selten und wurde viermal beobachtet, wobei der Vorgang im einzelnen aber nur in drei Fällen verfolgt werden konnte. Diese drei Trennungen fanden in einer einzigen Kolonie statt. Zunächst die Situation (Abb. 9a): In einer siebenzelligen Kette sind zu Beginn der Beobachtung Zellen 1 und 2 noch ungestreckt oder im Beginn der Streckung, Zellen 3 und 4 in Prophase (Abb. 9a); Zelle 5 ist abgestorben, Zelle 6 befindet sich gerade in Anaphase der zu besprechenden acytokinetischen Häutungsteilung und die zweite Endzelle (Nr. 7) in Streckung. Die Zellen 3 und 4 werden etwa 45 Minuten später in die Häutungsteilung eintreten. Die Beobachtung, daß drei Nachbarzellen der abgestorbenen Zelle diesen wenig häufigen Vorgang einleiten, läßt vermuten, daß die Teilungen durch die tote Zelle induziert wurden; diese Teilungen laufen außerdem, wie im folgenden gezeigt wird, vorzeitig ab.

Die Zellen 3 und 4, die nun näher verfolgt werden sollen (Abb. 9), sind zu Beginn der Mitose 24,5 $\mu \mathrm{m}$ (Zelle 3) bzw. $25 \mu \mathrm{m}$ (Zelle 4) lang, während die Längen von Metaphasezellen gleicher Breite bei vegetativer Zellteilung oder normaler Trennteilung $27-28 \mu \mathrm{m}$ betragen würden. Die Kernteilung wird also eingeleitet, wenn die Zelle gegenüber einer Zweiteilung noch nicht voll gestreckt ist, und darauf bezieht sich auch der oben verwendete Ausdruck „vorzeitig“. Bereits während der Metaphase kommt es in der Nähe der epithekalen Hörner zur Ablösung des Protoplasten von der Wand. Im Verlauf von Ana- und Telophase (Abb. 9c-f, Spindeln!) kontrahiert sich der Protoplast nun rasch und verlagert sich aus der Epitheka in die Hypotheka. Diese durch die Mitose induzierte Spontankontraktion, die man auch als Spontanplasmolyse des Protoplasten bezeichnen kann, setzt also in einem Kernteilungsstadium ein, in welchem bei normalen Zweiteilungen die Furche sichtbar würde. Merkwürdig und vorerst unerklärlich bleibt die Tatsache, daß während der Kontraktion des Protoplasten noch eine Streckung der Schalen stattfindet: bei Zelle 4 von $25 \mu \mathrm{m}$ auf $28,3 \mu \mathrm{m}$ und bei Zelle 3 von $24,5 \mu \mathrm{m}$ auf $26,5 \mu \mathrm{m}$.

Sobald sich die Protoplasten maximal kontrahiert haben, nehmen sie an ihrer freien Oberfläche die Form einer normalen Theka an. Abbildung $9 \mathrm{~h}$ zeigt dann den Beginn der Schalenbildung auf der freigelegten Oberfläche von Zelle 4, deren Mutterzelle sich inzwischen von 28,3 auf $30 \mu \mathrm{m}$ weiter verlängerte. Für diese Streckung kann man sich im Gegensatz zur oben erwähnten wenigstens eine Vorstellung machen: Die den Endschalen zukommenden Randfilamente könnten sich beim Vorwachsen in Unebenheiten der Epivalva, etwa die Borstenfenster, eingestemmt und beim weiteren Vorwachsen die Epitheka von der Hypotheka abgeschoben haben. Die Filamente selbst wurden an den neuen Schalen der Zellen 3, 4 und 6 nicht gesehen, doch ist an ihrem Vorhandensein nicht zu zweifeln, da sie auch bei den ähnlich ablaufenden Dauersporenkeimungen auftreten (Abb. 14). Schließlich findet die Trennung der beiden Theken statt (Abb. 9 i für die Zellen 3 und 4).

Das Auswachsen der Borsten wurde nur in den Anfangsstadien untersucht. Die junge Borste (Abb. 9g) steht - anders als bei normalen $Z$ weiteilungen (Abb. $5 \mathrm{k}$ ) - fast senkrecht zur Kolonieachse. Auch in dieser Hinsicht besteht eine Ahnlichkeit zur acytokinetischen Häutungsteilung während der Dauersporenkeimung, wobei später typische 


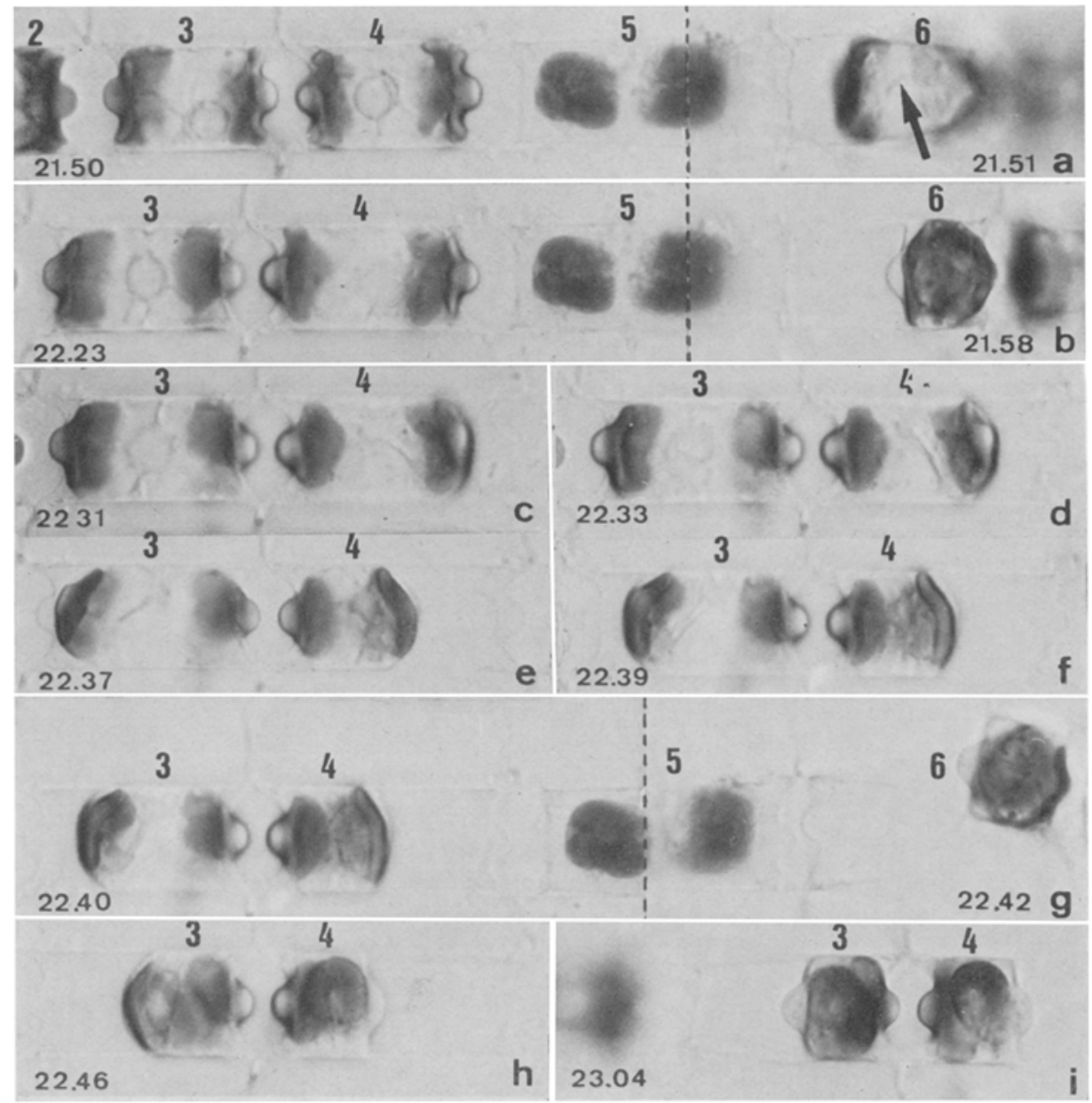

Abb. 9: Clatetoceros didymum. Acytokinetische Kolonietrennung. (a) Zelle 5 ist abgestorben und bewirkt offenbar Trenntellungen in Zellen 3 und 4 (frithe Prophasen) und in Zelle 6 (Telophase, Spindel schräggestellt: Pfeil; induzierte Plasmolyse hat begonnen). (b) In Zelle 4 löst sich die Kernhülle auf; Protuberanz in Zelle 6 bereits ausgebildet. (c) und (d) Auflösen der Kernhülle in Zelle 3; Zelle 4 in Telophase mit schräggestellter, sich in (d) etwas drehender Spindel; beginnende induzierte Plasmolyse. (e) und (f) Zelle 3 in Telophase mit deutlicher Spindel und Plasmolyse; Kontraktion ron Zelle 4 fast beendet. Kerne sind aufeinander zu gewandert. (g) Spindel in Zelle 3 beginnt sich aufzulösen; Zelle 6 hat sich von Kolonie abgelöst, Borsten wachsen aus. (h) Protuberanz in Zelle 4 ausgebildet. (i) Zellen 3 und 4 haben sich als zweizellige Kolonie aus Fadenverband gelöst; Dauerlebendbeobachtung mit Zeitangaben. (a), (b) und $(g)$ aus $z w e i \mathrm{zu}$ verschiedener Zeit (Zeitangaben!) belichteten Teilaufnahmen zusammengesetzt (gestrichelte Trennlinie!). Weitere Erklärungen im Text; (1000:1)

Endborsten entstehen. So haben wir auch hier keinen Zweifel, daß nach acytokinetischen Kolonietrennungen schließlich Endborsten entwickelt werden.

Das Ergebnis der geschilderten Trennprozesse ist für die betrachtete Kolonie ein aus den Zellen 1 und 2 gebildeter Faden, der rechts mit einer leeren Epitheka endet, 
eine zweizellige Kolonie (Zellen 3 und 4) mit Endschalen, eine tote Zelle mit beiderseitig anhängenden leeren Epitheken, die somit elegant eliminiert wurde, und eine aus den Zellen 6 und 7 gebildete normale $z$ weizellige Kolonie.

Schließlich ist noch das Verhalten der Kerne und Plastiden während der geschilderten Vorgänge zu erörtern. Der durch acytokinetische Trennteilung entstandene Protoplast besitzt gegenüber dem durch Zellteilung entstandenen zwei Kerne und zwei Plastiden. Aus weiter unten zu schildernden Beobachtungen in analogen Fällen (vgl. p. 408) ist anzunelımen, daß der überzählige Kern pyknotisch und schließlich aufgelöst wird, die Plastiden aber beide erhalten bleiben, und daß entsprechend die Plastidenteilung in der Interkinese vor der sich anschließenden Zweiteilung ausfällt.

\section{Zellgröße, Allometrie und entwicklungsgeschichtliche. Potenz}

Die in Kuitur erzeugten Erstlingszellen aus Auxosporen von Chaetoceros didymum sind im Mittel 34,7 $\mu \mathrm{m}$ (maximal $39 \mu \mathrm{m}$ ) breit, womit die obere Grenze des Breitenbereichs angegeben ist. Extrem schmale Zellen, welche bereits Unregelmäßigkeiten und Ausfälle bei der Borstenbildung zeigen, liegen bei etwa $7 \mu \mathrm{m}$ Apikallänge.

Wie bei allen Diatomeen finden sich auch bei $C$. didymum Allometrien der Zellform, die in Verbindung mit dem gesetzmäßigen Zellbreitenwechsel stehen und hier besonders auffällig sind. Soweit sie das Längen-Breitenverhältnis und die Gestalt des Zellquerschnittes betreffen, wurden sie auf p. 389 behandelt. Die früh-interphasische Zellänge bleibt im Breitenwechsel anscheinend unverändert, so daß hier die bei Stephanopyxis festgestellte (v. STosch \& Drebes 1964) partielle Kompensation des Volumenverlustes schmaler Zellen durch Längenerhöhung fehlt. Für den Gestaltwechsel der "Fenster" zwischen den Zellen, bei Gleichbleiben der Protuberanzen in Größe und Form, vergleiche man Abbildung $7 \mathrm{a}$ mic Abbildung $15 \mathrm{a}$ und für jenen Dauersporen Abbildung 12k mit Abbildung 14a.

Unser Klon ist wie alle bisher untersuchten Diatomeen monözisch. Beim Herabteilen der Zellen gibt es wie üblich nach einem Bereich hoher bis mittlerer Zellbreiten, in dem nur vegetative Entwicklung möglich ist, einen solchen geringerer bis kleinster "A A pikallängen ", in welchem daneben noch Sexualzellen differenziert werden können. Die Zellbreite an der oberen Grenze des sexuellen Größenbereichs wurde nicht genau bestimmt, sie dürfte bei etwa $19 \mu \mathrm{m}$ liegen. Innerhalb des "sexuellen Bereichs" können sich ganz schmale Zellen von etwa $10 \mu \mathrm{m}$ abwärts nur noch männlich differenzieren und Zellen etwas höherer Zellbreiten Oogone und Spermatogone bilden. Ob nach oben noch ein Breitenbereich mit rein weiblicher Potenz folgt, wie bei Melosira warians (v. Sтоsсн 1951) und Biddulphia rbombus (v. STOSCH 1956), wurde nicht ermittelt. Dauersporen entstehen aus maximal breiten Zellen bis herab zu solchen (etwa $10 \mu \mathrm{m}$ breiten), die noch Oogone zu bilden vermögen.

\section{Bildung der Dauersporen}

Viele Chaetoceros-Arten sind zur Bildung von Dauersporen befähigt; die wichtigste Literatur dazu wurde in der Einleitung angefüht. Bei der Mehrzahl der Spezies 
sind die Dauersporen-Mutterzellen von den vegetativen Zellen nicht deutlich verschieden; sie entstehen in Paaren, gelegentlich aber auch einzeln. Die Dauerspore selbst bildet sich innerhalb der Mutterzelle, wobei ihre beiden Valven nacheinander und jeweils im Gefolge einer acy tokinetischen Mitose ausgeschieden werden. Derartige innere Kernteilungen verursachen an Stelle einer Furchung nur eine einseitige Kontraktion des Protoplasten, eine gerichtete Spontanplasmolyse. An der freigelegten Oberfläche wird dann die neue Schale ausgeschieden, während der überzählige Tochterkern der Mitose pyknotisch und später resorbiert wird.

Diese Mitosen bzw. die von ihnen erzeugten pyknotischen Kerne wiesen wir nach bei $C$. compressum, $C$. teres und $C$. costatum. Nach beiden Kernteilungen entstehen nur Valven. Dabei paßt sich der Mantel der umgriffenen Schale in den Mantelrand der umgreifenden Schale ein (v. STosch in ETTL, et al. 1961\%). Die reife Spore liegt dann nach beiden Seiten mehr oder weniger frei in der Mutterzelle (Abb. 10). Ahnlich verhält sich Bacteriastrum byalinum (siehe z. B. Meunier 1913), wie von Drebes (1972) genau geschildert wurde.

Nach diesem Modus werden auch die Dauersporen von C. costatum gebildet, die in Abbildung 10 nach Kulturmaterial wiedergegeben sind. An früheren Darstellungen der Dauersporen dieses Chaetoceros finden wir neben derjenigen von MEUNIER (1913,

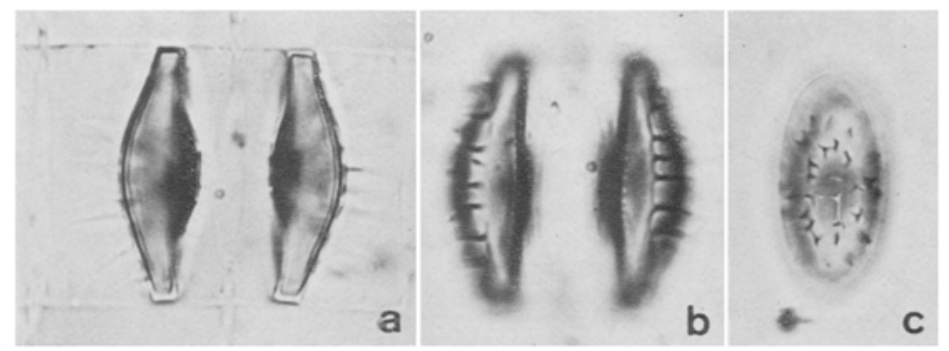

Abb. 10: Chdetoceros costatum, (a) Paar won Sporen innerhalb der Mutterzellen; außen die stärker gewölbten Epivalven der Sporen. (b) Gleiches Sporenpaar, hohe Einstellung. (c) Aufsicht auf Epivalva; $(1000: 1)$

dort als C. crinitum Schütт [?]) die Abbildungen von Cupp (1943, Fig. 79) und von GAARDER (1951, Fig. 5), Bei Sporenformen, die der unseren allgemein ähneln, fehlen allen drei die Borsten an den Unterschalen, was aber mit den Entwicklungsstadien der betreffenden Proben zusammenhängen kann. Die von GAARdER abgebildeten Sporen zeigen außerdem im Vergleich zu unserer Form einen erheblich dichteren Besatz mit kürzeren Stacheln. Vielleicht existiert mehr als eine Varietät von C. costatum. Die Epivalva der Dauerspore ist an der Ubergangstelle zwischen Mantel und Diskus und auf der Fläche von Kieseldornen besetzt. Die Dornen auf der Fläche sind im Querschnitt meist dreistrahlig, außerdem besitzt der freie Mantelrand eine grobe Streifung. Die Hypovalva trägt kurze Dörnchen nư im zentralen Bereich.

Im zweiten, viel selteneren Typus der Dauersporenbildung, dem $C$. didymum

* Chaetoceros compressum Klon II wurde in dieser Arbeit fälschlich als $C$. messanensis bezeichnet; letztere Art ist tropisch, und Sporen scheinen bei ihr nicht bekannt zu sein. 
folgt (daneben C. cinctum GRAN, C. radicans ScHütT und C. furcellatum BAnteY), sind die Mutterzellen nahezu immer gepaart, und ihre Hypovalven zeichnen sich durch Borstenpaare aus, die von anderen Borstentypen der Kolonie stark abweichen. Die Spore ist wenigstens bei $C$. didymum (siehe auch MANGIN 1912) im Prinzip so gebaut, wie diejenige des häufigen Typus, liegt aber der Mutterzellen-Hypovalva so eng an, daß ihre eigene Hypovalva ohne Präparation kaum zu erkennen ist (siehe Abb. $5 \mathrm{e}$ in v. Stosch \& KowAllik 1969). Letztere wurde damals ohne Kenntnis der Arbeit Mangrns und auch der Sporen selbst als nicht vorhanden angesehen, und die Sporenbildung von $C$. didymum in ETTL et al. (1967) unter $1 \mathrm{~b} \beta$ der dort gegebenen Klassifkation der Dauersporen unrichtig eingeordnet. In Wirklichkeit liegt nur eine Sonderform des Chaetoceros-teres-Typs $2 \mathrm{a} \beta$ vor.

Dauersporen entstehen bei $C$. didymum vor allem in älteren Kulturen. Die Neigung dazu ist deutlich abhängig von der genetischen Konstitution der Klone. Von 10 aus Auxosporen, also sexuell entstandenen Klonen, lieferten nur drei Klone sehr leicht Dauersporen. Bei Klon III J traten Sporen bereits in schwach besiedelten Kulturen auf, wobei große Teile des vegetativen Materials verbraucht wurden; die Gesamtproduktion der Kultur stieg daher nur langsam an. Die Temperaturansprüche für die Sporenbildung wurden nicht im einzelnen untersucht. Es hat sich jedoch gezeigt, daß höhere Temperatur $\left(21^{\circ} \mathrm{C}\right.$ an Stelle von $\left.15^{\circ} \mathrm{C}\right)$ die Sporenbildung fördert. Bei $9^{\circ} \mathrm{C}$ und tiefer wurden Dauersporen nicht mehr beobachtet.

Die Entwicklung der Dauersporen dauert unter den Beobachtungsbedingungen 36 bis 48 Stunden, gerechnet vom Einsetzen der heterovalvaten Teilung, die zur Bildung eines Paares von Sporenmutterzellen führt. Daher konnte der Gesamtvorgang nicht von einer Zelle ausgehend durchbeobachtet werden. Die (Dauersporen-)Paar-Mutterzelle ist im Augenblick der Metaphase noch nicht von einer sich zur vegetativen Vermehrung anschickenden Zelle zu unterscheiden. Die Furche schneidet dann aber im Vergleich zur normalen Zellteilung sehr viel spitzer ein (vgl. Abb. 12a mit 7a), das sich entwickelnde Fenster zwischen den Heterovalven ist schmal rechteckig, und die Protu-

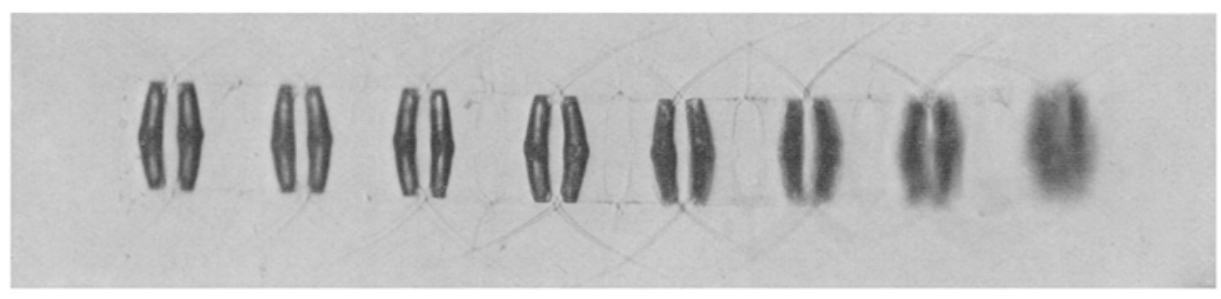

Abb. 11: Chaetoceros didymum. Kolonie mit Dauersporenpaaren; $(300: 1)$

beranzen werden nur angedeutet. Die danach auswachsenden Borsten (Abb, 12c und $\mathrm{i}-\mathrm{k}$ ) sind wesentlich dicker als gewöhnliche Kolonieborsten, werden aber zur Spitze hin ganz allmählich schmäler (Abb. 11). Ihre Wachstumsgeschwindigkeit ist mit $7 \mu \mathrm{m}$ pro Stunde vergleichsweise gering.

Die Borsten haben ungefähr die Form eines Parabelastes und bleiben im Unterschied zu normalen Borsten in der Apikalebene der Zelle. Kolonien mit reichlicher 


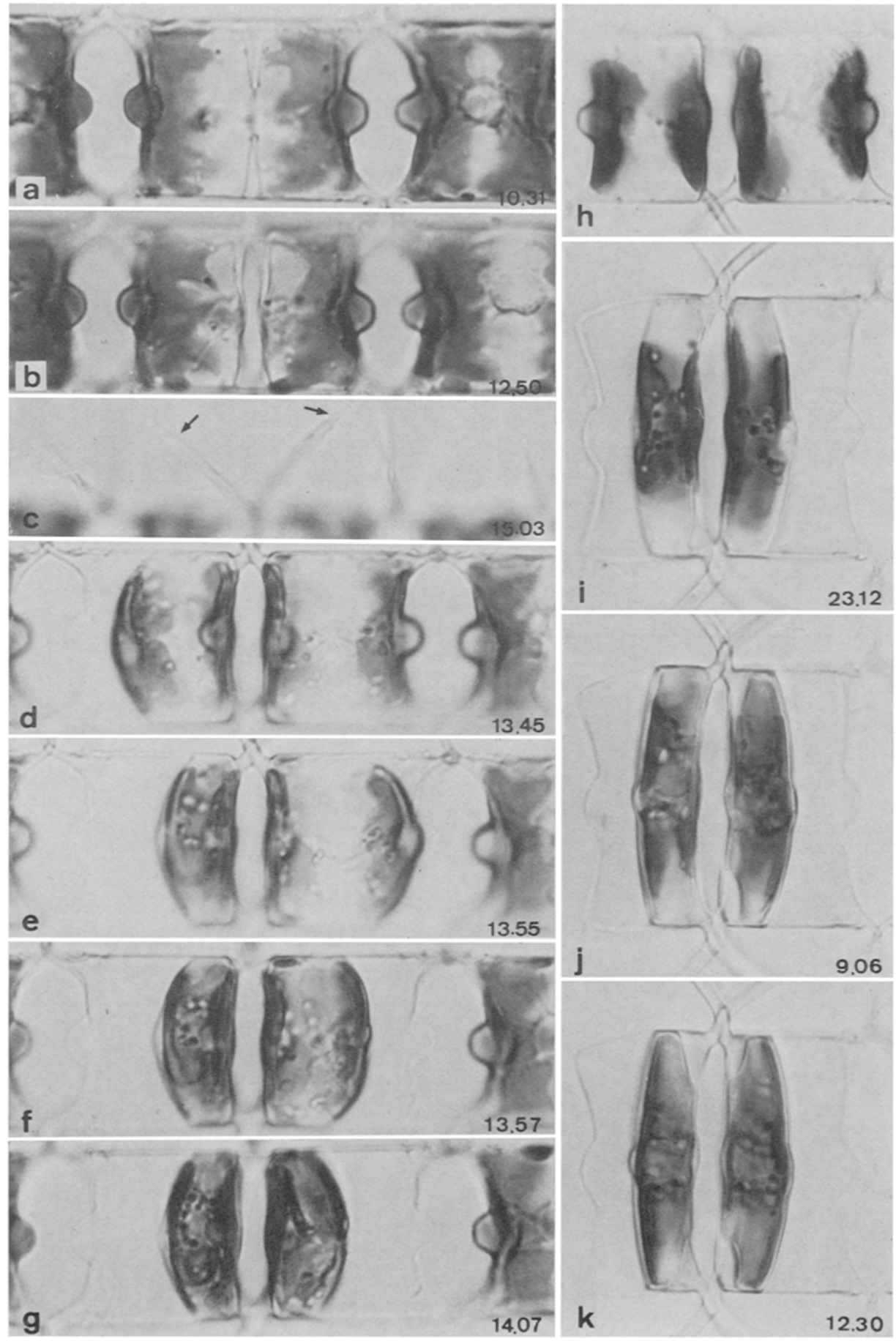

Abb. 12 
Dauersporenbildung bekommen dadurch ein eigenartiges Aussehen (Abb. 11). Achselfächer fehlen den Borsten der Hypovalven von Dauersporen-Mutterzellen (Abb. 13b), doch kann an ihrer Stelle gelegentlich elektronenmikroskopisch ein kurzes ungeteiltes Fädchen nachgewiesen werden. Wegen der größeren Dicke dieser Borsten kann hier leichter als an anderen Borstentypen gesehen werden, daß eine dünne Plasmaseele apikal vorauswächst und die Ausscheidung der viel weiteren Kieselhülle erst etwa $5 \mu \mathrm{m}$ hinter ihrer Spitze beginnt. An deren apikalem Ende entsteht dann eine deutliche Stufe (Abb. 12c).

Eine weitere Besonderheit der Heterovalven zeigt Abbildung 13b, in der das Schalenpaar noch relativ jung ist (etwa 2 Stunden nach der Cytokinese). In das Fenster der Paar-Mutterzelle, das zunächst vom Gürtel bedeckt ist, wachsen parallel zur Pervalvarebene von jeder Heterovalva zwei Kieselsäurelamellen aus. Dabei liegt die eine Lamelle oberhalb, die andere unterhalb der Pervalyarebene. Später scheinen sich die gegenüberliegenden Lamellen zu treffen und zu vereinigen, wodurch das Fenster elektronenmikroskopisch fast undurchstrahlbar wird.

In der lichtmikroskopischen Aufnahme der Abbildung 13a sind die Dauersporen bereits gebildet. Der Gürtel der Paar-Mutterzelle, welcher in Abbildung 13b noch erkennbar über dem Fenster liegt, ist infolge der der Sporenbildung vorausgehenden Streckung vom Fenster abgezogen, so daß die erwähnte Sekundärlamelle nun freiliegt; man sieht, besonders bei dem rechten Sporenpaar, daß auch sie Offnungen für die Borsten ausspart. Sehr selten kann eine einzelne Endzelle als Dauersporen-Mutterzelle dienen, wobei die Endvalva dann die Stelle der Hypovalva der Dauersporen-Mutterzelle einnimmt. Offensichtlich endete die Bildung einer Paar-Mutterzelle in einer - ebenfalls heterovalvaten - Trennteilung, wobei normale Endborsten an Stelle der Dauersporenborsten entstanden. Dadurch erhält auch die Endschale das Paar von Kieselsäurelamellen, die in diesem Fall naturgemäß frei enden.

Im nächsten Entwicklungsschritt wird innerhalb jeder Mutterzelle infolge einer acytokinetischen Mitose die Sporen-Epivalva gebildet. Das geschah in den beobachteten Abläufen nach $Z$ wischenschaltung einer Dunkelperiode, und zwar im ersten Fall, bei dem die heterovalvate Teilung am frühen Vormittag lag, etwa 23 Stunden später. Im anderen Falle, wo die heterovalvate Teilung erst gegen Ende der Dunkelperiode erfolgte, setzte die acytokinetische Mitose bereits nach 11 Stunden ein. Die Streckung der Dauersporen-Mutterzelle in Vorbereitung der ersten schalenbildenden inneren Mitose nimmt sehr viel geringere Ausmaße an, als wenn eine Vermehrungsteilung oder die Teilung einer Paar-Mutterzelle erfolgen soll; sie führt auf eine Länge von $21,6 \mu \mathrm{m}$ gegenüber 32,6 $\mu \mathrm{m}$ (gemittelt aus je 8 Messungen). Die Teilung und Umlagerung der Plastiden erfolgte etwa 2 Stunden vor der inneren Mitose. Der Kern wandert zum

Abb. 12: Chatoceros didymum, Dauersporenbildung. (a) und (b) Heterovalvate Teilung liefert zwei Sporenmutterzellen mit Hypovalven, die strukturell von den vegetativen abweichen. (a) Furchung. (b) Dauersporen-Mutterzellpaar mit beginnender Borstenbildung; Nachbarzelle redits in Metaphase zur heterovalvaten Teilung. (c) Borsten des Mutterzellpaares im Wachstum; plötzliche Verjüngung am Kieselmantel zur vorauseilenden protoplasmatischen "Core" erkennbar (Pfeile). (e)-(g) Anderes Mutterzellpaar in acytokinetischer Bildung der Dauersporen-Epivalven. (h) Rechts Anaphasefigur eines anderen Zellpaares während der gleichen Teilung gut zu erkennen; Rückzug der Plasmaoberfläche hat ganz rechts soeben begonnen. (i)-(k) Andere Serie. (j) Plasmolyse zur Bildung der Dauersporen-Hypovalven in redter Zelle.

(k) Nahezu fertige Sporen. Mit Zeitangaben. Weitere Erklärungen im Text; $(1000: 1)$ 
gleichen Zeitpunkt im oberen oder unteren Wandbelag in das Zentrum der Zelle, wo er auch noch bei Eintreten der Mitose liegt. Die Kernteilung findet meist mit einer schräg zur Längsachse der Zelle gestellten Spindel statt (Abb. 12d und h, rechte Zelle), und in der späten Anaphase beginnt die Spontankontraktion des Protoplasten mit einer Räumung der Bereiche nahe den Borstenbasen der Epitheka (Abb. 12h). Sehr rasch entsteht eine gerundete Kuppe (Abb. 12d), aus der zunächst noch das dort liegende Pyrenoid als Vorwölbung heraussteht, das sich dann aber bald in die Kuppe einsenkt (Abb. 12d-f). Die Plasmolyse geht weiter, bis der Protoplast der prospektiven Dauerspore weniger als das halbe Volumen der Mutterzelle erreicht hat. Die freigelegte Oberfläche besitzt zu diesem Zeitpunkt (etwa 15 Minuten nach Beginn der Kontraktion) eine gleichmäßige Krümmung, in deren Scheitel sich darauffolgend eine stumpfe Spitze oder bei breiteren Zellen eine schwache Vorwölbung, das Aquivalent der Protuberanz, ausbildet. Doch geschieht dies vermutlich schon im Zuge der Valvenbildung, die sich auf der freigelegten Oberfläche abspielt und auf ihr den Valvendiskus liefert, während der kurze Valvenmantel zwischen den Gürtel der Mutterzelle und dem an ihn anstoßenden Protoplasten ausgeschieden wird. Die Wölbung der so gebildeten Dauersporen-Epitheka ist flacher bei sehr breiten, höher bei schmalen Zellen (vgl. Abb. $12 \mathrm{j}$ mit Abb. $12 \mathrm{~g}$ und Abb. 14a). Das Verhalten der Kerne in Telophase und danach ist im Leben schwer zu sehen. Der eine Tochterkern gelangt in die Rückzugskuppe und der andere scheint sich nach Aufhören des Spindeldruckes auf ihn zuzubewegen. Cytologische Präparate (Abb. 24, 25) zeigen zu etwas späterem Zeitpunkt beide Kerne vereinigt nahe am Zentrum der sich bildenden Valva, worauf schließlich einer von beiden degeneriert und pyknotisch wird. Auf Einzelheiten gehen wir weiter unten (p. 435 ff.) ein.

Nach einer weiteren Dunkelperiode läuft dann die zur Bildung von Unterschalen führende zweite gezielte und dadurch formbildende Spontanplasmolyse ab, ohne daß zuvor eine Teilung der Plastiden erfolgte. Auch sie ist das Ergebnis einer inneren Mitose, die jedoch infolge der Materialanhäufung in der lebenden Zelle nicht gesehen, im cytologischen Präparat aber demonstriert werden konnte. Wieder abortiert ein Tochterkern (Abb. 24d, 25d, e). Der äußere Effekt der induzierten Plasmolyse in dem eingeschränkten Raum zwischen Dauersporen-Epivalva und Mutterzell-Hypovalva ist gering. Bei schmäleren Zellen wird nur die nächste Umgebung der Borstenbasis geräumt, und die neue Hypovalva, die der Mutterzellen-Hypovalva angepreßt ist, läßt hier einen kleinen dreieckigen Raum frei (Abb. 14a, b); bei breiten Zellen sind die Aussparungen größer (Abb. 12j, k). Wie Abbildung 13d zeigt, sind die Aussparungen nur Teil einer den ganzen Mantelrand der Hypovalva umlaufenden Hohlkehle. Diese letztere ist, wie die Abbildung erkennen läßt, mit zarten Rippen oder Feldern versehen.

Nach Fertigstellung lösen sich die Dauersporenpaare von den Epivalven der Mutterzellen und sinken zu Boden (Abb. 14a).

\section{Keimung der Dauersporen}

Dauersporen entstehen in älteren Kulturen bei beginnendem Nährstoffmangel. Es kommt aber durchaus vor, daß sie unter diesen Umständen auch wieder keimen. Voll- 
ständig und innerhalb von 24-28 Stunden geschieht dies, wenn man die Sporenpaare in frisches Medium überträgt. Dormancy-Phänomene konnten dabei nicht beobachtet werden.

Im Zuge der Keimung muß der Organismus die Dauersporen-Valven durch gewöhnliche Endschalen ersetzen. Dieses gechieht durch Schalenabwurf, herbeigeführt durch zwei aufeinanderfolgende acytokinetische Mitosen mit anschließender Bildung je einer normalen Endschale. Umgekehrt kann die Dauersporenbildung als eine Häutung beschrieben werden, bei der nach Entstehung der Dauersporenschalen die Mutterfrustel abgeworfen wird.

$\mathrm{Zu}$ Beginn der Keimung streckt sich die Dauerspore (Abb. 14b, c). Dabei wird an ihrer Hypovalva ein Gürtel ausgebildet. Hat die Spore die doppelte Länge erreicht, so wird der in Richtung zur Sporen-Epivalva hin verschobene Prophasekern sichtbar

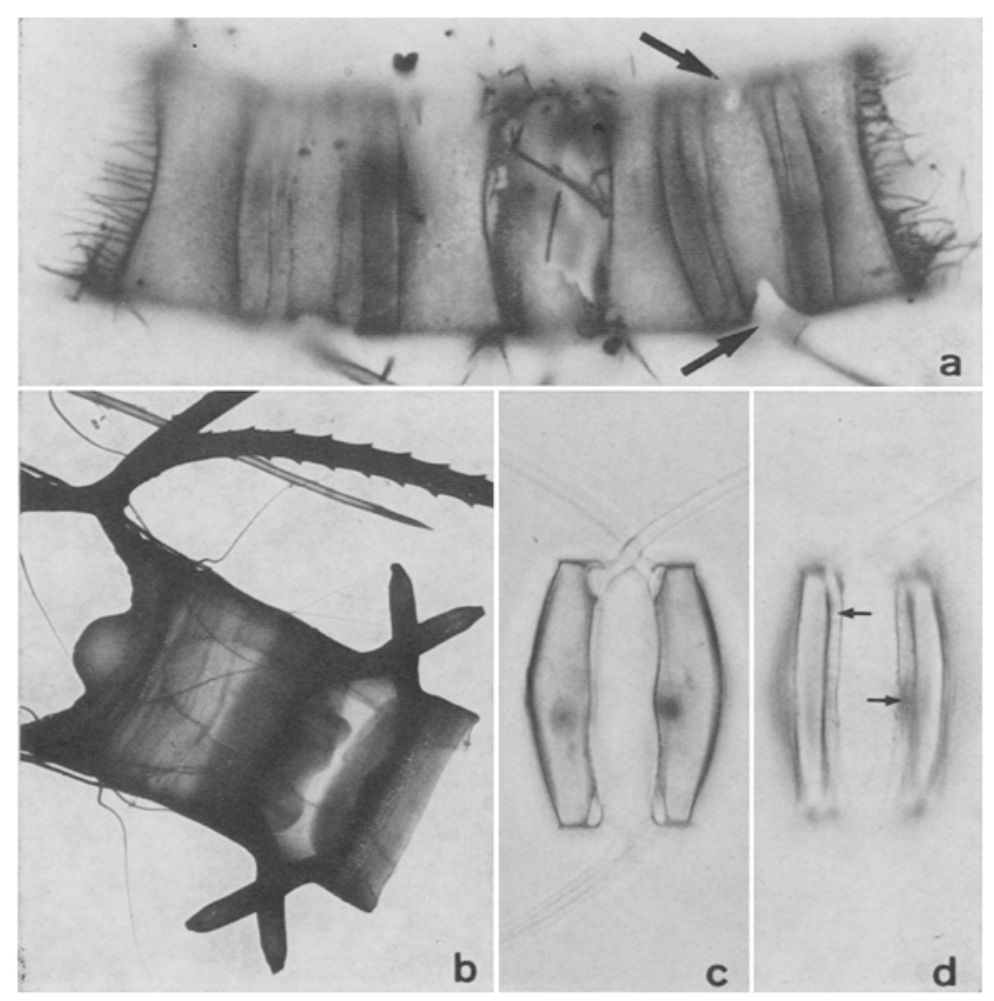

Abb. 13: Chaetoceros didymum. (a) Ursprünglich zweizellige Kolonie hat zwei Paare von Dauersporen gebildet; links und rechts sind die Filamente an den Endschalen zu erkennen. Bei beiden Dauersporenpaaren haben sich die sekundär in den Interzellularraum vorgewachsenen Kiesellamellen vereinigt, aber Borstenöffnungen freigelassen, deutlich bei rechtem Dauersporenpaar (Pfeil). Überfärbtes EKE-Präparat; $(1000: 1)$. (b) Dauersporen-Mutterzellpaar mit auswachsenden Borsten. Sekundäre Kiesellamellen schieben sich innerhalb des Gürtels der PaarMutterzelle in den Interzellularraum vor. Oben links: Paar von vegetativen Sonderborsten; elektronenmikroskopisch; (ca. 1500:1). (c) und (d) Dauersporenpaar in zwei optischen Einstellungen. Die Kannelierung der in (c) im optischen Schnitt sichtbaren Dauersporen-Hypovalva läuft um die Schale (d) und zeigt zarte Längsrippung (Pfeil); $(1000: 1)$ 
(Abb. 14c, d). Die Plastiden liegen noch in den Valven. Der Kern teilt sich nun mit schräggestellter Spindel, und während der Anaphase beginnt die polarisierte Spontanplasmolyse des Protoplasten aus der Epitheka heraus (Abb. 14e-g). Sobald die Ränder

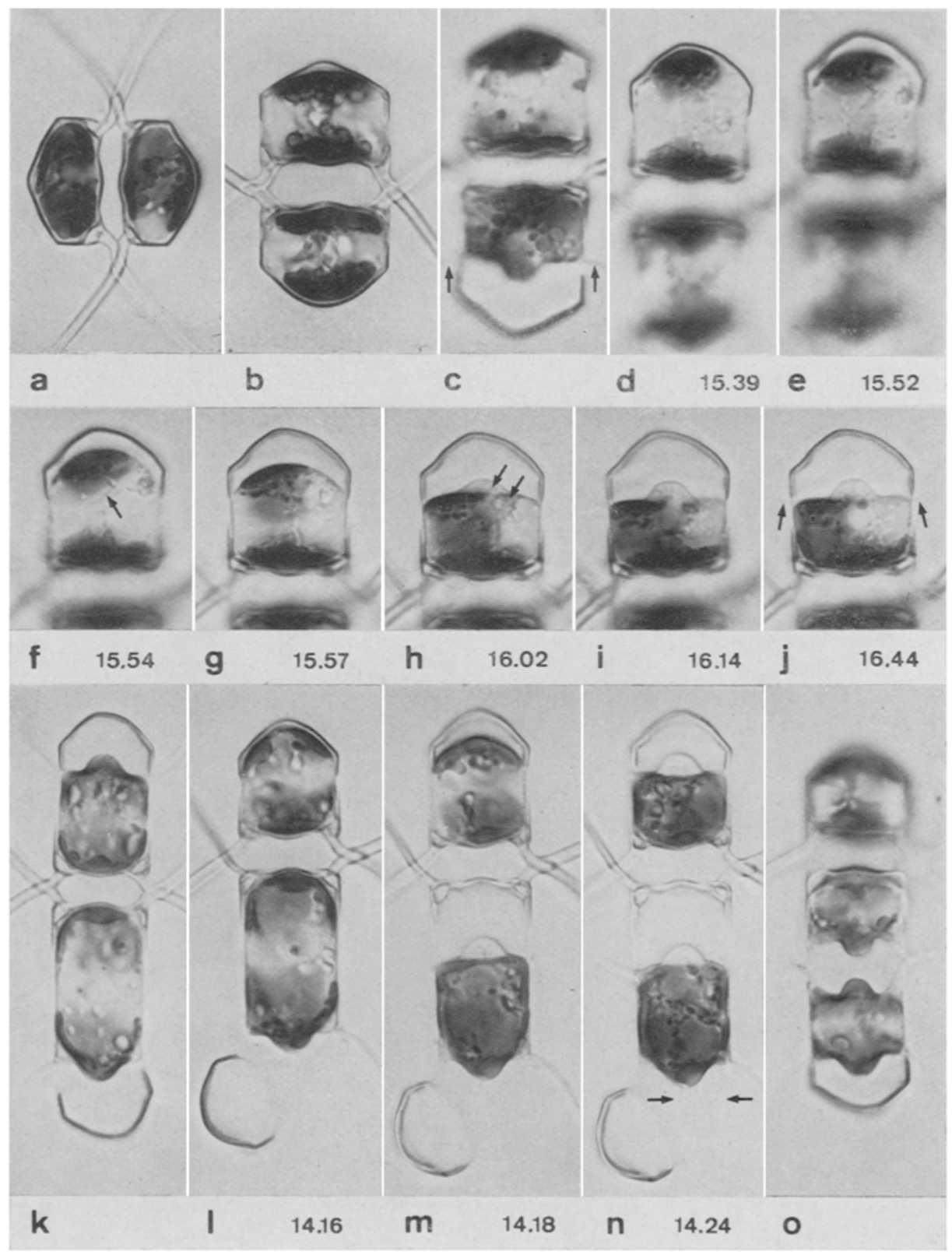


des gewölbten Rückzugsmeniskus die Höhe des epivalvaren Mantelrandes erreicht haben, kommt die Bewegung zur Ruhe. Der Meniskus flacht sich ab, wobei auch die Protuberanz herausmodelliert wird (Abb. 14h, i). Bereits während der Telophase wandert die zunächst zentral im Meniskus liegende Plastide seitlich auf die Pleura zu (Abb. $14 \mathrm{e})$. An die freigewordene Stelle tritt in die sich entwickelnde Protuberanz der nächstgelegene Tochterkern hinein. Nach cytologischen Präparaten folgt bald auch der zweite Tochterkern. Der eine von beiden Kernen degeneriert später und wird pyknotisch. Danach erscheinen die Borsten (Abb. 14j). Wenn diese bereits eine beträchtliche Länge erreicht haben, wandert die Plastide zurück, so daß das Pyrenoid schließlich in die Protuberanz gelangt. Die neuen Valven sind vom Typus der Endvalven. Auch die Kieselsäurefilamente werden gebildet, sind aber an den einzelnen Schalen verschieden deutlich und wohl auch verschieden kräftig. Vermutlich bewirken sie die Trennung der Dauersporen-Epivalven von der neuen Valva (Abb. $14 \mathrm{k}-\mathrm{n}$ ).

Für die weitere Entwicklung bestehen zwei Alternativen: (a) Die DauersporenHypovalva und die an ihr zuvor entstandene Pleura werden durch eine Häutung abgestoßen. Dazu (Abb. 14b-n, untere Zelle) streckt sich die Zelle erheblich und tritt dann in eine zweite acytokinetische Mitose ein. Die Richtung der damit einhergehenden polarisierten Plasmakontraktion ist zur ersten entgegengesetzt. Die Dauersporenkeimung wird schließlich durch die Schalen- und Borstenbildung abgeschlossen, wodurch eine einzellige Kolonie mit zwei Endschalen entstanden ist. (b) Die Keimlingszelle stredkt sich und absolviert danach eine normale Zellteilung mit dem Resultat einer zweizelligen Kolonie, als deren eine Endschale die Sporen-Hypovalva fungiert (Abb. 14o). Ob letztere später durch Häutung entfernt wird, ist unbekannt.

Frühere Beobachtungen der Keimung von Chaetoceros-Sporen stammen von Lohmann (1920) und Mrchailova (1962), jene der letzteren an C. lauderi. In beiden Fällen ist es wahrscheinlich, daß die Vorgänge sich ähnlich abspielen wie bei unserem Objekt. Zur Beurteilung im einzelnen sind die gegebenen Zeichnungen jedoch nicht detailliert genug; insbesondere fehlen auch Beobachtungen der Entwicklungsabläufe. Da das letztere auch für eigene Erfahrungen mit C. compressum-Keimungen zutriff, verzichten wir auf die Diskussion der bei diesen beobachteten Abweichungen im Bau der Keimlinge gegenüber dem oben Geschilderten.

Abb. 14: Chaetoceros didymum, Dauersporenkeimung. (a) Dauersporenpaar, aus der Mutterzelle herausgefallen. (b) Dauersporenpaar, beginnende Keimung. (c) Obere Zelle in Prophase zur ersten Häutungs-Acytokinese, die die Dauersporen-Epivalva durch eine Endschale ersetzen wird; bei unterer Zelle Abwurf der Dauersporen-Epivalva bereits vollzogen, Endborsten an neuer Valva wachsen aus (Pfeile). (d)-(j) Serienbeobachtung einer ersten Keimungs-Acytokinese: (d) frühe Metaphase. (e) und (f) Späte Anaphasen mit beginnender Spontanplasmolyse. (f) Spindel (Pfeil) knickt ab; (g) Tochterkerne in Telophase, nähern sich einander. (h) Beide Kerne liegen in Protuberanz (Pfeile). (i) Protuberanz fertig entwickelt. (j) Borsten der neuen Endvalva wachsen aus (Pfeile). (k) Untere Zelle nach starker Streckung in Prophase zur zweiten Häutungsteilung; obere Zelle in beginnender Streckung zur gleichen Teilung. (l)-(n) Beobachtungserie: untere Zelle in zweiter Häutungs-Acytokinese, obere in erster Häutungsteilung. (1) Untere Zelle beginnt mit Ruckzug aus Dauersporen-Hypovalva. (m) Protuberanz der $z$ weiten Endvalva fertiggestellt. (n) Endborsten wadsen aus; Kieselfilamente an Epivalva sichtbar (Pfeile). (o) Sporenpaar, dessen obere Spore mit der Keimung beginnt, wathrend die untere die Sporen-Epivalva acytokinetisch abgeworfen und sich dann cytokinetisch geteilt hat. $Z$. T. mit Zeitangaben. Weitere Erklärungen im Text; $(1000: 1)$ 
Die Keimung der Spore von Bacteriastrum (DREBEs 1972) ähnelt unserem obigen Fall (a); beide Sporenschalen werden durch acytokinetische Häutungen abgeworfen.

\section{Sexuelle Fortpflanzung}

Sexualisierung tritt bei Chaetoceros didymum unter ähnlichen Bedingungen ein wie die Dauersporenbildung, d. h. im 16-Stunden-Tag bei $15^{\circ} \mathrm{C}$ und z. B. 1000 Lux. Doch beginnt sie gewöhnlich in jüngeren Kulturen als diese und hört bei dichter werdendem Bewuchs wieder auf. C. didymum ist, wie schon bemerkt, monözisch. Man beobachtet jedoch in einem Größenbereich, der beide Geschlechter zuläßt (siehe p. 403) in der Mehrzahl entweder rein männliche bzw. weibliche Kolonien, seltener solche, die Spermatogone und vegetative Zellen bzw. Oogone und vegetative Zellen gemischt enthalten. Zwittrige Kolonien werden nur gelegentlich beobachtet. Der Grund hierfür ist unbekannt.

Der Beginn der Differenzierung von Geschlechtszellen ist relativ locker an den LichtDunkel-Wechsel gekoppelt. Die erste Teilung in den Spermatogonangien setzt zwei bis drei Stunden vor Lichtbeginn ein, kann aber in Einzelfällen ebensoviele Stunden danach noch stattfinden. Die ersten empfängnisfähigen Oogone (siehe p. 419 ff.) werden gegen 14 Uhr, d. h. etwa 6 Stunden nach Lichtbeginn beobachtet. Etwa um die gleiche Zeit können die ersten Spermien des Tages reif sein.

\section{Entstehung der Spermien}

Das Spermatogonangium produziert gewöhnlich in drei aufeinanderfolgenden Teilungsperioden acht nackte diploide Spermatogone, die dann während der frühmeiotischen Schwellungsphase das Spermatogonangium öffnen. Jedes Spermatogon wird durch die beiden anschließenden meiotischen Teilungen vollständig in vier Spermien aufgeteilt.

Um die Zeit des Lichtbeginns findet man Spermatogonangien in später Prophase neben solchen, die schon eine Teilung hinter sich haben. Diese unterscheiden sich im ersteren Zustand von entsprechenden vegetativen Zellen durch etwas geringere Strekkung (Abb. 15a, noch nicht voll gestreckt), kleinere und blassere Plastiden und manche durch schwächere Ausbildung der Protuberanzen an einer ihrer Schalen, was darauf schließen läßt, daß mindestens solche Spermatogonangien bereits durch die vorhergehende Zellteilung differenziert wurden. Weiterhin treten Spermatogonangien um mehrere Stunden früher in die Teilung ein als die vegetativen Zellen der gleichen Kultur.

Die Furche der ersten Cytokinese (Abb. 15b-c) ähnelt derjenigen einer gewöhnlichen Vermehrungsteilung. Nach Brechen des Spindelrestes runden sich jedoch die Menisken allmählich halbkreisförmig bei breiterer Schalenansicht ab (Abb. 15d). Auch lösen sich die Protoplasten von den Borstenbasen. Es kann entweder zur Ausbildung schwacher Protuberanzen an den neuen Oberflächen kommen (Abb. 15f, mittleres Spermatogonangium), was auf die Bildung einer Schale hinweist, oder die Kuppe bleibt 
häufiger rand ( $\mathrm{Ab}$. $15 \mathrm{f}$. oberes und unteres Spermatogonangium) und scheidet auch in diesem Fall meist eine sehr dünne Valva aus (Abb. 15j, k). Dadurch ist die Zelle in zwei Halbspermatogonangien aufgeteilt. Diese Schalen sind in beiden Fällen äußerst zart und daher schwer zu erkennen. Borsten entstehen an ihnen niemals ( $\mathrm{Abb}$. 16a-c zeigt ihre Kieselstruktur bei stärkerer Vergrößerung). Schließlich kann die neue Oberfläche auch nackt und das Spermatogonangium damit ungefächert bleiben. C. didymum kann sich also alternativ zwischen dem Biddulpbia mobiliensis-Typ mit Halbspermatogonangien und dem Lithodesmium-Typ ohne solche (v. Sтоосн 1954) bewegen.

Bei den weiteren Teilungen werden keine Schalen mehr gebildet. Nach der ersten Spermatogonangienteilung liegen die Plastiden noch in den Valven der Mutterzelle. In der zweiten Hälfte der Interphase kommt es zur Plastidenteilung (Abb. 15e Mitte, $\mathrm{f}-\mathrm{k}$ Mitte). Die neuen Plastiden nehmen dann im allgemeinen eine im Spermatogon etwa opponierte Lage ein, wobei die Verbindungslinie ihrer Pyrenoide aber meist einen Winkel zur Längsachse der Kolonie bildet, wie es die Abbildungen zeigen. Die Polarisierung der Protoplasten in die Längsachse der Kolonie wird also häufig aufgegeben. Demgemäß schneidet die Furche der nächsten Teilung nicht senkrecht, sondern mehr oder weniger schräg zu dieser Richtung ein (Abb. 15e-k, nicht aber im unteren Spermatogon der mittleren Zelle in 15e, wo die ursprüngliche Polarität erhalten blieb).

Die beiden Teilungen innerhalb eines Spermatogonangiums sind nicht selten mehr oder weniger asynchron. Die Tochterprotoplasten bleiben nackt und runden sich ziemlich rasch $\mathrm{ab}$ (Abb. 15g, h obere und untere Zelle, $\mathrm{j}-1$ mittlere Zelle). Nach Teilung und Umlagerung der Plastiden (Abb. 15i obere und untere Zelle) kommt es innerhalb von etwa 2 Stunden zur dritten und - zumindest bei schmäleren Spermatogonangien - letzten mitotischen Teilung (Abb. 15j-1 obere und untere Zelle). Nicht selten bleibt die Durchfurchung des einen Protoplasten während der zweiten Teilung unvollständig, und die Furche geht dann früher oder später wieder zurück. Was in diesem Fall mit den Tochterkernen geschieht, ist unbekannt, doch kann man nach dem Verhalten anderer Diatomeen vermuten, daß die Zelle dann oder während der darauffolgenden Teilung tetraploid wird. Jedenfalls teilen sich auch in diesem Fall die zwei Plastiden in der Interphase. Ebenso kann die nächste Zellteilung stattfinden, die dann zwei Tochterzellen mit je zwei Plastiden liefert. Ein solches Spermatogonangium enthält schließlich sechs statt normal acht Spermatogone (Abb. $15 n$ untere Zelle, Plastiden hier erneut geteilt). Nad diesen mitotischen Teilungen tritt eine Pause von 4-5 Stunden ein, während der sich die Plastiden je zweimal teilen, so daß das normale Spermatogon nach seiner Umwandlung zur meiotisch prophasischen Spermatocyte vier Plastiden enthält (vgl. untere Mutterzelle: in Abb. 15k mit zunächst einer Plastide, in Abb. $15 \mathrm{~m}$ mit zwei Plastiden und Abb. 15n oder $\mathrm{p}$ mit vier Plastiden).

In der Folge werden die Plastiden nicht mehr geteilt, sondern nur noch verteilt. Während dieser Entwicklung nehmen die Plastiden fortlaufend an Größe ab. Ob von der ersten Zellteilung im Spermatogonangium an überhaupt noch Plastidensubstanz synthetisiert wird, läßt sich nicht abschätzen.

In den Spermatocyten, die sich nun in der meiotischen Prophase befinden, entsteht eine sich rasch vergrößernde Vakuole (Abb. 15o und p), welche die Protoplasten auf etwa das Drei- bis Vierfache ihres Volumens aufbläht. Auch das geschieht häufig asynchron unter den Spermatocyten einer Mutterzelle. Es genügt jedoch, daß etwa vier die- 


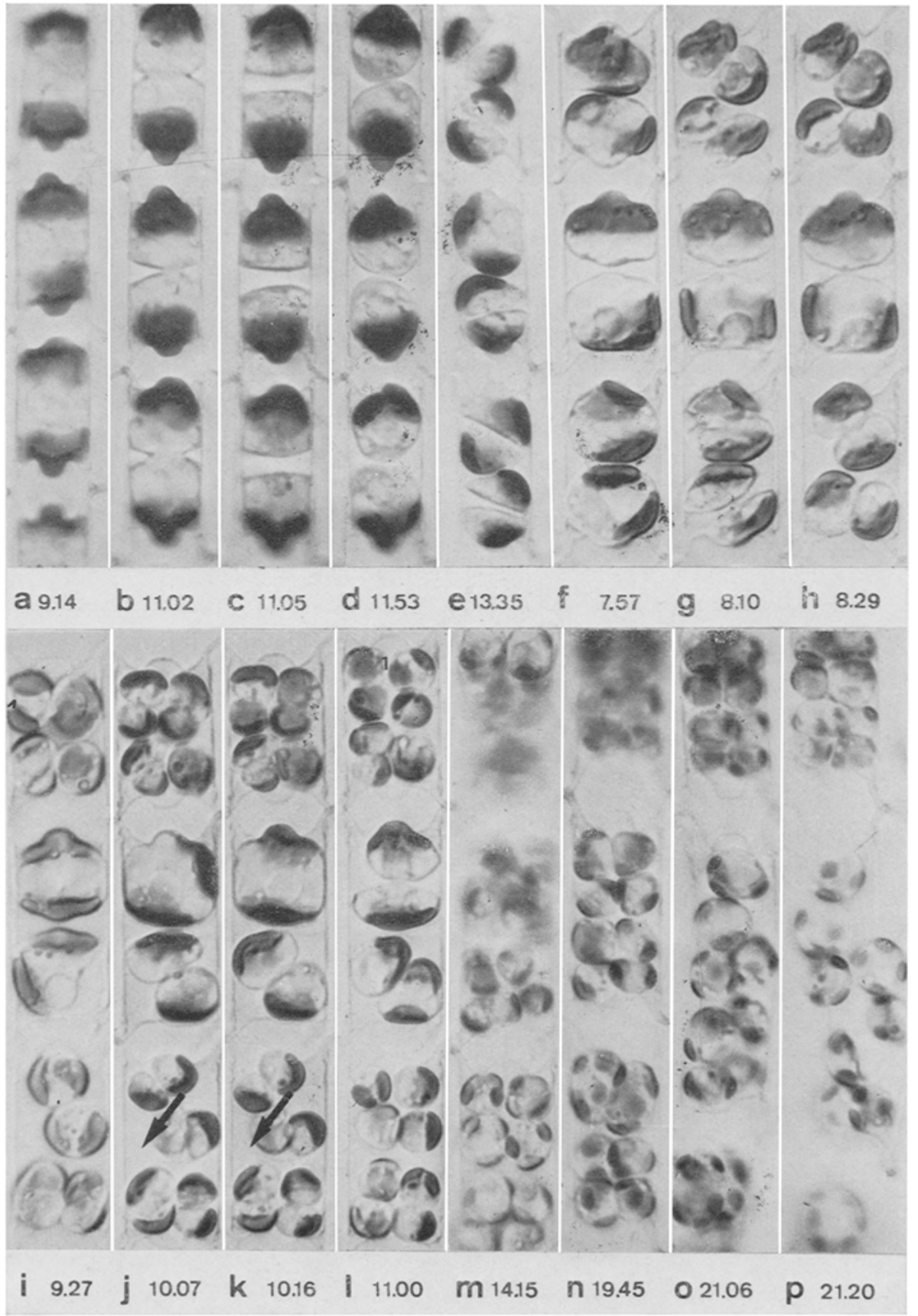

Abb. 15 


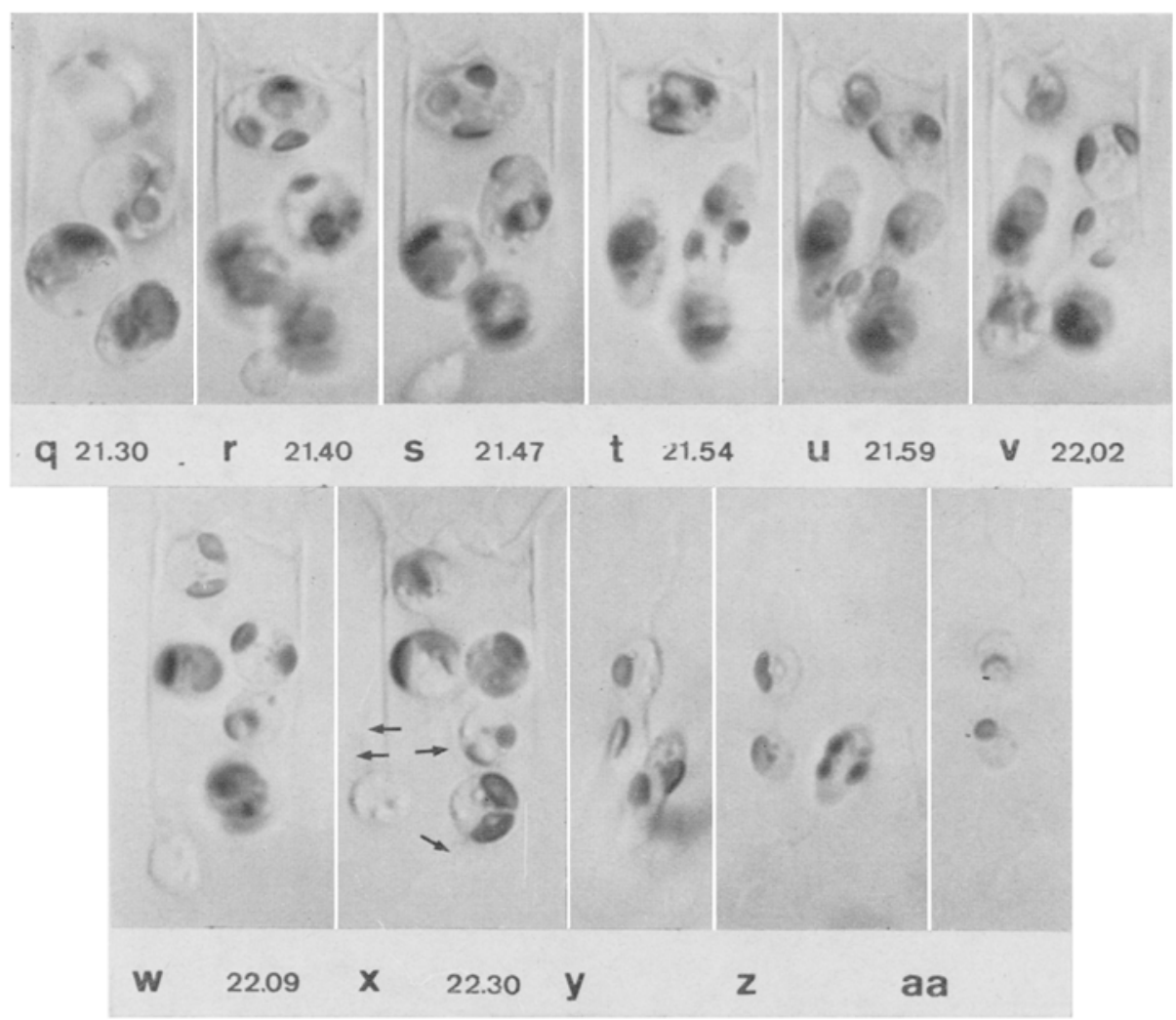

Abb. 15: Chaetoceros didymum, Spermatogenese. (a)-(e) Aufnahmeserie: mitotische Differenzierung der Spermatogone, Ein- bis Vierzellstadium. (f)-(l) Andere Aufnahmeserie der Spermatogonentstehung, $Z$ wei- bis Achtzellstadium; in ( $j)$ und $(k)$ die nach der ersten Teilung gebildeten Schalen sichtbar (Pfeile). $(\mathrm{m})-(\mathrm{x})$ Andere Serie: $(\mathrm{m})-(\mathrm{n})$ Achtzellstadium im Spermatogonangium; $(m)-(p)$ Schwellungsphase und Offnen des Spermatogonangiums; $(q)-(v)$ erste meiotische Teilung der Spermatocyten; (w)-(x) Interphase mit Bildung der Geißeln (Pfeile). (y)-(aa) Einzelbilder der zweiten meiotischen Teilung. Mit Zeitangaben. Weitere Erklärungen Text. (a)-(p) (1000:1), (q)-(aa) (1500:1)

ser Spermatocyten gleichzeitig angeschwollen sind, um das Spermatogonangium zu öffnen. Nachhinkende Spermatocyten führen die Schwellung dennoch etwas später durch.

Die Spermatocyten sind nun grundsätzlich frei, und die eine oder andere fällt dann auch heraus, ebenso wie etwa vorhandene Halbspermatogonangien-Schalen. Knapp eine Stunde nach Beginn der Schwellung ist die Vakuole wieder kollabiert. Unmittelbar darauf setzt die erste meiotische Teilung mit einer Streckung der Spermatocyte (Abb. $15 \mathrm{q}-\mathrm{s}$ ) ein. Dieser Zustand dürfte der späten Metaphase der ersten meiotischen Teilung entsprechen. Die Zelle verlängert sich rasch weiter (Abb. 15t) und schnürt sich darauf hantelförmig ein (Abb. 15u). Sehr bald runden sich die beiden Tochterprotoplasten jeder Spermatocyte $a b$ und legen dabei die dünne fadenförmige Spindel oder den Spin- 
delrest frei (Abb. 15v). Schließlich reißt oder bricht die Spindel, und die Halbspindeln werden rasch resorbiert. Dieser Vorgang vom Beginn der Zellstreckung an dauert etwa 20 Minuten.

Etwa 15 Minuten später erscheint an der kugelförmigen Interkinesezelle ein Paar von kurzen Geißeln (Abb. 15x, unten links), die nahe beieinander entspringen. Diese verlängern sich im Laufe der nächsten 10 Minuten, wobei ihre zunächst schwache Bewegung allmählich lebhafter wird. Die Geißeln weichen dabei auseinander, bis sie nach weiteren 10 Minuten einander gegenüberliegen (Abb. 15x unten rechts). Die Zelle beginnt sich daraufhin zu strecken und wird innerhalb von etwa 15 Minuten hantelförmig (Abb. 15y). Die Geißeln wachsen weiter in die Länge, und ihre Schlagfolge nimmt zu. Schließlich reißt das Plasma in der Hantelbrücke auf. Die Spindel wird wieder als dünner Strang freigelegt, und die Körper der beiden Spermien runden sich ab (Abb. 15z links, aa). Die Frequenz des Geißelschlages steigert sich bei weiterer Verlängerung der Spindel (Abb. 15aa), die schließlich bricht, worauf die Spermien nach entgegengesetzten Richtungen mit hoher Geschwindigkeit davonschwimmen.

Die Geißel stellt wie diejenige von Lithodesmium (Manton \& v. Stosch 1966) und von Actinoptycbus undulatus sowie C. eibenii (v. STоsch 1958a) eine Flimmergeißel dar (Abb. 16d). Der Kern des Spermiums ist nicht so hoch kondensiert wie bei den Biddulphia-Arten und bei Lithodesmium, wo er fast homogen erscheint, sondern er hat etwa das Aussehen eines Chromocentren-Kerns (Abb. 19a), ähnlich wie bei Melosira varians (V. STOSCH 1951).
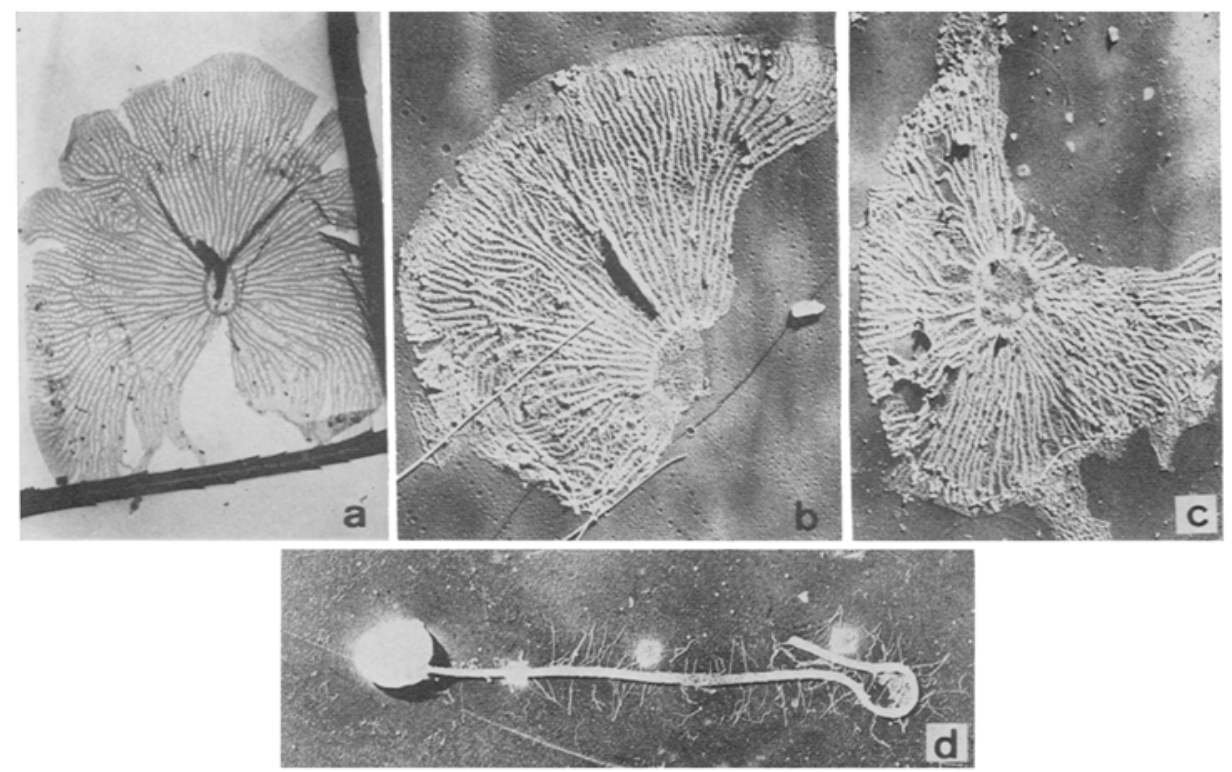

Abb. 16: Chaetoceros didymum, elektronenmikroskopische Aufnahmen. (a)-(c) nach der ersten Differenzierungsteilung im Spermatogonangium gebildete vereinfachte Schalen; (ca. 5000:1). (d) Spermium mit Flimmergeißel; (ca. 3000:1). (a) Direktpräparat, (b)-(d) mit Gold-Palladium bedampft, Negativkopie 
Nachzutragen bleibt das Verhalten der Plastiden. Die Spermatocyten besitzen, wie angegeben, gewöhnlich vier Plastiden. Diese werden normalerweise so verteilt, daß die Tochterzellen der ersten Teilung je zwei und die Spermien dann je eine Plastide erhalten (Abb. 15x, z links, aa). Doch kommen nicht selten Abweichungen von diesem Normalfall vor. Zunächst ist die untere Spermatocyte in Abb. 15q nur mit zwei Plastiden ausgerüstet; bei der ersten Teilung erhält die eine Tochterzelle zwei Plastiden, die andere keine Plastide (Abb. $15 \mathrm{w}$ und $\mathrm{x}$, unten rechts bzw. links); aus letzterer entstehen zwei plastidenfreie Spermien. Auch bei der Bildung der Meiose-II-Zelle in Abbildung $15 \mathrm{z}$ mit drei Plastiden ist eine anomale Verteilung erfolgt. Sowohl plastidenfreie Spermien als auch solche mit zwei Plastiden haben normale Beweglichkeit und können in das Oogon eindringen.

Unsere Bezeichnung der letzten beiden Teilungen als meiotisch läßt sich durch cytologische Beobachtung nur schlecht demonstrieren, da die Kernverhältnisse in den Spermatocyten von $C$. didymum wegen geringer Größe zu ungünstig sind. Doch folgt sie einmal aus dem Vergleich der Dauer der einzelnen Interphasen: Die Zeitintervalle zwischen den (mitotischen) Spermatogonienteilungen betragen etwa 21/2 bzw. 2 Stunden, worauf eine Pause von mehr als 5 Stunden folgt, während der die meiotische Prophase einschließlich Schwellungsstadium (Abb. 15p) abläuft. Die beiden meiotischen Cytokinesen selbst folgen danach ziemlich rasch aufeinander. Weiter geschieht die $\mathrm{Zu}-$ ordnung aus vergleichend entwicklungsgeschichtlichen Gründen: Ein Schwellungsstadium in der meiotischen Prophase findet sich bei allen centrischen Diatomeen. Ferner entstehen bei allen Centrales, welche bisher daraufhin untersucht wurden, die Geißeln in der meiotischen Interkinese. Schließlich läßt sich bei C. eibenii (vgl. Abb. 17) die Meiosis cytologisch leicht nachweisen.

Von weiteren Arten der Gattung liegen etwas genauere Beobachtungen nur für C. eibenii vor. Die Zellen enthalten zahlreiche Plastiden, und die Spermatogonangien liefern eine größere Anzahl von Spermatocyten (in Abb. 17c sind es 32). Schalen werden auch nach der ersten Cytokinese nicht gebildet. Die Mutterzellen bleiben geschlossen und lassen ihre Spermien durch die Borstenpforten austreten, die hier also noch eine weitere Funktion bekommen (Abb. 17c). Nähere Beobachtung zeigt, daß die Schwellungsphase der meiotischen Prophase nur angedeutet wird, ohne daß das Ausmaß der Schwellung genügt, um das Spermatogonangium zu öffnen. Die Meiosis läuft daher, wie Abb. $17 \mathrm{~b}$ zeigt, im geschlossenen Spermatogonangium ab. Zu erkennen ist der Zustand einer Metaphase I an den eng um die Spindel liegenden, unter Anaphasezug stehenden Chromosomenpaaren, deren Schenkel durch die Chiasmen noch gehalten werden. In den vorhergehenden diploiden Spermatogonien-Mitosen (Abb. 17a) sind die Chromosomenschenkel von der Spindel abgespreizt. Die Spermien führen zwei oder drei Plastiden.

Wenn in der älteren Literatur von Mikrosporen die Rede ist, wurden fast allgemein Spermatogone gesehen, so auch mehrfach bei Chaetoceros-Arten. Dazu nur wenige Angaben: Halbspermatogonangien fanden sich bei C. lauderi Ralfs (MeUnIER 1913) und C. lorenzianum Grunow (Subrahmanyan 1946). Schillers (1909) Abbildungen für die letzte Spezies zeigen diese nicht, und es ist zu bezweifeln, daß von ihm überhaupt Spermatogone gesehen wurden (Parasiten?). GRAN (1904) beobachtete in C. decipiens Cleve Stadien der Spermatogonentwicklung, wobei nach der ersten 


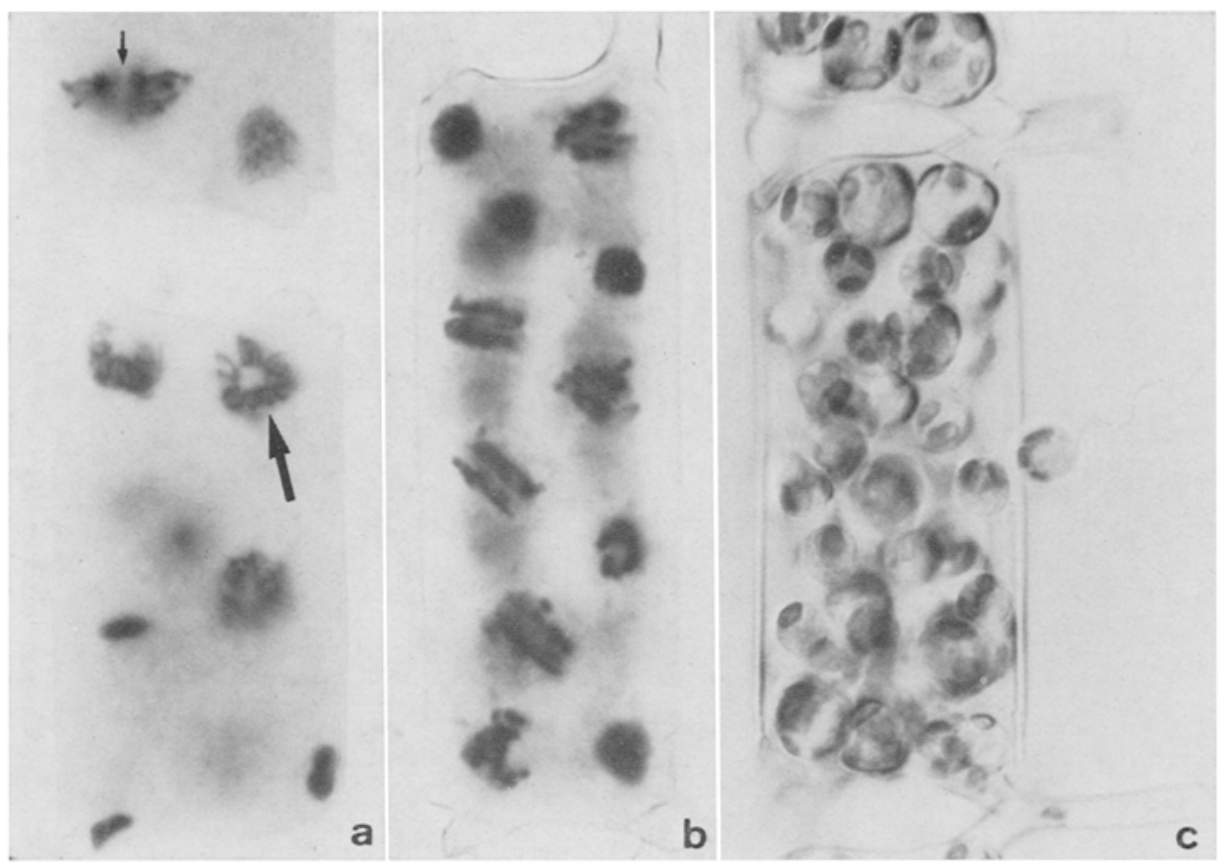

Abb. 17: Chaetoceros eibeniz. (a) und (b) Klon I. (a) Diploide Spermatogonmitosen; Aufsicht auf Metaphaseplatte mit Loch der Zentralspindel (großer Pfeil); in Nachbarzelle Metaphaseplatte in Seitenansicht (kleiner Pfeil). (b) Späte Metaphase der ersten meiotischen Teilung. (a) und (b) (1500:1). (c) Klon II. Spermatogonangium mit Spermien und mit Spermatocyten in Interkinese; Spermium verläßt Spermatogon durch Borstenpforte; $(1000: 1)$

Teilung anscheinend keine Schalen gebildet werden; die hier zahlreichen Plastiden vermehren sich ähnlich wie bei C. didymum während der Spermatogonteilungen. Auch in der Androgenese verhält sich Bacteriastrum byalinum (DREBEs 1972) ähnlich dem C. didymum. Jedoch entstehen selbst nach der ersten Mitose im Spermatogonangium offenbar keine Schalen.

In der vergleichenden Entwicklungsgeschichte seiner Spermatogonangien gehört Chatoceros in die Nähe der großen planktontischen Biddulpbia-Arten sowie von Lithodesmium, Bellerochea und Streptotheca (v: Sтовсн 1954). In allen diesen Fällen entstehen aus einer Mutterzelle relativ zahlreiche Spermatogone; bei den genannten Diatomeen und bei $C$. eibenii sind es mehr als bei $C$. didymum. Die Aufteilung der Spermatocyten während der Meiosis erfolgt bei Chaetoceros wie bei allen iibrigen der oben genannten Diatomeen hologen, d. h. ohne Aussonderung eines plasmatischen Restkörpers. Ein solcher fand sich jedoch bei Melosira (v. Sтовсн 1951, 1958b) und bei zwei Stephanopyxis-Arten mit merogener Spermienbildung (v. STOSCH \& Drebes 1964, Drebes 1966). Eine Besonderheit von $C$. didymum liegt darin, daß es in der vegetativen Zelle nur zwei Plastiden gegenüber zahlreichen bei den anderen genannten Arten besitzt. Infolge der auf p. 413 geschilderten Plastidenteilungen ist jedes Spermium in Normalfall mit einer, wenn auch außerordentlich kleinen Plastide ausgestattet. Diese 
Tatsache ist merkwürdig, da Plastiden für die Funktion der Diatomeen-Spermien generell überflüssig erscheinen. So produzieren Melosira-Arten, Stepbanopyxis, Biddulphia granulata (v. Sтоsсн 1956), Guinardia flaccida (unveröffentlicht) und manche Coscinodiscaceen (Hormes 1967, v. SToscH unveröffentlicht) plastidenlose Spermien. Bei den übrigen hologenen Spermiogenesen von Biddulphia-Arten, Streptotheca, Lithodesmium, Bellerochea werden die Plastiden während der Spermatogonien-Mitosen und nachher in der Meiosis ohne weitere Vermehrung nur mehr zufallsgemäß verteilt, wobei sie gleichzeitig an Größe verlieren.

\section{Oogon, Befruchtung und Entwicklung der Zygoten (Auxosporen)}

Das Oogon von Chaetoceros ist, um das Resultat vorwegzunehmen, wie bei Melosira varians (v. Srosch 1951), Cyclotella (Gertuer 1952) und Stephanopyxis (v. Stosch \& Drebes 1964) eineiig, da nach jedem der meiotischen Kernteilungsschritte, die ohne Furchung ablaufen, ein Tochterkern abortiert. Die Eizelle bleibt im Oogon eingeschlossen, und das Spermium dringt bereits in der meiotischen Prophase durch eine der Borstenpforten ein. Auf gleichem Wege tritt die Zygote aus, ohne die Verbindung mit der Mutterzelle zu verlieren. Sie wächst differentiell heran und scheidet darauf nacheinander die beiden Schalen der Erstlingszelle aus.

Wir schildern zunächst, um einen Überblick zu geben, das Schicksal einer Kolonie während zweier Beobachtungstage. Das Präparat wurde "gestern" (12. 11. 1966) um 9.00 Uhr hergestellt und die Photographie der Abb. 18a "heute" (13.11.) um 12.45 Uhr angefertigt. Die Kolonie bestand gestern um 16.40 Uhr aus acht Zellen: Zelle 1 teilte sich kurz darauf vegetativ in $1 \mathrm{a}$ und $1 \mathrm{~b}$. 1a teilte sich heute vegetativ weiter, $1 \mathrm{~b}$ wird zum Oogon. Die Zellen 2, 3, 4 waren gestern Oogone, die vor Beginn der Beobachtung befruchtet wurden und sich bis heute zu Auxosporen (Zellen 2 und 3 bereits Erstlingszellen; Zelle 4 erste Schale ausgeschieden) entwickelt haben. Zelle 5 teilte sich gestern durch eine Trennteilung, nach der die Tochterkolonien aber aneinander hängen blieben. Beide Tochterzellen (Zellen 5a und b) entwickeln sich heute zu Oogonen. Zelle 6 wurde gestern zum Oogon, welches um 16.40 Uhr befruchtet wurde (für Einzelheiten hierzu vgl. weiter unten); heute ist sie zur Auxospore geworden und befindet sich vor der ersten metagamen Mitose. Zelle 7 hatte sich gestern vegetativ geteilt, wie auch heute ihre Tochterzelle $7 a$, während $7 b$ zum Oogon wurde und im Augenblick der Aufnahme an beiden Borstenpforten mit Spermien besetzt ist. Zelle 8 hatte sich gestern vegetativ geteilt, 8a wird heute zum Oogon (Befruchtung etwa $15.10 \mathrm{Uhr}$ ), während sich $8 \mathrm{~b}$ eine Stunde früher vegetativ geteilt hatte. Es ist also ersichtlich, daß Schwesterzellen entweder beide zu Oogonen werden (Zelle $5 a$ und b), oder daß die eine von ihnen (zunächst vegetativ bleibt (Zellen 1a, 7a und $8 b$ ) und die andere zum Oogon wird (Zellen $1 \mathrm{~b}, 7 \mathrm{~b}$ und $8 \mathrm{a}$ ), und daß sich schließlich (Zellen $5 \mathrm{a}$ und b) auch Endzellen zu Oogonen differenzieren können.

Wir verfolgen nun die Befruchtung und Weiterentwicklung der schon genannten Zelle 6. Junge Oogone lassen sich nicht mit Sicherheit von solchen Zellen unterscheiden, die sich im gleichen Streckungszustand zur vegetativen Teilung anschicken, wenn auch 


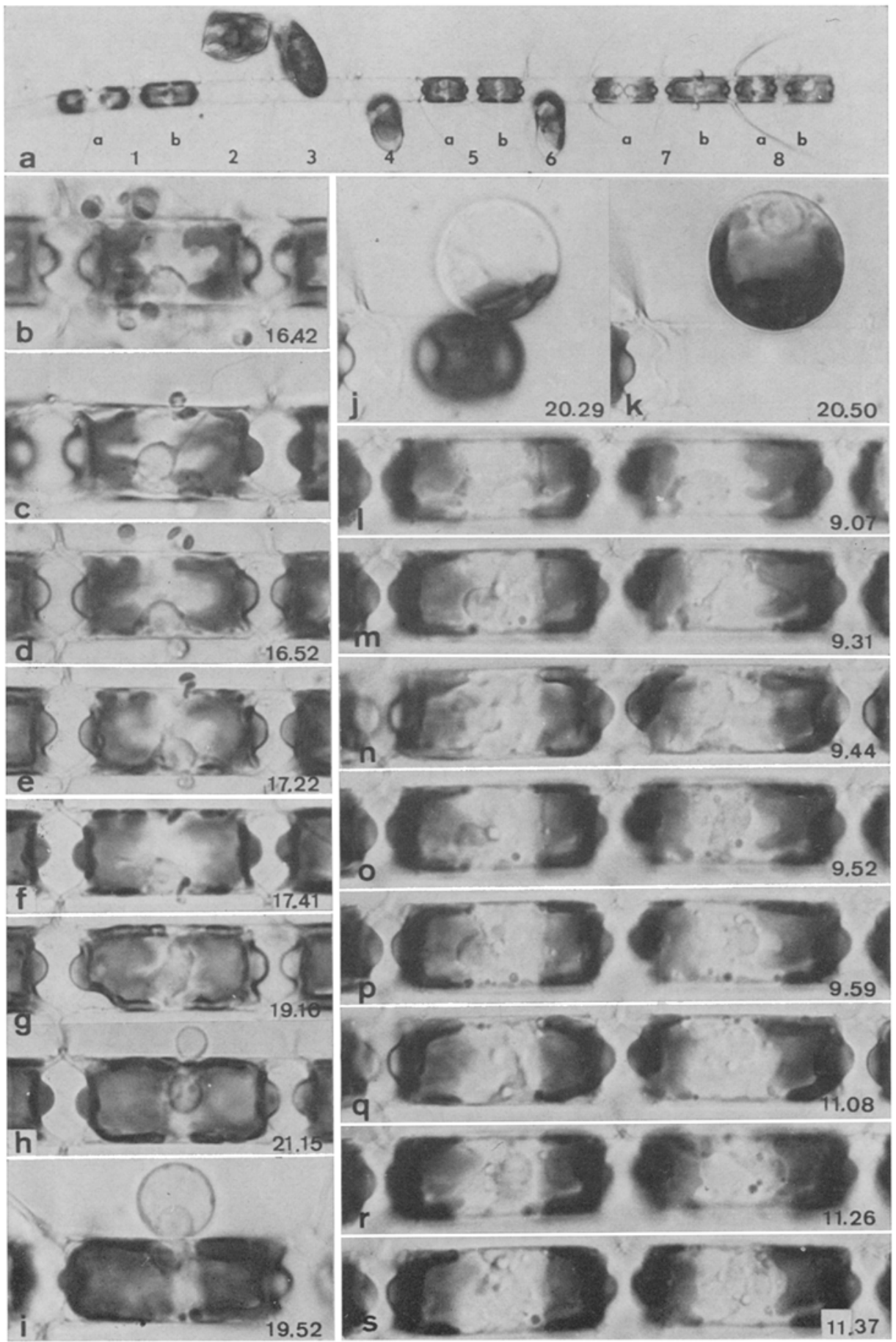



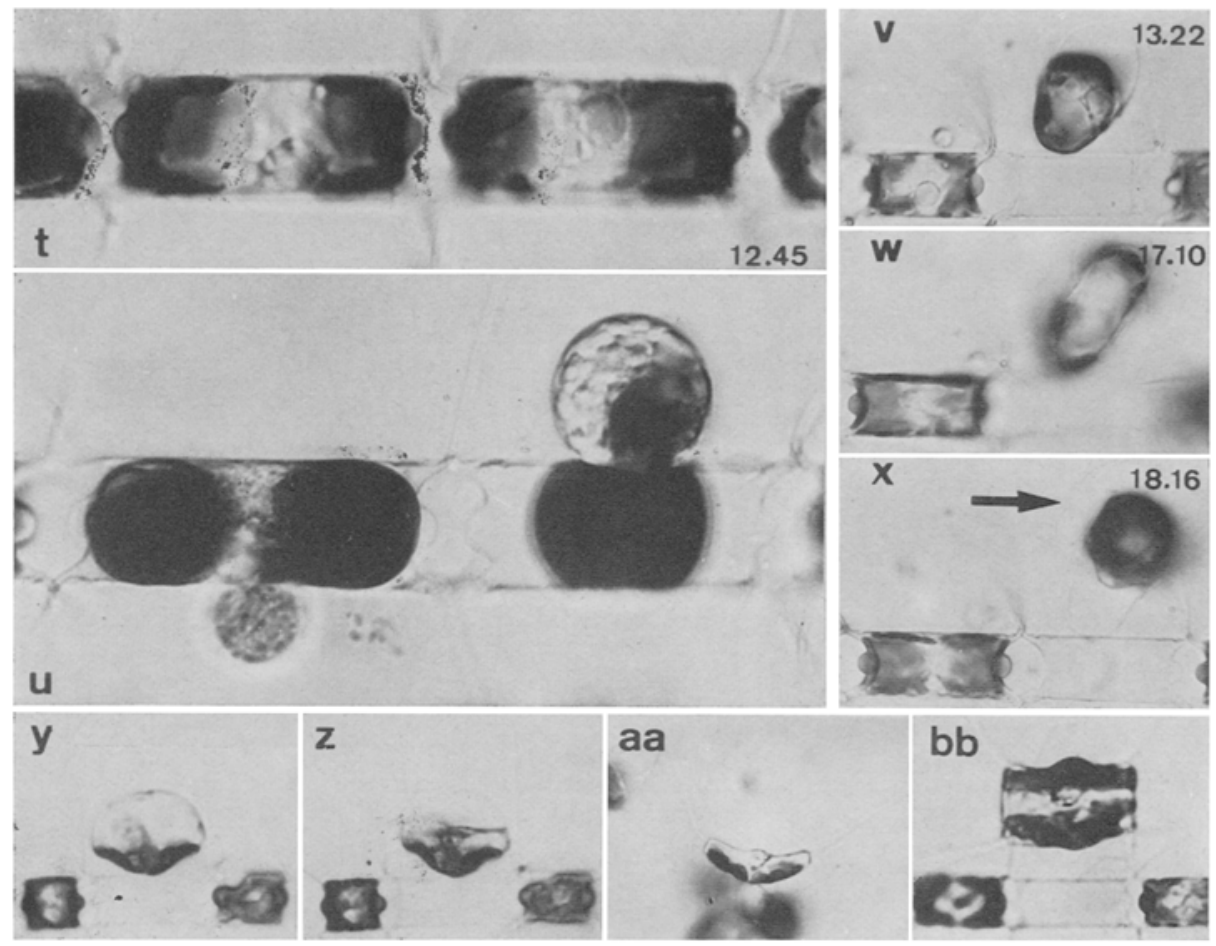

Abb. 18: Chaetoceros didymum. Oogonentwicklung, Befruchtung und Auxosporenbildung. (a) Kolonie mit vegetativen Zellen, Oogonen und Auxosporen; beachte Sonderborsten zwischen Zellen $7 \mathrm{~b}$ und 8a. Erklärung im Text. (b), (d)-(i) Beobachtungsserie: Befruchtung bis Beginn des Austretens der Zygote. (c) Einzelaufnahme eines Oogons mit an Borstenpforte rotierendem Spermium. (j)-(k) Aus einem anderen Oogon austretende Zygote. (1)-(t) Serienaufnahmen von Meiosis I und II in unbefruchteten Oogonien. (u) Austreten unbefruchteter Eizellen. (v)-(x) Serie junge Auxospore in schmaler Gürtelansicht: (v) Stadium kurz nach erster metagamer Mitose; (w) Streckung vor zweiter metagamer Mitose; (x) Stadium kurz nach zweiter metagamer Mitose; Auxosporenmembran abgestreift (Pfeil). ( $y$ ) Auxospore in breiter Gürtelansicht vor erster metagamer Mitose. (z) Spontanplasmolyse während erster metagamer Mitose. (aa) Auxospore nach erster metagamer Mitose mit fertiger Erstlingsschale. (bb) Erstlingszelle hat beide Erstlingsschalen fertiggestellt und beginnt Streckung zur ersten Zelltellung. Weitere Erklärungen im Text. (b)-(u) $(1000: 1),(\mathrm{y})-(\mathrm{x})(500: 1),(\mathrm{a}),(\mathrm{y})-(\mathrm{bb})$ $(300: 1)$

ihre Kerne in gewissen Stadien der meiotischen Prophase größer sind. Haben sie die entsprechende Reife erreicht, so geben sie sich dadurch zu erkennen, daß sie die in der Kultur vorhandenen männlichen Gameten anlocken. Noch später nimmt ihr Reservestoff- und Pigmentgehalt $z u$, und häufig strecken sie sich auf etwas größere Längen als vegetative Zellen. Ein zur Befruchtungsfähigkeit entwickeltes Oogon lockt zunächst schwächer, dann stärker die Spermien an. In diesem Zustand befindet sich das Oogon 6 der Abb. 18b seit einigen Minuten. Abbildung $18 \mathrm{c}$ zeigt ein anderes Oogon mit nur zwei Spermien in seiner Nähe. Berühren einzelne Spermien beim Umschwärmen des Oogons eine der Borstenpforten, an denen vermutlich zu diesem Zeitpunkt schon das Plasmalemma der Eizelle freiliegt, so halten sie hier Kontakt und rotieren an dieser 
Stelle mit weiterschlagender Geißel (Abb. 18c). Das kann recht lange dauern, bis schließlich ein Spermium, oder wie im Beispiel je ein Spermium an jeder der beiden Geißelpforten, "fixiert" wird, d. h. festhaftet. Im gleichen Augenblick verläßt die Mehrzahl der Spermien das Ei (Abb. 18d, gleiches Oogon wie Abb. 18b). In diesem speziellen Fall sitzt an der kernnahen Borstenpforte ein Spermium mit einer Plastide, an der gegenüberliegenden ein zweites mit zwei Plastiden. Es kommt zur Dispermie, da beide Spermien eindringen. Darüber hinaus bleiben aber häufig noch weitere männliche $\mathrm{Ga}$ meten mit ihrer Geißel an anderen Stellen der Oogonoberfläche haften, scheinen sich aber nicht wieder befreien zu können. Die so an einer Borstenpforte "fixierten" Spermien bewegen die Geißeln noch längere Zeit, bis diese schließlich erstarren; über das weitere Schicksal der Geißeln ist nichts bekannt. Das Eindringen der Spermien vollzieht sich - im Gegensatz zu Stephanopyxis (Drebes 1969) - langsam und kann am Verhalten der männlichen Plastiden verfolgt werden, während der winzige Spermakern im Eiplasma nicht zu erkennen ist. In Abbildung 18e beginnt eine Plastide des zweiplastidigen Spermiums in das Oogon hineinzuschlüpfen, und in Abbildung 18f, d. h. 50 Minuten nach dem Moment der "Fixierung “, liegen alle Plastiden innerhalb des Eies. Die kleinen männlichen Plastiden kötnnen dann noch lange im Ei gesehen werden, scheinen aber für die Entwicklung der Zygote keine Rolle zu spielen. Für den Spermakern wissen wir aus cytologischen Untersuchungen, daß er im Oogon liegen bleibt und auf die Fertigstellung des weiblichen Kerns wartet, um dann mit ihm zu verschmelzen (Abb. 19b-k). 21/2 Stunden nach der "Fixierung“" des Spermiums wurde dann eine Kernteilung im Ei gesehen (Abb. 18g), wahrscheinlich die erste meiotische Teilung. Die zweite meiotische Teilung fand, nach anderen Erfahrungen zu schließen, vermutlich 2 Stunden später während einer Beobachtungspause statt. Nicht lange danach beginnt die Zygote das Ei zu verlassen (Abb. 18h). Dies ist ein langsamer Prozeß, bei dem zuerst aus der kernnahen Geißelpforte ein kleines Plasmabläschen austritt, in das sich die Vakuole fortsetzt. Später folgt der Kern (Abb. 18i) und danach erst zwängen sich die beiden Plastiden durch die Offnung (Abb. 18j, k). Mit Abbildung 18i gehen wir auf eine andere Zelle über, bei der das Bläschen um 18.22 Uhr erschien. In diesem Beispiel dauerte das Austreten der Zygote 21/2 Stunden.

Wir holen nun die Schilderung der meiotischen Teilungen nach. Es handelt sich um Oogone eines Präparates, in dem männliche Zellen nicht entwickelt wurden. Trotzdem schreitet die Meiosis im Oogon fort. Zu Beginn der ersten meiotischen Teilung löst sich die Kernhülle auf, und die sie umgebenden Dictyosomen verteilen sich. Einige Zeit später wird dann die annähernd rechteckige Meta- bis Anaphase-Figur erkennbar, und damit beginnen die Aufnahmen der Abbildung 181-t. Sie beziehen sich auf eine Kolonie, in der sich drei Oogone, davon zwei benachbarte, in fast gleichem Entwicklungszustand befanden. Letztere werden nun einander ergänzend verfolgt. Die zunächst in Längsrichtung der Zelle liegende Kernfigur (Metaphase I) der rechten Zelle (Abb. 18 , die linke Zelle ist bereits in später Anaphase) dreht sich, und die Spindel der späten Anaphase wird deutlich (Abb. $18 \mathrm{~m}$ ); sie stemmt die Tochterkerne auseinander, wird schließlich dünner (Abb. 18n, Telophase) und zuletzt unsichtbar. Die zwischen Metaphase und Anaphase der ersten meiotischen Teilung verstreichende Zeit ist länger als bei der Mitose, in diesem Fall 24 Minuten gegenüber 5 Minuten bei Abbildung $5 \mathrm{c}-\mathrm{f}$. Die Tochterkerne wandern nun rasch aufeinander zu und kommen in Kontakt. Beide 
nehmen zunächst an Größe ab, bis dann der eine noch kleiner (Abb. 18o rechts) und schließlich pyknotisch wird, was auch cytologisch belegt ist (Abb. $19 \mathrm{f}$ und g). Der überlebende Kern schwillt an (Abb. 18p, beide Zellen).

Etwa 2 Stunden nach Metaphase I löste sich in der linken Zelle die Kernhülle auf; 7 Minuten später befand sich der Kern in Metaphase und nach weiteren 5 Minuten in Telophase der zweiten meiotischen Teilung (Abb. 18q). Die Spindel steht in diesem Falle fast senkrecht zur Längsachse der Zelle. Zum gleichen Zeitpunkt befindet sich die rechte Zelle noch in Prophase; 2 Minuten später jedoch verschwindet auch hier die Kernhülle und nach weiteren 16 Minuten ist der Zustand einer späten Anaphase erreicht (Abb. 18r); die Spindel steht um $30^{\circ}$ zur Zellängsachse geneigt. Der Übergang von Meta- zur Anaphase nimmt also bei Meiose II nicht mehr Zeit (ca. 6 Minuten) in Anspruch als bei einer vegetativen Teilung. Wiederum wandern die Tochterkerne nach Auflösen der Spindel aufeinander zu, wie Abbildung 18s rechts zeigt. Einer der beiden Tochterkerne wird auch hier pyknotisch und schließlich resorbiert. Der überlebende Kern, nunmehr der haploide Eikern, schwillt darauf etwas an (Abb. 18t). Während jeder meiotischen Kernteilung kann sich der Protoplast lokal kontrahieren (wie in Abb. 18g); der damit einhergehende Volumenverlust entspricht vermutlich jenem, der auch bei mitotischen Kernteilungen regelmäßig zu beobachten ist.

Ist ein Spermakern im Ei, so findet offenbar bald nach der II. meiotischen Teilung die Kernverschmelzung statt. Aus cytologischen Beobachtungen wissen wir jedenfalls, $\mathrm{daß}$ diese noch im Oogon vor dem Austreten der Zygote erfolgt. Kommt es nicht zur Befruchtung, so treten die Eizellen nach unbekannter Zeitdauer trotzdem aus dem Oogon aus. Solche „Pseudozygoten“, die an dem reservestoffreichen körnigen Plasma und dem hohen Pigmentgehalt zu erkennen sind (Abb. 18u), gehen später zugrunde; ob sie davor noch befruchtet werden können, ist unbekannt.

Nach unseren Beobachtungen scheint der Ablauf der Meiosis nicht durch die Befruchtung beeinflußt zu werden. Die Zeitspanne zwischen erster und zweiter meiotischer Teilung schwankte z. B. bei fünf unbefruchteten Oogonen zwischen $1 \mathrm{Std}$. $40 \mathrm{Min}$. und $2 \mathrm{Std}$. $20 \mathrm{Min}$. und bei sechs vor der Meiosis befruchteten zwischen $1 \mathrm{Std}$. $30 \mathrm{Min}$. und 2 Std. 25 Min.

Die Cytologie der Meiosis im Oogon sei nur kurz besprochen, da unser Objekt wegen seiner geringen Zellgröße nicht besonders günstig für Beobachtungen im fixierten Zustand ist. Es wurden nur Zellen gezeichnet, die einen Spermakern enthielten, und es zeigte sich, daß dieses im Zygotän, nicht aber schon im Leptotän der Fall sein kann (Abb. 19b). Im Zygotän und Pachytän erhält der Oocytenkern seine maximale Größe. Die gepaarten Chromosomen des Pachytän (Abb. 19c) sind stark aufgelockert; später kondensieren sie sich und werden schließlich in Metaphase recht klein und stark färbbar. Während der Diakinese (Abb. 19d) verliert der Kern etwas an Volumen. Der Nukleolus ist verschwunden, und an den kondensierten Chromosomentetraden werden mehrfach mindestens zwei Chiasmen erkennbar. Die haploide Chromosomenzahl dürfte zwischen 8 und 10 liegen, an unseren Totalpräparaten ist sie nicht sicher zu ermitteln. Die Chromosomen rücken ähnlich wie bei der Meiosis anderer Diatomeen succedan in die Spindel ein (Ger't'Ler 1956, v. Sтолсн 1956), d. h. während einige Tetraden bereits unter dem Zug der Spindelfaser stehen, liegen andere noch frei neben der Teilungsfigur. In der Metaphase der Abbildung 19e sind bereits alle Chromosomen in 
die Spindel eingerückt und befinden sich unter Zug. Die Spindel ist durch die noch im hydrolysierten (RNS-armen) Präparat gut färbbaren Polkappen auffällig, die auch bei anderen Diatomeen (LAUTERBORN 1896, BĚLAǨ 1926) gefunden wurden. Sie dürf-

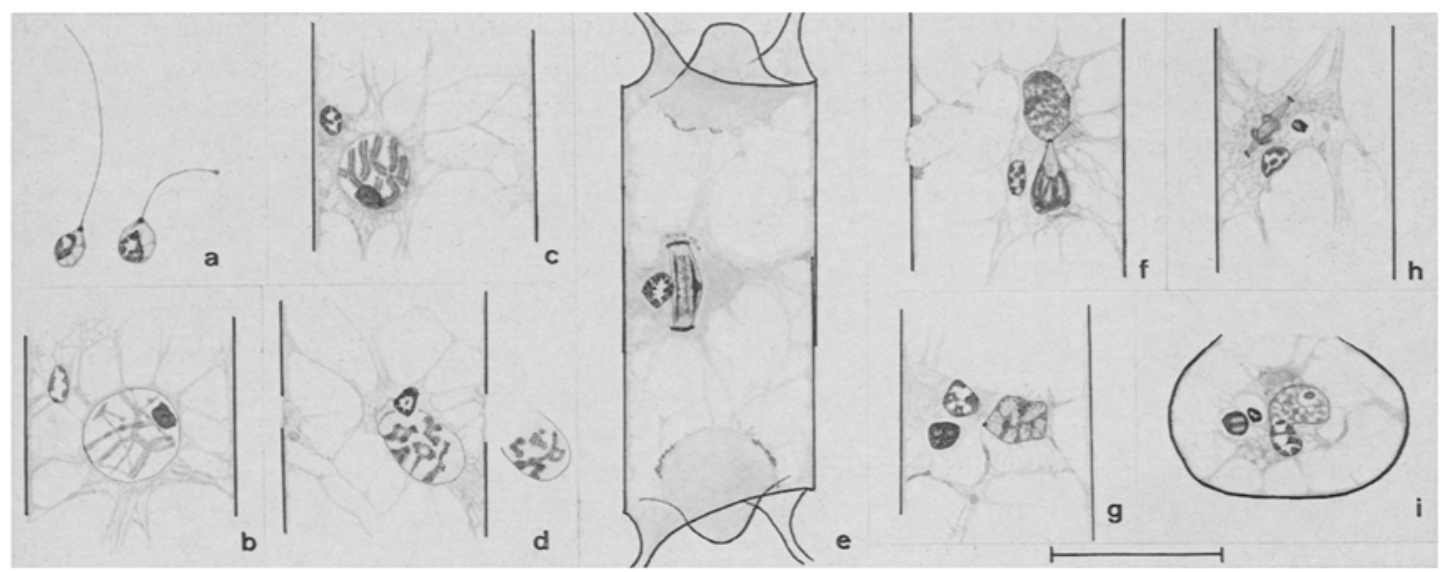

Abb. 19: Chaetoceros didymum, Spermien sowie Oogonentwicklung nach fixiertem Material (Bonin-EKE). (a) Zwei Spermien. (b) Zygotän. (c) Pachytän. Spermakern in (b) und (c) links oben. (d) Diakinese. Spermakern uber oberen Rand des meiotischen Kernes; rechts tiefere Einstellung des weiblichen Kernes. (e) Metaphase 1. Spermakern links neben Spindel; in den Protuberanzen die Pyrenoide. (f) Frühe Interphase, Beide Tochterkerne sind über ein Granum verbunden, der untere beginnt pyknotisch zu werden; links Spermakern. (g) Späte Interphase; rechts iberlebender Kern mit Granum, links pyknotischer Kern unterhalb des Spermakernes. (h) Anaphase der zweiten meionischen Teilung. Rechts neben Spindel pyknotischer Kern, links unter diesem Spermakern. (i) Oogon annähernd im Querschaitt. Der dichtere Spermakern verschmilzt mit Eikern, links die beiden pyknotischen Kerne. (Maßstab $10 \mu \mathrm{m}$ )

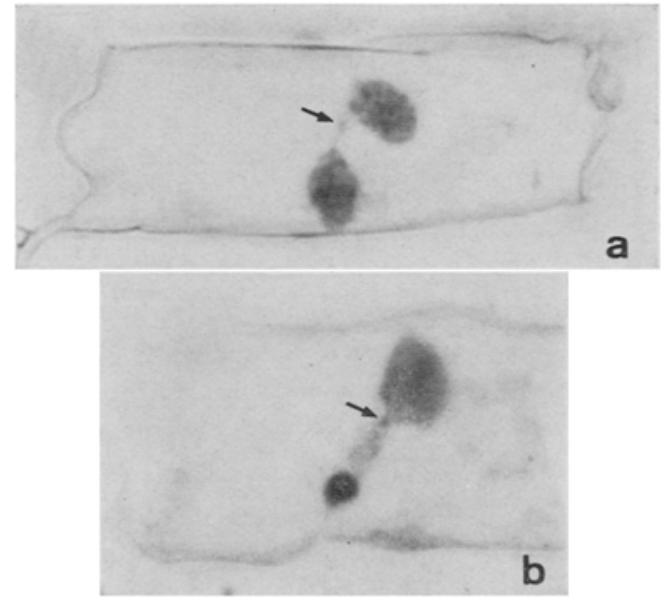

Abb. 20: Chaetoceros didymum, Oogonien in Interphase. (a) Beide Tochterkerne noch gleich grois, beide mit fibrillärer Verbindung zum Granum (Pfeil). (b) Pyknotischer Kern hat sich yom Granum (Pfeil) abgelöst, hinterläß3t aber anscheinend noch fibrilläre Strukturen; überlebender Kern in Verbindung mit Granum. (Bouin-EKE; 2000:1) 
ten dem "vesikulären Material" in Metaphase I der Spermiogenese von Litbodesmium entsprechen (MANTON et al. $1969 \mathrm{a}, \mathrm{b}$ ).

Bemerkenswert sind noch die Vorgänge während des Kernabortes. Nach der Wiederannäherung erscheinen die Kerne über ein stark färbbares Körnchen verbunden zu sein, zu dem hin der degenerierende Kern stärker als der tiberlebende ausgezogen ist (Abb. 19f, 20a). Später bleibt das Granum anscheinend an der Oberfläche des überlebenden Kernes, während der pyknotische Kern freigesctzt ist (Abb. 19g). In Abbildung $20 \mathrm{~b}$ ist das Chromatin des pyknotischen Kernes schon stark kondensiert, und am uberlebenden Kern ist das Granum zu erkennen, auf das wir in der Diskussion noch eingehen werden.

Die Kernfigur der zweiten meiotischen Teilung (Abb. 19h) zeichnet sich durch geringe Größe und dünne, schwache Chromosomen aus. Der pyknotische Kern aus der ersten Teilung ist noch zu erkennen. Der Spermakern scheint sich nach dem Eindringen nicht zu verändern. Abbildung $19 \mathrm{i}$ zeigt dann seine Fusion mit dem Eikern sowie die beiden pyknotischen Kerne.

Die nach dem Austreten aus dem Oogon zunächst kugelförmige Auxospore (Abb. $18 \mathrm{k}$ ), in der die beiden Plastiden vorerst an der Basis liegenbleiben, wächst nun anisometrisch. Sie nimmt dabei eine in Seitenansicht (d. h. im Blick auf die prospektive schmale Gürtelseite der Erstlingszelle) birnförmige (Abb. 18v) und von der breiten Gürtelseite her betrachtet, beilförmige*t Gestalt an (Abb. 18y). Es findet also ein GröBenwachstum mit Bevorzugung der Richtung der zukünftigen Apikalachse statt. Dabei steht gewöhnlich die präsumptive Pervalvar-Achse der Erstlingszelle senkrecht, oder wie in Abbildung 18v-x etwas schräg zur Kolonieachse. Die Apikalebene der Auxospore ist meist senkrecht zur Apikalebene der Kolonie (wie in Abb. 18a, Zellen 4 und 6, und $18 \mathrm{v}-\mathrm{x}$ ) orientiert, wodurch eine genauere Beobachtung der Auxosporenentwicklung erschwert wird. Nur selten sind beide Ebenen parallel wie in Abbildung $18 \mathrm{y}-\mathrm{bb}$.

Bei den Centrales sind bisher nur Auxosporenhüllen beschrieben worden, die um mehr oder weniger isometrisch wachsende Auxosporen ausgeschieden wurden (REIMANN 1960, v. STosch \& Drebes 1964). Sie bestehen mit einer noch zu besprechenden Ausnahme aus organischer Wandsubstanz, die mit Kieselschuppen armiert ist. Auch bei C. didymum werden - wahrscheinlich während der isometrischen Wachstumsphase zunächst Schuppen ausgeschieden (Abb. 21a), die sich aber während des weiteren anisometrischen Wachstums oder danach von der Auxospore ablösen und offensichtlich verlorengehen (Abb. 21b, c). Unter dieser Schuppenhülle wird nun eine Bänderstruktur ausgebildet $(\mathrm{Abb} .21 \mathrm{a}-\mathrm{c})$. Diese erscheint aber nicht als gesonderte Schicht, sondern ist mit der schuppenführenden Primärhülle verbunden. Wir bezeichnen sie als "Präperizonium" (vgl. auch v. STOSch \& Kowallik 1969). Dieses stellen wir zunächst nur durch Abbildung 21 und die schematische Darstellung von Abbildung 22 vor und werden auf seine Bildung erst in der Diskussion eingehen. Durch diese Struktur wird offenbar das anisometrische Wachstum der Auxospore gestützt und auf die „angestrebte“ Beilform begrenzt. Innerhalb der Auxospore kommt es danach zur ersten metagamen Mitose (GeItLeR 1952, 1953), einer acytokinetischen Teilung, die eine differentielle Spontanplasmolyse induziert (Abb. 18z). Diese räumt den distalen Teil der Auxospore, und an

\footnotetext{
* Gemeint ist ein Beilkopf, genauer eine Gestalt wrie in Abbildung 22.
} 

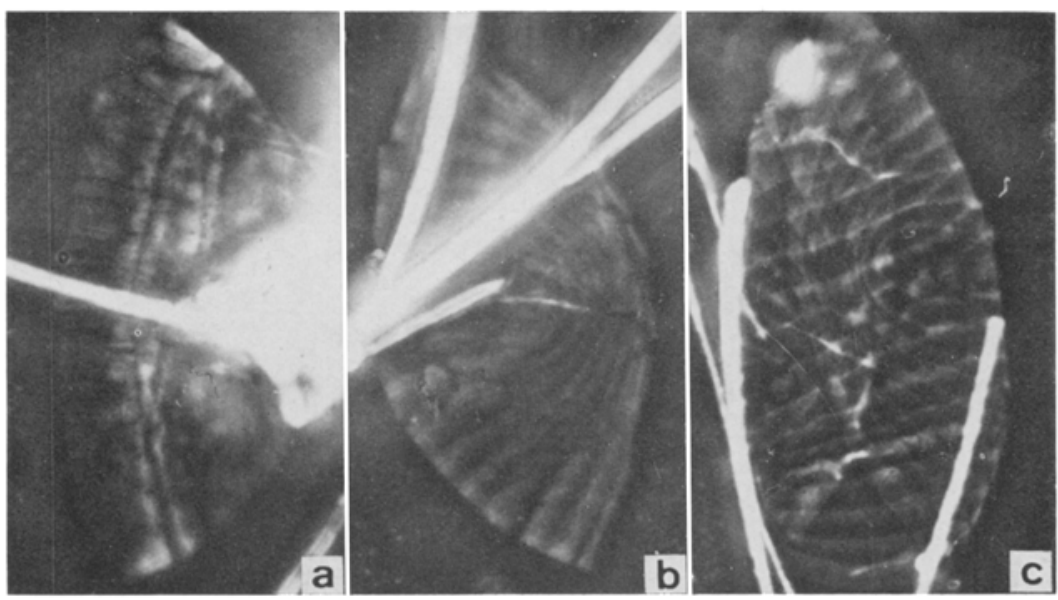

Abb. 21: Chaetoceros didymum, Auxosporenmembranen. (a) Noch jung, lose mit Schuppen bedeckt. (b) und (c) Alter, Schuppen abgestoßen; nur noch die Bänderstrukturen des Präperizoniums erhalten. Glühpräparat, Anoptralkontrast; $(1500 ; 1)$

der neugeschaffenen Plasmaoberfläche wird darauf die erste Valva der Erstlingszelle ausgeformt (Abb. 18aa). In einem Falle geschah dies $71 / 2$ Stunden nach Beendigung des Zygotenaustritts. Die Bildung der ersten Schale wird durch das Auswachsen der Borsten abgeschlossen, wobei die Auxosporenhülle durchbrochen wird (Abb. 18aa). Danach erst verlagert sich eine der beiden mütterlichen Plastiden zur neuen Valva hin (Abb. 18v). Gleichzeitig setzt ein Stredkungswachstum der Zelle ein, in dessen Verlauf anscheinend eine Pleura aufgebaut wird (Abb. 18w). Die Auxosporenmembran reißt nahe ihrer Basis auf, und ihr distaler Teil sitzt dann als Kappe über dem Scheitel der nun fertiggestellten ersten Theka (Abb. 18x). Die Zelle tritt danach wieder in eine acytokinetische, die zweite metagame Mitose ein, die wiederum von einer formbildenden Plasmolyse begleitet ist. Dadurch zieht sich der Protoplast aus dem Basalteil der Auxosporenmembran auf eine Front zurück, an der dann die zweite Valva ausgeschieden wird (Abb. 18x). Die Erstlingszelle von Abbildung 18bb befindet sich dann bereits wieder in Streckung vor der ersten Zellteilung. Bei dem Oogon, dessen Befruchtung und

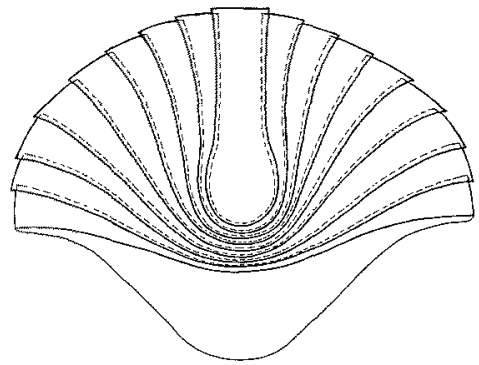

Abb. 22: Chaetoceros didymum. Schema der Struktur des Präperizoniums in breiter Seitenansicht. (Erklärung im Text) 
Weiterentwicklang in Abbildung $18 \mathrm{~b}$ und $\mathrm{c}-\mathrm{k}$ verfolgt wurde, fand die zweite metagame Mitose etwa 24 Stunden nach Beendigung des Austretens der Zygote statt. Beide metagamen Mitosen wurden im Leben gesehen. Der eine der beiden Tochterkerne wird jeweils pyknotisch, was für beide Teilungen cytologisch nachgewiesen ist. Die Resorption dieser überzähligen Kerne scheint, wie auch bei anderen Diatomeen, rasch zu erfolgen (GeItler 1952, 1953). Dies kann aus ihrem Fehlen in etwas älteren Entwicklungsstadien der durch sie induzierten Schale geschlossen werden. In der späten Telophase einer $z$ weiten metagamen Teilung wurde beobachtet, daß beide Tochterkerne wie bei der Dauersporenbildung durch ein an der Plasmaoberfläche im Valvenzentrum lokalisiertes Körnchen vereinigt waren (Abb. 25a).

Die Diskussion wird sich mit einigen älteren Angaben über die Sexualität von Chaetoceros befassen. Werfen wir jetzt einen Blick auf die Auxosporenentstehung bei anderen Chaetoceros-Arten, so scheint seitliche Auxosporenbildung allgemein zu erfolgen. Nur treten bei C. debile CIEve (YENDo \& IKARI 1918) und bei C. radicans (IKARI 1921) die Auxosporen nicht wie bei den übrigen Arten aus einer der beiden Borstenpforten aus, sondern aus der breiten Seite des Gürtels.

Eine andere Besonderheit findet sich bei C. eibenii, dessen Auxosporen nach Befunden an natürlichem Material (PAvillard 1921) direkt in Dauersporen umgewandelt werden. Wir haben dieses Verhalten auch in Kulturen festgestellt, die Vorgänge jedoch nicht laufend verfolgt. Aus den am lebenden und fixierten Material beobachteten Einzelstadien ergibt sich aber folgendes Bild: In der ausgetretenen Zygote führt nach der anisometrischen Wachstumsphase die erste metagame Mitose zu einer im Längsschnitt halbkreisförmigen Valva. Diese scheidet unter Streckung der Zelle einen Gürtel aus, wobei die Auxosporenmembran aufreißt. Ihr distaler Teil liegt in Abbildung 23 über der Rundung der ersten Schale. Die zweite acytokinetische Mitose liefert nun die Epitheka der Dauerspore; diese besitzt einen schwach gewölbten Diskus und einen kurzen zylindrischen Mantel. In letzteren greif dann der schmale Mantel der DauersporenHypovalva herein, deren Diskus breite Glockenform annimmt, wie die Abbildung

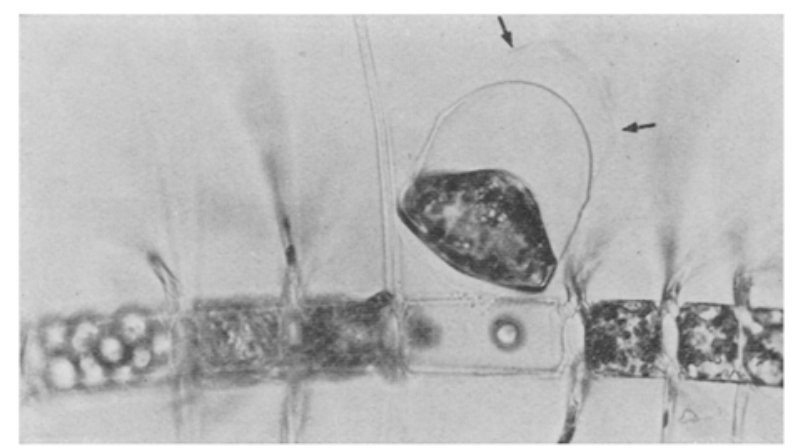

Abb. 23: Chaetoceros eibenii. Auxospore, nach Bildung der Dauerspore. Es folgen von oben nach unten: Der leicht geknitterte abgerissene distale Teil der Auxosporenmembran (Pfeile), die gleichmäßig gewölbte Valva der Erstlingszelle mit anschließendem zylindrischen Gürtel, die Danerspore selbst und darauf der proximale, mit der Geißelpforte verbundene Teil der Auxosporenmembran. Die Dauersporen-Hypotheka ist hoch gewölbt, die Epitheka flacher und mit kurzem zylindrischen Mantel versehen. Links Spermatogonangium mit Spermatogonen; $(500: 1)$ 
zeigt. Diese dritte Schale wird ebenfalls durch eine Acytokinese (eine „dritte metagame Mitose") induziert. Die Dauerspore entsteht an dieser Stelle obligatorisch. Merkwürdigerweise sind aber in vegetativen. Koloniezellen von $C$. eibenii niemals Sporen gefunden worden.

Die Keimung der in der Auxospore gebildeten Dauersporen von C. eibenii kann (bei $21^{\circ} \mathrm{C}$ ) bereits wenige Tage nach ihrer Bildung (bei $15^{\circ} \mathrm{C}$ ) erfolgen. Dabei werden, wahrscheinlich durch acytokinetische Mitosen vermittelt, nacheinander die beiden Dauersporenvalven abgeworfen und durch Kolonie-Endschalen ersetzt.

Grundsätzlich ähnlich wie bei dieser Art werden nach GRAN (1912) die Dauersporen in den Auxosporen von C. pseudocrinitum Ostenfeld gebildet. Doch treten in diesem Falle Sporen auch in vegetativen Zellen auf, vorausgesetzt, daß BRuNeL (1962) mit seiner Vermutung über eine Identität von C. ingelfianum OsTeNFELD mit $C$. psevdocrinitum recht hat. Wir halten dies für wahrscheinlich.

Bei $C$. van beurckii GRAN und Bacteriastrum byalinum schließlich kann innerhalb der fertigen Erstlingszelle sogleich eine Dauerspore gebildet werden (IKARI 1926 bzw. Drebes 1967). Sonst verhält sich die Zygote dieser letzten Art sehr ähnlich derjenigen von C. didymum; nur trägt die erste Schale (wie bei C. eibenii) innerhalb der Auxospore noch keine Borsten, denn solche werden erst von der Hypovalva der Erstlingszelle gebildet. Auf die Auxosporenhüllen gehen wir noch ein.

\section{DISKUSSION}

Wir haben über Zellteilung, Kolonieteilung, Dauersporenbildung und -keimung, Entstehung der Gameten und der Auxosporen bereits in den vorhergehenden Abschnitten vergleichende Betrachtungen angestellt und verweisen für weitere Angaben auf v. STOSCH \& Drebes (1964) sowie für vegetative Vorgänge auf ETTL et al. (1967). Im folgenden sollen noch einige weitere Fragen besprochen werden, die an ältere Beobachtungen über Gameten- und Auxosporenbildung von Chaetoceros, an die Morphogenese der Auxosporen, den Polymorphismus der Schalenformen und an die Induktion der Valvenbildung (insbesondere auch durch Mitosen) anknüpfen. In diesem Zusammenhang soll auch die mögliche Rolle des Paracentrosoms zur Diskussion kommen.

Chatoceros ist, wie eingangs bemerkt, diejenige Gattung unter den zentrischen Diatomeen, bei der zuerst Hinweise darauf gegeben wurden, daß die Auxospore nicht, wie bis dahin meist angenommen, Produkt eines vegetativen Vergrößerungsvorganges, sondern einer Gamie sei. PERsIDsky (1929) untersuchte fixiertes Expeditionsmaterial von $C$. boreale und $C$. densum, zweier relativ großer Arten, die dem von uns kultivierten C. eiberii nahestehen. Er kam zu dem Schluß, daß in der Auxosporenmutterzelle eine Meiosis ablaufe und vier Kerne produziere, von denen dann zwei autogam fusionieren, und die beiden restlichen zugrunde gehen. Wir wollen versuchen, dieses Ergebnis auf dem Hintergrund unserer Erfahrungen verständlich zu machen.

Die Planktonproben Persioskys wurden mit Jodtinktur fixiert und dann mit $1 \%$ Chromsäure nachbehandelt. Wir wissen aus eigenen Beobachtungen, daß Jodfixierungen von marinen Diatomeen, so lebensähnlich sie Plastiden und, wie Persidskys Bilder zeigen, auch die Dictyosomen erhalten, eine hoffnungslose Verquellung des Chromatins 
zur Folge haben, auch wenn sie sehr rasch durch konventionelle Kernfixierer gefolgt werden. Tatsächlich machen die Kerne in Persidskys Zeichnungen einen "homogenen " Eindruck, und es kann dann wohl nicht mehr zwischen Spermakernen und pyknotischen Kernen unterschieden werden. So deuten wir die „vierkernigen Stadien" als durch Verwechslung eines oder zweier Spermakerne mit Gonenkernen entstanden. Die „Kernverschmelzungsstadien" bei Anwesenheit zweier weiterer Kerne (z. B. PERsidskys Fig. 10) sind vermutlich auf solche Kerne zu beziehen, die sich nach einer meiotischen Teilung vor der Pyknose des einen von ihnen einander genähert haben. In wirklichen Kernfusionen bei Diatomeen (siehe auch Abb. 19i), so auch von C. eibenii, kommt der Größenunterschied der beiden Sexualkerne viel stärker zum Ausdruck als bei den durch Persidsky derart interpretierten Zuständen. Durch diese Deutung lassen sich die Zeichnungen Persidskys mit unseren Befunden in Übereinstimmung bringen. Es ist aber natürlich nicht unmöglich, daß bei einzelnen Chaetoceros-Arten auch autogame Prozesse im Oogon vorkommen. Vier Kerne würden dann aber wohl keinesfalls gleichzeitig auftreten können. Daß solche gefunden wurden, spricht gegen eine Autogamie bei den Chaetoceros-Arten Persidskys.

Die vom gleichen Autor (1935) geäußerte Annahme einer Autogamie bei Melosira varians hatten wir (v. STOSCH 1951) durch Vergleich seiner, die wirklichen Verhältnisse gut wiedergebenden Abbildungen mit unseren Befunden auf eine oogame Allogamie hin korrigieren können. Wir fanden in unseren Kulturen keinen Hinweis darauf, daß "Mikrosporen" von Chaetoceros als Iso- oder Anisogameten, wie dies SCHLLER (1909) glaubte, oder nach der Auffassung Persidrys und einem Experiment Braaruds (1939) als Zoosporen fungieren können. Auch nach Erfahrungen mit vielen anderen Centrales können wir "Mikrosporen" nur als Spermatogone oder Spermien ansehen. Wir erinnern aber noch an eine Beobachtung WeNDTs, die von GeITLER (1932, p. 11) ausführlich zitiert wird. WENDT sah in Atlantik-Plankton vorherrschend zwei ChaetocerosFormen, die größere mit "Mikrosporen", die kleinere stark umschwärmt von Flagellaten, welche den "Mikrosporen “ der größeren ähnelten. Betrachtet man die schmalen Zellen als Oogone, so würde dieses mit einer Beobachtung HaRgRaves’ (1972) zu erklären sein, nach der bei C. diadema (Err.) GRAN die Zellen mit "microspores (male)" systematisch breiter seien als diejenigen, welche Auxosporen bilden. Wir sind aber aus zwei Gründen vorerst skeptisch hinsichtlich der von HARgRAves erwähnten Mikrosporen. Erstens fanden wir bisher niemals bei einer Centralen Spermatogonien oder Spermatogonangien, die konsequent breiter als die Oogonien gewesen wären, auch bei Chaetoceros nicht, und zweitens kann man wegen unzureichender Vergrößerung und auf Grund der angewendeten optischen Mittel nicht sicher sein, ob wirklich männliche Zellen in Fig. 2B seiner Arbeit abgebildet wurden. Bei der Beobachtung WeNDTs besteht natürlich noch die Möglichkeit, daß die Oogonien eines schmalen Taxons Spermien eines breiteren unspezifisch angelockt haben.

Abschließend sei noch bemerkt, daß Auxosporen und "Mikrosporen" bei Chaetoceros-Arten in Kultur erstmalig von Gross (1937) erhalten wurden.

Wir wenden uns der Formbildung der A u x os pore und im Zusammenhang damit der Auxosporenmembran zu. Wir hatten für zentrische Diatomeen mit isometrisch wachsenden Zygoten bereits dargelegt (v. STоsсн \& Drebes 1964, pp. 247, 248 und 250), daß hier die Auxosporenmembran aus Kohlenhydratschichten mit ein- oder 
aufgelagerten rundlichen Kieselschuppen besteht. Beim Größenwachstum der Zygote werden neue Schuppen und Schichten organischer Substanz appositionell angelagert, so daß die Schuppendichte pro Oberflächeneinheit während der Flächenzunahme der Membran annähernd gleich bleibt. Dieses Konstruktionsprinzip hält die Auxosporenhülle trotz ihrer „Verkieselung " flexibel, so daß die Formbildung der Zygote während ihres Schwellungswachstums allein durch die isotropen Spannungsverhältnisse innerhalb der Auxosporenmembran, durch die Form der Austrittsöffnung und die Dynamik des Austrittsvorgangs aus dem Oogon, d. h, rein mechanisch erklärt werden kann. Das gleiche trifft offenbar für die isometrische Phase von später anisometrisch wachsenden Auxosporen wie derjenigen von Chaetoceros und einiger Biddulphiaceen zu, ebenso wie auch für die gleichen Stadien bei den Tabellarioideen unter den Pennales. Bei solchen Arten, bei denen die Eier vor der Befruchtung aus dem Oogon entlassen werden, z. B. Lithodesmium, die Zygote also nicht mehr durch die Austrittsöffnung beeinflußt werden kann, wächst die Zygote in der isometrischen Phase zur Kugelform heran.

Bei C. didymum zeigten wir nun auch für eine zentrische Diatomee, daß das anschließende anisometrische Wachstum von der Ausscheidung von Kieselsäure-Ringen begleitet ist.

Die Bänder sind wahrscheinlich das statische Mittel, die angestrebte Formbildung zu ermöglichen. Sie werden zentrifugal nacheinander angelegt, und zwar offenbar in der Weise, daß im späten Kugelstadium das gurtartige erste Band über der prospektiven „Beilschneide“ hängend ausgeschieden wird, welches bei weiterer Schwellung der Zygote bereits das Wachstum in der prospektiven Transapikalrichtung einschränkt. Das Wachstum weicht daher nach den Richtungen der späteren Apices aus, worauf die $z w e i t e$ als Bandring ausgebildete Kieselstruktur appositionell mit ihrem proximalen Rand unter den Rand des Primärbandes greifend ausgeschieden wird. In entsprechender Weise werden alle folgenden Ringe abgelagert (Abb. 22), wie dies bereits für das in ähnlicher Weise entstehende Pennaten-Perizonium geschildert wurde (v. SтоsсH 1962). Wir kennen solche Strukturen bei mehreren Biddulphiaceen schon seit einigen Jahren (unveröffentlicht), werden aber auf diese hier nicht weiter eingehen. Es sei lediglich bemerkt, daß die primäre Schuppenhülle dort beständiger ist als bei Chaetoceros, im übrigen aber in beiden Fällen schuppen- und ringeführende Schichten ohne Zwischenraum miteinander vereinigt erscheinen. Bei den Pennaten finden wir vergleichbare Bänderstrukturen im Perizonium, die das zigarrenartige Auswachsen der Auxospore stïtzen. Das Perizonium ist aber eine von der zuerst gebildeten Zygotenmembran durch einen $Z$ wischenraum getrennte Struktur. Dies läßt sich besonders deutlich in solchen Fällen zeigen, in denen die Zygotenmembran nicht - wie anscheinend bei der Mehrzahl der pennaten Diatomeen - später aufgelöst wird oder zerreißt, sondern dehnbar ist und vom heranwachsenden Perizonium passiv erweitert wird. Das aber ist unter den bisher näher untersuchten Pennaten nur bei den Tabellarioideen der Fall, und zwar bei allen sieben Arten aus drei Gattungen, die wir näher studierten (v. STOSCH 1958c, 1962 und v. STOSCH \& Mitarbeiter, unveröffentlicht). Hier werden, wie bei den Centrales, in allen Fällen rundliche Kieselschuppen in die Zygotenmembran während ihrer isometrischen Wachstumsphase eingelagert.

Der Unterschied zwischen den Auxosporen dieser Pennaten und denjenigen anisometrischer Centrales besteht also darin, daß Schuppen und Bänderstrukturen bei 
ersteren in getrennten Schichten liegen, bei letzteren aber miteinander verwachsen. Da es naheliegt, beide Typen von Bänderstrukturen als homolog anzusehen, können wir bei den erdgeschichtlich älteren Centrales von einem Präperizonium sprechen (siehe auch v. Stosch \& Kowallik 1969, pp. 469-470), das also ein in die Auxosporenhülle integriertes Schichtsystem darstellt. Im einzelnen macht das Präperizonium von Cbaetoceros insofern einen primitiveren Eindruck, als alle Bänder bis auf das erste komplette Ringe darstellen, während bei dem Perizonium von Rbabdonema arcuatum der am besten untersuchten Pennate, nur das zweite Band noch fast geschlossen sein kann (v. Sтолсн 1962, Tafel 2, Fig. 14), die übrigen Perizoniumbänder aber Halbringen von Chaetoceros entsprechen. Die „Ringelperizonien“ vieler Pennales sind also nicht mehr als absolute Neubildung aufzufassen, wie dies früher (v. Sтозсн 1962) angenommen wurde, da sich bei den anisometrisch wachsenden Centrales bereits ähnliche Strukturen finden.

Insoweit sind die Auxosporenhïllen der Centrales von denjenigen der Pennales durch das Alternativmerkmal „einfach" gegen „in zwei getrennten Schichten ausgebildet" eindeutig verschieden. Bei dem Chaetoceros entwicklungsgeschichtlich nahestehenden Bacteriastrum fand Drebes (1972) jedoch, daß die an einer Borstenpforte ansitzende Zygote sich innerhalb ihrer kugelförmigen primären Hülle auf eine bikonvexe (Terrinen-)Form mit schwächerer Krümmung ihrer distalen, stärkerer ihrer proximalen Fläche zusammenzieht. Die Hülle der derart verkleinerten Zelle ist in ihrem distalen Teil aus zur Pervalvarachse der Auxospore symmetrischen, einander dachziegelartig deckenden konzentrischen Ringen aufgebaut, während ihr proximaler Teil im Wasserpräparat keine Struktur erkennen läßt. Da diese Bandsysteme bei Bacteriastrum im Gegensatz zu jenen von Chaetoceros in einer von der primären Auxosporenhiille durch einen Abstand getrennten eigenen Hülle liegen, müssen wir sie dem Gesagten und der bei v. Stosch \& Kowallik (1969) gegebenen Definition gemäß als Perizonium bezeichnen. Damit wäre dann die scharfe Trennung zwischen Centrales und Pennales im Merkmal Auxosporenhüllen durchbrochen. Allerdings sehen wir darin keinen Grund, die taxonomische Unterscheidung zwischen den beiden großen Diatomeengruppen aufzugeben.

Den zugehörigen vegetativen Zellen entsprechend unterscheidet sich das Präperizonium von Chatoceros und das Perizonium von Bacteriastrum durch die bilaterale Symmetrie im ersten, die radiäre im zweiten Falle. Während jedoch die Notwendigkeit derartiger Strukturen für die Ausbildung der biradiaten Chaetoceros-Erstlingszelle einleuchtet, ist das bei dem multiradiaten Bacteriastrum nicht der Fall. Ahnliche Formen wie diejenige der Bacteriastrum-Erstlingszelle werden (wenn man von den später entwickelten Borsten absieht) bei den Coscinodiscaceen direkt von der kugeligen primären Auxospore aus durch die beiden metagamen Mitosen allein entwickelt. Das Perizonium von Bacteriastrum hat daher den Charakter eines Rudimentes, der sich vermutlich in der Folge eines stammesgeschichtlichen Überganges von der biradiaten zu einer multiradiaten Zellorganisation herausbildete. Bacteriastrum wäre also durch Erwerb einer sekundär höheren Symmetrie und durch die Trennung von Befruchtungsmembran und Perizonium über die Entwicklungsstufe von Chaetoceros hinaus fortgeschritten. Das Perizonium von Bacteriastrum ist demjenigen der Pennales nur durch seine Eigenständigkeit, nicht aber durch seine Gestalt ähnlich, und diese Besonderheit könnte man 
terminologisch etwa durch „Paraperizonium" auszeichnen, sollte aber „Präperizonium" (DREBES 1972) vermeiden.

Wir besprechen weiter einige Probleme der Schalenmorphogenese, die an unserem Objekt besonders deutlich zu erkennen sind. Mehrere Schalentypen im Lebenskreislauf werden hier nicht nach Cytokinesen, sondern durch acytokinetische Mitosen gebildet. Da kürzlich über die verschiedenen Möglichkeiten der Schaleninduktion berichtet wurde, wie sie nach dem Satz Geitlers: „Keine Schalenbildung bei Diatomeen ohne Mitose" realisiert sind (v. STOSCH \& KowALlik 1969) können wir diese Zusammenhänge als bekannt voraussetzen. Wir werden uns jedoch später noch mit dem Problem der zellmechanischen Ursachen dieses Satzes zu beschäftigen haben.

Wie bereits in v. STOSCH \& Kowallik (1969) herausgestellt wurde, sind bei Diatomeen nicht alle Kieselsäureausscheidungen von Mitosen abhängig. $\mathrm{Zu}$ den Ausnahmen gehören die Auxosporenhüllen mit ihren Schuppen und Bändern sowie die Zwischen- und Gürtelbänder, wobei die letzte Gruppe zwar von einer vorausgegangenen Valvenbildung abhängig ist, ihr aber nicht zwangsläufig folgt, wie die Mehrzahl der Dauersporenformen zeigt. Abhängig von Mitosen sind aber alle Valvenbildungen. Von den vier bekannten Schalen induzierenden Mitosetypen werden in der Schalenmorphogenese von Chaetoceros nur zwei, vegetative äquale Zellteilungen und acytokinetische Mitosen, beobachtet; Inäqualteilungen mit kernhaltiger Kleinzelle, wie z. B. bei der Dauersporenbildung ron Stephanopyxis (v. Stosch \& Drebes 1964), oder solche mit kernloser Kleinzelle (vgl. v. STosCH \& Kowallik 1969) kommen nicht vor. Jede dieser beiden Mitosetypen kann bei $C$. didymum mehrere morphologisch unterschiedene Schalenformen produzieren.

Nach äqualen Teilungen entstehen folgende Schalentypen: (1) normale Schalen im Inneren der Kolonie, (2) Schalen, die sich von den ersteren nur durch Haltung und Dicke der Borsten unterscheiden („Sonderborsten“); (3) Endschalen bei Kolonieteilungen, die durch Borstenrichtung und Stärke, die Filamente und einen zentralen Porus von den Innenschalen verschieden sind; (4) die Heterovalven der Dauersporen-Mutterzellpaare, abweichend durch enge Fenster, geringe Ausbildung der Protuberanz, die Kiesellamellen im Fenster, Borstenform und -richtung und das Fehlen der Achselfächer; (5) schließlich die nach der ersten Spermatogonangienteilung fakultativ ausgeschiedenen sehr dünnen Schalen, die meist keine Protuberanz und nie Borsten besitzen.

Alle genannten Valven können heterovalvat entstehen. Bei den unter (2), (4), (5) genannten ist dies immer der Fall. Um zu erläutern: normale Schalen entstehen heterovalvat (v. STOSch \& Drebes 1964, p. 232), wenn sich eine einzellige „Kolonie "zur zweizelligen Kolonie teilt, wie nach der Dauersporenkeimung oder bei der Teilung der Erstlingszelle. Umgekehrt würden Endschalen isovalvat entstehen, wenn in einzelligen „Kolonien " als erste Teilung eine Trennteilung abläuft, was zwar nicht gesehen wurde, aber wahrscheinlich vorkommt.

Acytokinetisch werden die beiden Valven der Erstlingsschale gebildet, die, soweit bekannt, bei $C$. didymum den normalen Endschalen nach vegetativen Trennteilungen ähneln, von diesen jedoch vor allem infolge ihrer andersartigen Morphogenese abweichen. Bei anderen Diatomeen, wie z. B. C. eibenii und Bacteriastrum (siehe p. $427 \mathrm{f}$ ) können diese Schalen viel stärker von Normalschalen verschieden sein. Doch ist auch bei C. didymum (6) die erste Schale nach dem Auswachsen der Borsten konkav gekrümmt 
(Abb. 18aa), scheint aber später in die gewöhnliche Form umzuspringen; Einzelheiten sind jedoch nicht bekannt. Sie ist übrigens neben der Hypovalva der keimenden Dauerspore die einzige Valva, die den Gürtel ohne Anwesenheit einer Gegenschale ausbildet; (7) ist die zweite Valva in der Auxospore hinsichtlich der Borstenentwicklung ungewöhnlich. Ferner entstehen (8) Endschalen im acytokinetischen Typ der Trennteilung und ebenso (9) bei den Dauersporenkeimungen. Schließlich werden acy tokinetisch (10) die Dauersporen-Epivalva und (11) die entsprechende Hypovalva gebildet, die beide morphologisch stark voneinander und von allen übrigen Schalen verschieden sind. Faßt man (6)-(9) als Endschalen zusammen, so iberschneiden sich äquale und acytokinetische Valvenentstehungen nur bei den Endschalen. Hier ist das Ergebnis, soweit bekannt, im wesentlichen unabhängig davon, ob es durch Cytokinesen oder durch innere Mitosen erzielt wird.

Faßt man trotz der bestehenden morphologischen und entwicklungsgeschichtlichen Unterschiede alle Endschalen zu einem Typ zusammen, dann verfügt $C$. didymum immerhin noch über die genetische Information für insgesamt sieben Valventypen. Darüber hinaus besteht für C. didymum die Möglichkeit, nach mitotischen Kernteilungen während der Spermatogenese keine Schalen zu bilden. Es scheint, daß unsere Art (neben einigen anderen Chaetoceros-Arten) hinsichtlich der vielfältigen Valventypen das Maximum unter Diatomeen darbietet.

Uber die Mechanismen, welche zur jeweils „gewünschten“ Schalenform führen, ist wenig bekannt. Wahrscheinlich wird in den meisten Fällen der jeweilige Valventyp bereits durch die Gestalt der Furche bzw. der Plasma-Oberfläche bestimmt, die sowohl bei der normalen Cytokinese als auch nach der ihr morphogenetisch analogen acytokinetischen Spontanplasmolyse freigelegt wird. Für die Furchungen kann dies besonders deutlich an der Bildung der Heterovalven für die Dauersporen-Mutterzellen gezeigt werden. Die sich entwickelnde Teilungsfigur ist fast von Anfang an von derjenigen bei der Zellteilung verschieden. Nach der ersten Sporangienmitose wird das unterschiedliche Resultat etwas später sichtbar. Bei den acytokinetischen Mitosen sieht die Rückzugskuppe des Protoplasten unter ähnlichen äußeren Bedingungen verschieden aus, wenn sich einerseits eine normale Valva (Endschale) und andererseits eine SporenEpivalva bilden soll. Auch das Ergebnis der inneren Mitose für die Sporen-Hypovalva ist eine eng lokalisierte Konvexplasmolyse ( $\mathrm{Abb} .12 \mathrm{j}$ ), wie sie sonst nirgends vorkommt. Die besondere Form dieser Valva kann wohl kaum allein durch den in diesem Falle herrschenden Raummangel erklärt werden.

Furchungen und gerichtete Plasmolysen haben also morphogenetischen Charakter, eine der Besonderheiten in der Formbildung der Diatomeen.

Die fertigen Plasmaoberflächen geben allerdings nur eine erste Näherung der endgültigen Valvenform. Diese Primärgestalt wird, wie auf p. 397 f. für Kolonie-Innenschalen geschildert, durch die anschließende Ausbildung der verkieselten Zellwand umgeformt.

Fragen wir nach dem Determinationszeitpunkt für die Alternative zwischen zwei möglichen Schalenformen, so wird anscheinend die Trennteilung dann eingeleitet, wenn die Kolonie eine den Außenbedingungen konforme Größe erreicht hat. Eine von mehreren sich früher oder später teilenden Einzelzellen muß dann das Signal "Trennschale bilden" von der Kolonie erhalten. Es ist dies auch die einzige Teilung, deren späteres 
Resultat nicht schon in der Gestalt der Furche sichtbar wird, und es kann nicht ausgeschlossen werden, daß die Bestimmung der zu bildenden Schale selbst kurz nach der Furchung noch unentschieden ist. Einige Zeit nach der Bildung der Protuberanzen und noch vor Beginn des Borstenwachstums entfernen sich die Tochterschalen voneinander, wahrscheinlich wegen des Auswachsens der Kieselfilamente, womit das Verwachsen der später entstehenden Borsten verhindert wird. Diese Filamente kennzeichnen aber gerade den besonderen Schalentypus. Die seltene acytokinetische Trennung (vgl. p. 401) wird möglicherweise durch ein "Notsignal" verursacht und läßt die betreffende Zelle im frühreifen, d. h. wenig gestreckten Zustand zur inneren Teilung und damit zur Bildung von nur einer End- und Trennschale kommen.

Andere Spezialvalwen werden offenbar als Folge einer Prozeßkette determiniert. Bei den beiden Dauersporenschalen geschieht dies spätestens kurz vor der heterovalvaten Bildung der Mutterzell-Hypovalven, wodurch dann die beiden morphogenetischen Acytokinese-Schritte im voraus festgelegt sind; bei den metagamen Mitosen ist die Ursachenkette noch läger. Sie beginnt einerseits mit der Induktion zur männlichen Entwicklung mit ihren zahlreichen Cytokinesen und andererseits mit dem Einsetzen der Oogenese. Alle diese Sonderschalen entstehen, soweit bekannt, alternativ oder höchstens zweimal hintereinander (metagame Mitosen, Sporenkeimung) im Wechsel zu dem vorher gebildeten Schalentyp.

Es bleibt noch die Frage zu erörtern, warum für jede Valvenentstehung eine vorausgehende Mitose, und sei es in Form einer Acytokinese, nötig ist. Zunächst muß allerdings darauf hingewiesen werden, daß der Zusammenhang Mitose-Valvenbildung neuerdings in Frage gestellt wurde, bzw. als Spezialfall einer noch allgemeineren Gesetzmäßigkeit angesehen wird: OEY \& SCHNEPF (1970) nahmen an, daß nicht erst die Mitose, sondern bereits ein früheres Ereignis, der Übergang von der $2 \mathrm{C}$ - in die $4 \mathrm{C}$ Phase des Kernes Valvenbildung induziere. Die zentrische Diatomee Cyclotella cryptica bildet unter Colchicin-Einfluß von 24 (bzw. 48) Stunden Dauer in $20 \%$ (bis 30\%) der Zellen "Lateralschalen". Die betreffenden Zellen sind langgestreckt, tragen an der Oberfläche einer äquatorialen Einschnürung einen breiten Ring mit Valvenstruktur und enthalten einen $4 \mathrm{C}$-Kern (seltener $2 \mathrm{C}$-Kerne). Die Autoren nehmen nun an, diese 4 C-Kerne seien Ergebnis einfacher Colchicin-Mitosen, d. h. einer Chormatidentrennung unter Ausfall der Kernteilung. Solche Zellen sollen zu einem Zeitpunkt, über den nur Vermutungen geäußert werden können, die ringförmigen Lateralschalen deponieren. Wir müssen aber feststellen, daß der zur Entstehung der $4 \mathrm{C}$-Kerne implizierte Modus unbewiesen ist. Er gründet sich (OEY \& SCHNEPF 1970, p. 205) nur auf das Postulat: "Colchicin blockiert die Mitose und die Cytokinese", nicht aber auf direkte Beobachtung, abgesehen von derjenigen, daß die Zellenzahl unter Colchicinwirkung nicht oder kaum mehr erhöht wird. Wir vermuten dagegen nach unseren Erfahrungen an anderen Diatomeen, daß hier eine Mitose und anschließend eine unvollständige Cytokinese abgelaufen ist. Auch bei Stephanopyxis (v. STоSCH unveröffentlicht) führen (spontan) nicht zu Ende geführte Cytokinesen zu ringförmigen „Lateralschalen“, und die oben erwähnte Einschnürung bei Cyclotella scheint uns geradezu Indikation für eine vorhergegangene unvollständige Furchung zu sein. Im einheitlichen Zellraum würden Tochterkerne dann aufeinander zuwandern und durch Fusion sekundär in den $4 \mathrm{C}$-Zustand gelangen können. Solches ist nach unvollständigen diploiden Cytokinesen 
an Spermatogonen von Melosira moniliformis (v. SToscr 1958b, p. 275) und Lithodesmium undulatum (MaNToN et al. 1969a, p. 299 oben, dort allerdings nicht ausführlicher geschildert) im Leben gesehen worden. Die zweikernige Zelle von Cyclotella der Abbildung $5 \mathrm{c}$ bei Oey \& Schnepf (1970) könnte sogar als ein Teilungsstadium interpretiert werden, welches zu einer Zelle wie in Fig. $5 b$ führt. Nur die aufgefundenen $4 \mathrm{C}$-Zellen ohne Lateralschalen stellen nach unserer Auffassung Ergebnisse echter C-Mitosen dar. Für Dauerbeobachtungen am lebenden Objekt, dem einfachsten Weg zur Entscheidung für oder wider die Auffassung der Heidelberger Autoren, ist Cyclotella cryptica wegen ihrer geringen Größe leidex wenig geeignet.

Wir nehmen also weiterhin an, daß nach Gertukers Satz die Valvenbildung von einer Mitose abhängig ist. Mögliche Gründe für diesen Zusammenhang wurden früher (v. STOsсH \& KowAllik 1969) diskutiert und brauchen dabei im einzelnen nicht wiederholt werden. Hervorgehoben sei aber, das wurde auch im Vorhergehenden deutlich, daß die Mitose durch die von ihr eingeleiteten gerichteten Plasmolysen Oberflächen spezifischer Gestalt schaff, die dann gleichsam als embryonale Vorstufen für die Schalenbildung selbst dienen. Im Falle der Endschalen ist die Gestalt dieser Menisken unabhängig davon, ob sie durch eine Zweiteilung oder durch eine innere Mitose hervorgerufen werden, obwohl diese beiden Prozesse voneinander sehr verschieden ablaufen. Derart entstandene Menisken können als notwendige Voraussetzung für diese oder jene Schalenform angesehen werden und können in ihrem morphogenetischen Charakter offenbar nur durch Mitosen bewirkt werden. Künstlich erzeugte Oberflächen sind, soweit bekannt, als solche nicht in der Lage, Schalen zu bilden.

Auf dem Niveau der cytologischen Organisation der Zelle muß noch das merkwürdige, die Tochterkerne verbindende Granum diskutiert werden, auf das wir bei den Dauersporen-Acytokinesen (Abb. 24a), einer metagamen Mitose (Abb. 25a) und nach den meiotischen Kernteilungen im Oogon (Abb. 19f, g und Abb. 20a, b) aufmerksam wurden, da dieses möglicherweise für den Zusammenhang Mitose-Valvenbildung von grundlegender Bedeutung ist. Daß die Granen überhaupt beobachtet werden können, hängt wahrscheinlich damit zusammen, daß die Bouin-Fixierung extranukleäre Strukturen verhältnismäßig gut erhält.

Zunächst einige ergänzende Beobachtungen: Nicht nur nach Acytokinesen, sondern auch nach normalen Cytokinesen sieht man mit den Tochterkernen anscheinend verbundene Grana, die nahe der Plasmaoberfläche meist in der Mitte der prospektiven Schalen liegen (Abb. 25b). Es besteht dann einmal die Möglichkeit, daß diese Körnchen in bezug auf die Teilungsfigur äquatorialer Herkunft sind und damit den Enden der Halbspindeln nach Art der Flemming-Körper tierischer Zellen entsprechen oder daß sie - auf den ersten Blick weniger plausibel - von den Polen der Teilungsfigur stammen und centrosomenähnlichen Charakter haben.

Für die erste Möglichkeit spräche vor allem die Analogie zum Phragmoplasten vieler anderer pflanzlicher Zellen. Weniger wahrscheinlich wird sie aber bereits durch Abbildung 25b, in der die Granen der beiden Tochterzellen nicht genau einander gegenübersteken. Sucht man nun nach etwas früheren Telophasen, in denen die Tochterzellen noch nicht völlig getrennt sind (Abb. 24a), so erkennt man, daß die Plasmabrücke, in der die - im Präparat unsichtbare - Spindel liegt, räumlich von den weiter rechts an der Plasmaoberfläche der Furche placierten Granen entfernt ist. Es scheint, daß sich die 

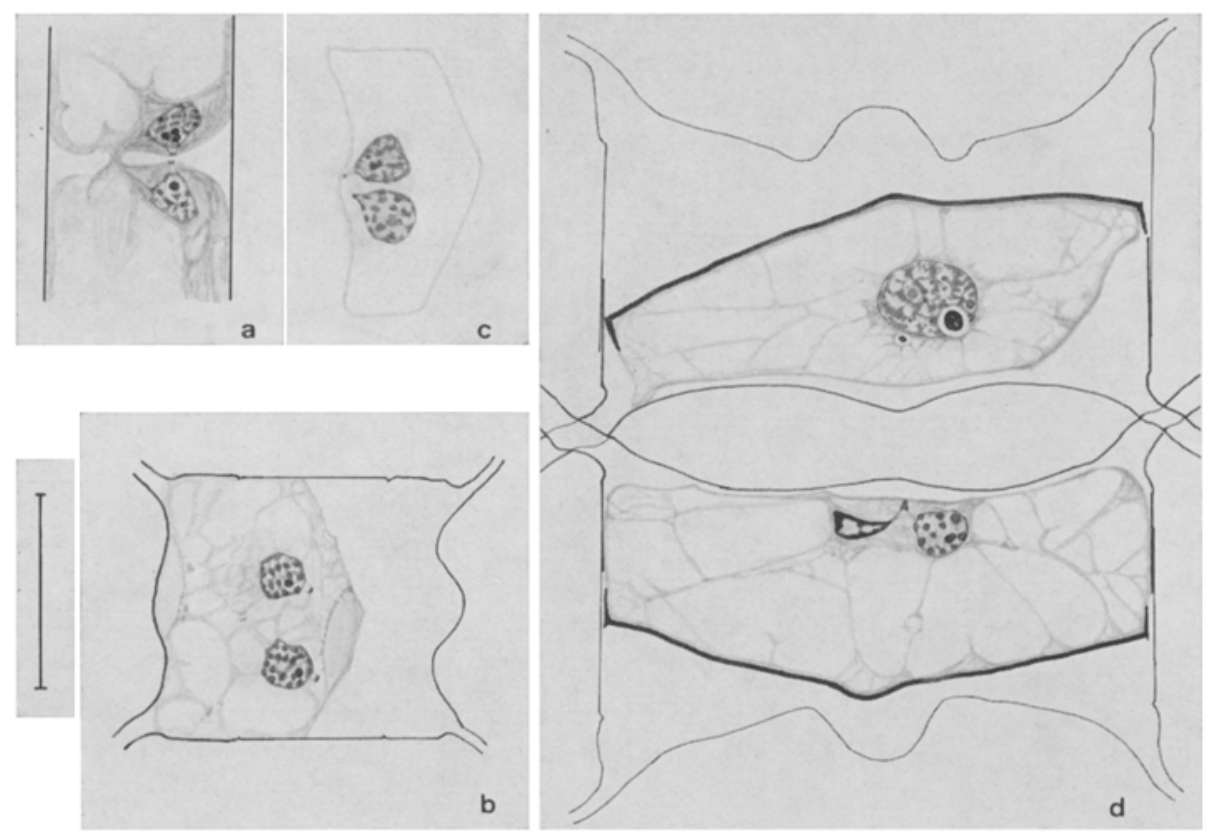

Abb. 24: Chatoceros didymum. (a) Späre Telophase einer vegetativen Teilung. Plasmabrücke zwischen den Tochterzellen noch vorhanden; rechts Tochterkerne mit anhängenden Grana beiderseits an Teilungsspalt. Optischer Schnitt in etwa $45^{\circ}$ zur Apikalebene. (b) DauersporenMutterzelle in später Telophase der ersten acytokinetischen Mitose. Jeder der beiden Tochterkerne mit Granum verbunden und zu der durch induzierte Plasmolyse gebildeten Plasmakuppe (rechts) gerichtet; in dieser Pyrenoid, ebenso in der Protuberanz gegeniiber. (c) Z weite SporenAcytokinese. Kerne und Granen einander bereits stärker genähert und an Rückzugsmeniskus liegend; nur Plasmaoberflächen eingezeichnet. (d) Dauersporenpaar kurz nach zweiter acytokinetischer Mitose. Untere Zelle im Stadium etwas später als (c); beide Kerne hängen jetzt an einem im Zentrum der prospektiven Schale liegenden Granum, der linke in beginnender Pyknose. Obere Spore mit überlebendem Kern, rechts über ihm der pyknotische Kern der zweiten Mitose, links unten neben ihm wahrscheinlich derjenige der ersten sporenbildenden Mitose. Bouin-EKE; (Maßstab $10 \mu \mathrm{m}$ )

'Teilungsfigur ringförmig einkrümmte und dadurch die beiden Granen an die Zelloberflächen gebradt worden sind. Sie wären danach polarer Herkunft und centrosomenartiger Natur. Später, wenn Schalen und Borsten bereits ausgebildet sind, kann man das Granum immer noch mit dem zu ihm ausgezogenen Kern verbunden wiederfinden (Abb. 25c). Das Granum scheint also ein im Zellzyklus zumindest nicht kurzlebiges Organell zu sein. Um ein echtes Centrosom, das ein der Geißelbasis homologes Centriol enthalten müßte, handelt es sich nach den Befunden an Litbodesmium (MANToN et al. 1969 a b, 1970a, b) sehr wahrscheinlich nicht. Geißelbasen treten dort nur unmittelbar vor dem Auswachsen der Spermiengeißeln - in ihrer spezifischen Organisation de novo - auf.

Die von uns beobachteten Granen lassen sich am besten mit den "Centrosomen" vergleichen, die LAUTERBORN (1896) in immer noch unübertroffenen Beobachtungen an der großen pennaten Kieselalge Surirella studierte und durch den Zellzyklus verfolgte. 


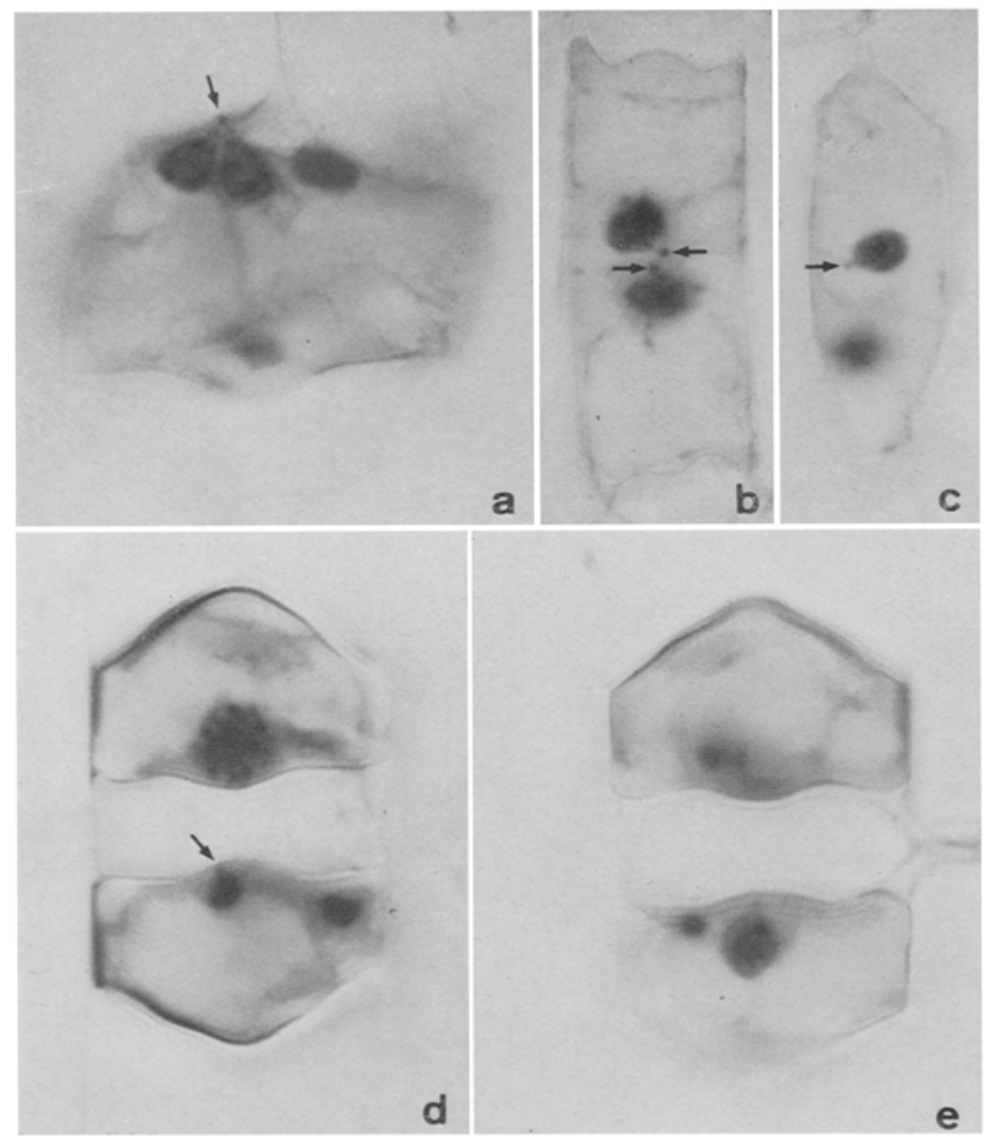

Abb. 25: Chaetoceros didymum. (a) Telophase der zweiten metagamen Mitose. Die Tochterkerne hängen am Granum (Pfeil), das in Plasmaoberflache der Rückzugsfront liegt. Untere Begrenzung stellt erste Schale der Erstlingszelle dar, darunter gewölbte Auxosporenmembran. (b) Späte Telophase einer vegetativen Zellteilung; Kerne mit Granen (Pfeile) verbunden an Plasmagrenzen, die hier bei Fixierung aufeinandergefallen sind. (c) Ahnliche Zelle, weiter entwickelt. Kern nach Ablösen von Plasmaoberfläche noch mit Granum (Pfeil) verbunden; Verhältnisse in unscharf eingestellter Schwesterzelle ähnlich. (d) Dauersporenpaar. Obere Zelle in Prophase zur zweiten sporenbildenden Acytokinese; unten in früher Telophase, linker Kern mit Granum (Pfeil) an Plasmaoberfläche. (e) Dauersporenpaar. Untere Spore einige Zeit nach zweiter Acytokinese; links pyknotischer Kern nahe Plasmaoberfläche. (Bouin-EKE; $1500: 1$ )

Wir werden nach Manton et al. (1970b) für das Lauterbornsche "Centrosom" den Terminus „Paracentrosom“ verwenden. Dieses wurde durch Drum et al. (1966) elektronenmikroskopisch an einer Surirella untersucht: Gegenüber einem echten Centrosom ist es bei Surirella aber von völlig unähnlicher Struktur. Bei Lithodesmium (MaNToN et al. 1969), aber auch anderen pennaten Diatomeen besitzt es keine besonders auffälligen feinstrukturellen Eigenschaften (DRuM et al, 1966).

Das Paracentrosom von Surirella gelangt nach der Cytokinese durch Drehung des Kernes, mit dem es durch Strahlung (nach Drum et al. wohl aus Tubuli bestehend) verbunden ist, von seiner polaren Lage am Ende der Spindel schließlich zwischen Kern 


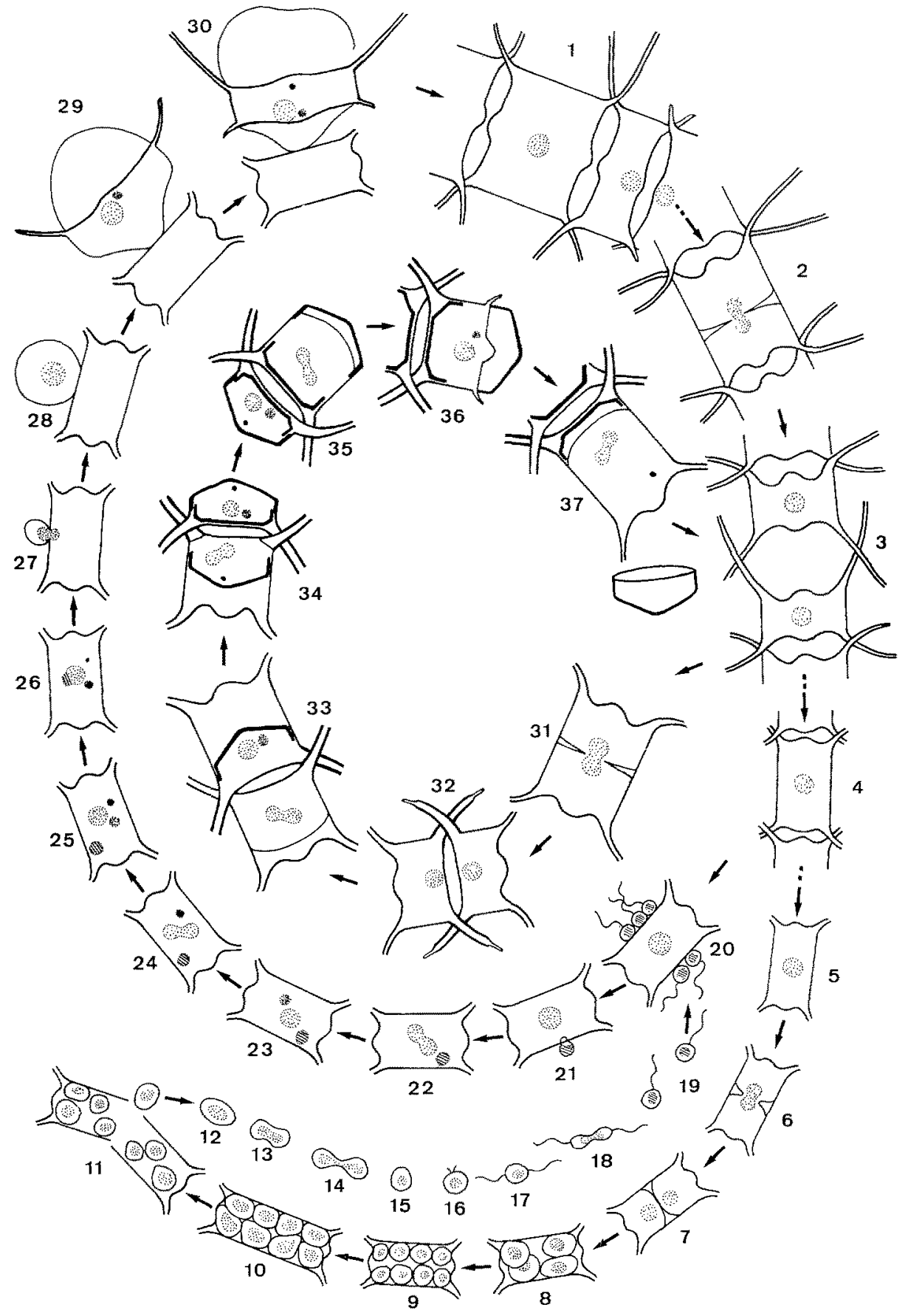

Abb. 26 
und Furchungsfläche. Es bleibt allerdings weiter von dieser entfernt als das Granum von Chaetoceros und sendet dann "Strahlungen" auch in das Plasma gegen die prospektive Schale hin aus. Nach LAUTERBorn ist das Paracentrosom bei Surirella während großer Teile des Zellzyklus auch im Leben sichtbar, konnte aber im Zeitraum der Entwicklung der Zentralspindel von später Prophase bis zur Anaphase auch färberisch nur schwer vom Material der Spindelpole unterschieden werden. Aus dem möglicherweise gleichen Grunde können wir unsere Grana an den beiden, stärker färbbaren Polkappen der Metaphase und Anaphase von Chaetoceros nicht identifzieren und verzichten daher auf die Wiedergabe solcher Stadien. Das Paracentrosom der LitbodesmiumSpermatogone und -Spermatocyten verschwindet anscheinend während der Entwicklung der Spindel völlig zugunsten des spindle precursor und ist dann auch elektronen-

Abb. 26: Chaetoceros didymum. Schematische Darstellung des Entwicklungszyklus. Auf die zeichnerische Darstellung der Zweischaligkeit des Kieselskelettes wurde mit Ausnahme der Dauersporen verzichtet; außerdem wird bei den Teilabbildungen 5-11 und 20-34 nur die jeweilige Zelle abgebildet; die Art der Verwachsung ihrer Borsten mit denjenigen der Nachbarzellen ergibt sich aus den Teilabbildungen 1-4. Pyknotische Kerne sind zum Unterschied zu überlebenden Kernen dichter punktiert oder schwarz ausgezeichnet; die Kernteilungsstadien sind in ihrem Umriß, nicht jedoch mit Spindel und Chromosomen dargestellt. 1-5 Vegetative Vermehrung. 1 Kolonie maximaler Breite, aus Auxospore hervorgegangen; linke Zelle in prophasischer Streckung, rechtes Zellpaar post-telophasisch mit beginnender Borstenbildung. 2 Zellteilung; Anaphase mit Plasmafurchung. 3 Trennteilung mit bereits ausgewachsenen Endborsten. 4-5 Durch Zellverkleinerung entstandener Klon vor Eintritt in die sexuelle Phase. 6-19 Sexuelle Vermehrung: S permatogenese. 6 Anaphase der ersten Spermatogonangienmitose mit Plasmafurchung. 7 Spermatogonangium mit zwei Spermatogonien. 8 Spermatogonangium mit vier Spermatogonien. 9 Spermatogonangium mit acht Spermatogonien. 10 Schwellungsphase; Spermatogone prämeiotisch ("primäre Spermatocyten "). 11 Geöffnete Schale der Mutterzelle. 12-14 Erste meiotische Teilung führt zu "sekundären Spermatocyten". 15-17 Interphase der sekundären Spermatocyten mit Bildung der Geißeln. 18 Anaphase der zweiten meiotischen Teilung. 19 Befruchtungsfähiges Spermium. 20-26 Sexuelle Vermehrung: Oogenese und Befruchtung. 20 Von Spermien umschwärmtes Oogon in meiotischer Prophase; Spermakerne schraffiert. 21 Spermium dringt in Oogon ein. 22 Anaphase der ersten meiotischen Teilung im Oogon; Spermakern schraffiert. 23 Interphase zwischen erster und zweiter meiotischen Teilung mit pyknotischem Kern. 24 Anaphase der zweiten meiotischen Teilung. 25 Reifes Oogon mit Spermakern (schraffiert) und zwei pyknotischen Kernen. 26 Verschmelzung von Ei- und Spermakern. 27-30 A uxosporen-Entwicklung und Bildung der Erstlingszelle. 27-28 Zygote schlüpft seitlich aus der Mutterzelle aus. 29 Zygote (Auxospore) nach erster acytokinetischer (metagamer) Mitose und Bildung der ersten Theka; pyknotischer Kern dicht punktiert. 30 Erstlingszelle nach zweiter acytokinetischer Mitose mit zwei pyknotischen Kernen; Borsten der Hypotheka wachsen aus. 31-34 Dauersporen-Bildung. 31 Anaphase mit steilem Furchungsspalt, führt zur Bildung einer Dauersporen-Paarmutterzelle. 32 Dauersporen-Paarmutterzelle mit auswachsenden derben Borsten. 33 Untere Zelle während der ersten acytokinetischen Mitose (Anaphase) und beginnender Plasmakontraktion; obere Zelle nach erster acytokinetischer Mitose und Bildung der Dauersporen-Epivalva; pyknotischer Kern dicht punktiert. 34 Untere Zelle während der zweiten acytokinetischen Mitose und beginnender Plasmakontraktion nahe Mutterzell-Hypovalva; pyknotischer Kern als schwarzer Punkt dargestellt. Obere Zelle nach zweiter acytokinetischer Mitose und Bildung der Dauersporen-Hypovalva; beide pyknotischen Kerne abgebildet. 35-37 Dauersporenkeimung. 35 Dauersporenpar nach Ruheperiode; pyknotische Kerne in der oberen Zelle inzwischen resorbiert. Untere Dauerspore noch ungekeimt, obere Dauerspore nach Streckung in erster acytokinetischer Mitose (Anaphase), beginnende Plasmakontraktion. 36 Entstehung der normalen Endvalva während der Interphase; Endborsten wachsen aus. 37 Zweite acytokinetische Mitose mit beginnender Plasmakontraktion; pyknotischer Kern aus erster acytokinetischer Mitose der Dauersporenkeimung; Dauersporen-Epivalva bereits abgestoßen. Der fertige Keimling (nicht dargestellt) wäre nach Abwerfen der Dauersporen-Hypovalva eine vegetative Zelle mit zwei Paaren von Endborsten 
optisch nicht nachweisbar. Erst in der Anaphase wird es als amorphe Struktur rekonstruiert. Wir werden im weiteren die Granen von Chaetoceros als Paracentrosomen bezeichnen, obwohl wir lichtmikroskopisch nicht entscheiden können, ob sie strukturell den Paracentrosomen von Litbodesmium gleichen*.

Die nach den Acytokinesen beobachteten und mit dem Kern in Verbindung stehenden Grana sind anscheinend ebenfalls polarer Entstehung und damit Paracentrosomen. In der frühen Telophase der Abbildung 25d (zweite Acytokinese während der Dauersporenbildung) ist die Spindel noch zu erkennen. Das polare Granum nahe am linken Tochterkern hat sich dem Zentrum der prospektiven Schalen bereits genähert, während am Schwesterkern kein Granum unterschieden werden konnte. Abbildung 24b bezieht sich demgegenüber auf ein etwas späteres Kernstadium der ersten Dauersporenmitose. Die Spindel ist nicht mehr sicher erkennbar, und die beiden Kerne scheinen mit ihren Granen noch etwa gleichweit vom Meniskus entfernt zu sein. In Wirklichkeit liegen die zur Rückzugsfläche hin gerichteten Granen oberhalb der Bildebene und dort wahrscheinlich nahe der Oberfläche der Plasmakuppe. Abbildung $24 \mathrm{c}$ zeigt eine zweite Dauersporen-Acytokinese; beide Kerne und die distal von ihnen zu findenden Paracentrosomen haben sich einander und der prospektiven Valvenmitte genähert. Der rechte Kern ist vielleicht ein wenig dichter und kleiner. Danach scheinen sich die beiden Paracentrosomen zu einem Granum zu vereinigen, und der Beginn der Pyknose des einen Kernes wird deutlich (Abb. 24d, vgl. auch Abb. $5 \mathrm{c}$ in v. Stosch \& Kowallik 1969).

In der sich auf eine zweite metagame Mitose beziehenden Abbildung 25a ist nur ein Granum zu erkennen; die anhängenden Kerne sind aber noch gleichartig. In allen diesen Bildern sind die Kerne zum Paracentrosom hin mehr oder weniger ausgezogen und wahrscheinlich durch Fibrillen mit der Kernoberfläche verbunden. Da die Paracentrosomen bei diesen merkwürdigen Kernwanderungen vorauseilen, muß man wohl annehmen, daß die zugehörige Motorik in ihnen lokalisiert ist oder an ihnen ansetzt und daß die Kerne dadurch nachgezogen werden. Zuletzt löst sich der abgerundete pyknotische Kern von Granum ab, während der überlebende weiter mit diesem verbunden bleibt (Abb. 25e) und mit ihm etwas zum Zellinneren hin abgerïckt ist.

Diatomeen anderer Gattungen wurden hinsidhtlich des Paracentrosoms bisher noch nicht untersucht, doch scheinen bei der Bildung der Dauersporen von C. costatum ähnliche Verhältnisse wie die hier geschilderten zu bestehen.

Eine Kernpyknose wird immer erst deutlich, wenn die beiden Paracentrosomen nach ihrer Annäherung optisch nicht mehr getrennt wahrgenommen werden können und die Kerne dadurch selbst größte gegenseitige Nähe erreicht haben. Es sei daran erinnert, daß auch nach der ersten meiotischen Teilung im Oogon die Tochterkerne vor und während der Degeneration des einen von ihnen über ein Granum verbunden sind (Abb. 19f, g; Abb. 20). Vermutlich handelt es sich auch dort um ein Doppel-Paracen-

* Vermutlich entspricht der von Crawrord (J. Pycol. 9, 50 [1973]) am Ruhekern von

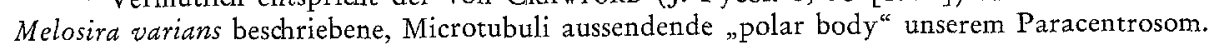


trosom, was aber durch Zwischenstadien nicht belegt werden kann; nur die vorhergehende Kernwanderung wurde im Leben beobachtet. Bei anderen Diatomeen haben wir, vermutlich wegen der Wahl des Fixierungsmittels, keine Beteiligung von Granen nachgewiesen, wohl aber in einigen Fällen aufeinander zuwandernde Kerne vor und deren gegenseitige Nähe während der Pyknose im Oogon gesehen. Für Pyknosen bei Diatomeen ist jedoch ein Kernkontakt keine conditio sine qua non, denn es gibt Fälle, bei denen bereits die Degeneration einsetzt, wenn die Kerne noch auf Distanz liegen, manchmal bei noch sichtbarer Telophasespindel (z. B. bei Cymbella aspera, GeITLER 1956; Melosira varians, v. Sтовсн 1951; Rhabdonema adriaticum, v. STоsCH unveröffentlicht). In Stephanopyxis-Oocyten wurde dieser Fall einmal sogar als Abweichung neben der gewöhnlich stattfindenden Kontakt-Degeneration beobachtet (v. STosch \& DREBEs 1964).

Kehren wir nun abschließend zur Valvenbildung zurück, so ist festzustellen, daß sowohl nach cytokinetischen wie auch nach acytokinetischen Mitosen von Chaetoceros ein mit dem Kern verbundenes Granum, das Paracentrosom, oberflächennahe in das Zentrum der prospektiven Schale gelangt, also den Ort des Beginns der Kieselsäureausscheidung. Dies könnte die im Zellgeschehen singuläre Situation darstellen, die den Zusammenhang zwischen Schalenbildung und Mitose nach dem Satz Gertrers „verursacht" . Sie tritt unabhängig davon ein, welcher Schalentyp im einzelnen gebildet wird. Das Paracentrosom wäre dann eine Art Organisationszentrum für die Valvenbildung.

Die während der Meiosis im Oogon auftretenden Granen gelangen nicht an die Plasmaoberfläche. In diesem Fall werden aber auch keine Schalen gebildet. Da die Paracentrosomen bereits recht früh, d. h. noch vor Ende der Spontanplasmolyse in die Kuppe des Rückzugsmeniskus bei der Acytokinese bzw. in die Mitte der Furchungsfläche bei der Cytokinese gelangen, könnten sie auch in die spezifische Formbildung dieser Menisken regulierend, etwa durch die LAUTERBonNschen Strahlungen, eingreifen. Dies ist im Augenblick eine vage Vermutung, da lichtmikroskopisch und mit unseren Methoden keine Strahlungen zu sehen sind. Nicht gravierend erscheint uns jedoch, daß Tubuli in den Spermatocyten von Litbodesmium fehlen, weil diese Zellen weder spezifische Formbildungen leisten noch später Schalen ausscheiden. Diese lichtmikroskopisch nicht mehr befriedigend $\mathrm{zu}$ analysierenden Verhältnisse fordern die elektronenmikroskopische Untersuchung heraus. Die Schwierigkeit ist jedoch, daß die Stadien von Cytokinese oder Acytokinese wegen der kurzen Dauer der Kernvorgänge innerhalb des Zellzyklus zu selten sind, um Massenfixierungen lohnend erscheinen zu lassen. Man muß also entweder synchronisieren können oder zu Einzelpräparation nach vorheriger lichtmikroskopischer Stadienkontrolle schreiten.

\section{ZUSAMMENFASSUNG}

1. Der Lebenszyklus von Chaetoceros didymum EHRENBERg wird an Kulturmaterial im Leben und cytologisch untersucht, und ergänzend werden Angaben über einige andere Arten der Gattung gemacht. 
2. Licht- und elektronenmikroskopische Studien des Zellbaues liefern Grundlagen für das Verständnis der Entwicklung. Eine besondere Rolle in der Gattung spielt der Gürtel durch Ausbildung von Borstenbuchten und Borstenpforten. Dadurch wird trotz Ausstattung der Zellen mit starren Borsten, die den Gürtelzylinder überragen, eine Koloniebildung ermöglicht. Die Borstenpforten dienen außerdem als Eintrittsöffnung für die Spermien ins Oogon und als Austrittsstellen für die Zygoten, bei C. eibenii auch der Entlassung der Spermien aus dem Spermatogonangium.

3. Vegetative Teilung, äquale heterovalvate Kolonietrennteilung und ein unerwarteter Typ von acytokinetischer Trennteilung werden geschildert. Die Trennungen werden durch Bildung einer besonderen Valvenart, der Endschale, ermöglicht.

4. Dauersporen sind das Ergebnis von drei Mitoseschritten, deren erster heterovalvat und äqual ein Paar von gestaltlich differenzierten Sporenmutterzell-Hypovalven liefert. Die beiden nächsten Teilungen sind Acytokinesen (innere Mitosen), welche nacheinander die Entwidklung von Epivalva und Hypovalva der Dauerspore verursachen.

5. Die Sporenkeimung führt infolge von zwei Acytokinesen gewöhnlich zum Abwurf der beiden Sporenvalven und zu ihrer Ersetzung durch Kolonie-Endschalen, so daß einzellige "Kolonien" entstehen.

6. Die Spermatogenese folgt entweder dem Biddulphiam oder seltener dem Lithodesmium-Typ, d. h. es werden nach dem ersten Mitoseschritt im Spermatogonangium reduzierte Schalen gebildet, oder die Schalenbildung unterbleibt. Gewöhnlich entstehen in drei Teilungsschritten acht Spermatogone pro Mutterzelle, die dann das Spermatogonangium durch eine Schwellung in der späten meiotischen Prophase öffnen und die - ähnlich wie bei Litbodesmium - hologen vier eingeißelige Spermien entstehen lassen. Wie bei allen bisher untersuchten Centrales wachsen die Geißeln paarweise während der meiotischen Interphase aus. Die beiden Plastiden der Mutterzelle teilen sich nach jedem spermatogonialen Mitoseschritt einmal und nach dem letzten (d. h. vor der Meiosis) zweimal, so daß jedes Spermium im Normalfall eine Plastide erhält.

7. Das Spermium besitzt eine Flimmergeißel.

8. In der Oocyte degeneriert nach jedem Meioseschritt ein Kern, so daß eineiige Oogone resultieren. Das Spermium kann durch eine der Geißelpforten bereits im Zygotän der Meiosis eintreten; die Kernfusion folgt nach Abschluß der Meiosis im Oogon.

9. Die Zygote tritt durch die Borstenpforte als Plasmakugel aus, bleibt aber an dieser hängen und wächst weiter anisometrisch zu einer Beilgestalt heran. Dieses Wachstum wird durch ein aus Kieselsäureringen bestehendes "Präperizonium“ gestützt, welches wir als homolog dem Perizonium der Pennales betrachten. Im Gegensatz zum letzteren bleibt es mit der durch Schuppen charakterisierten Auxosporenhülle der isometrischen Wachstumsphase vereinigt.

10. Zwei acytokinetische (metagame) Mitosen innerhalb der Auxosporenhülle verursachen nacheinander die Ausscheidung der beiden Schalen der Erstlingszelle.

11. Vergleichende Betrachtungen über die Bauverhältnisse folgen im Anschluß an die einzelnen Kapitel. In der abschließenden Diskussion sind besonders frühere Beobachtungen über die Sexualität von Chaetoceros, die Morphogenese der Auxo- 
spore, der Schalenpolymorphismus und die Auslösung der Schalenbildung durch Mitosen behandelt. Beobachtungen über das Paracentrosom werden mitgeteilt und dessen mögliche Rolle bei der Schalenbildung diskutiert.

\section{ZITIERTE LITERATUR}

BĚLAǨ, K., 1926. Der Formwedhsel der Protistenkerne. Ergebn. Fortschr. Zool. 6, 1-420.

BLAsCo, D., 1970. Estudio de la morfologia de Chatoceros didymus al microscopio electrónico. Investigación pesq. 34, 149-155.

Braarud, T., 1939. Microspores in Diatoms. Nature, Lond. 143, 899.

Bruner, J., 1962. Le phytoplancton de la Baie des Chaleurs. Les Presses Univ. Montréal, Montréal, $225 \mathrm{pp}$.

Coombs, J., Lauritis, J. A., Darley, W. M. \& Volcani, B. E., 1968a. Studies on the biochemistry and fine structure of silica shell formation in diatoms. V. Effects of colchicine on wall formation in Navicula pelliculosa (BréB.) Hrrse. Z. Pflanzenphysiol. 59, 124-152.

- - - 1968b. Studies on the biochemistry and fine structure of silica shell formation in diatoms. VI. Fine structure of colchicine-induced polyploids of Navicula pelliculosa (BréB.) HILsE. Z. Pflanzenphysiol. 59, 274-284.

Cupp, E. E., 1943. Marine plankton diatoms of the west coast of North America. Bull. Scripps Instr Oceanogr. 5, 1-238.

Drebes, G., 1966. On the life history of the marine plankton diatom Stephanopyxis palmeriana. Helgoländer wiss. Meeresunters. 13, 101-104.

- 1967. Bacteriastrum solitarium Mangrn, a stage in the life history of the centric diatom Bacteriastrum byalinum. Mar. Biol. 1, 40-42.

- 1969. Stephanopyxis turris (Centrales). Geschlechtliche Fortpflanzung, Differenzierung der Oogonien, Auxosporenbildung. Inst. wiss. Film, Göttingen. Encyclopaedia Cinematographica, Film E 1344, 1-10.

- 1972. The life history of the centric diatom Bacteriastrum byalinum Lauder. Nova Hedwegia (Beih.) 39, 95-110.

Drum, R. W., Pankratz, H. S. \& Stoermer, E. F., 1966. Electron microscopy of diatom cells. In: Diatomeenschalen im elektronenmikroskopischen Bild. T. 6. Ed. by J.-G. HeLMCKE \& W. KRIEGER. Cramer, Lehre, 24 pp.

Ettr, H., Müller, D. G., Neumann, K. \& Stosch, H. A. von, 1967. Vegetative Fortpflanzung, Parthenogenese und Apogamie bei Algen. Handb. PflPhysiol. 18, 597-776.

GAARDER, K. R., 1951. Bacillariophyceae from the "Michael Sars" North Atlantic Deep Sea Expedition 1910. Rep. scient. Results Michael Sars N. Atlant. deep Sea Exped. 2 (2), 1-36.

Geitier, L., 1932. Der Formwechsel der pennaten Diatomeen. Arch. Protistenk. 78, 1-226.

- 1952. Oogamie, Mitose, Meiose und metagame Teilung bei der zentrischen Diatomee Cyclotella. Ost. bot. Z. 99, 506-520.

- 1953. Das Auftreten zweier obligater metagamer Mitosen ohne Zellteilung während det Bildung der Erstlingsschalen bei den Diatomeen. Ber. dt. bot. Ges, 66, 222-227.

- 1956. Automixis, Geschlechtsbestimmung und Pyknose von Gonenkernen bei Cymbella aspera. Planta 47, 359-373.

- 1967. Die Zweiteiligkeit der Chromatophoren bei Diatomeen und Chrysophyceen. Ơst. bot. Z. 114, 183-188.

Gran, H. H., 1897. Botanik. Protophyta: Diatomaceae, Silicoflagellata og Cilioflagellata. Norw. N.-Atlant. Exped. 24, 1-36.

- 1904. Die Diatomeen der arktischen Meere I. Teil - Die Diatomeen des Planktons. Fauna arct. 3, 511-544.

- 1908. Diatomeen. Nord. Plankt. (Bot.) 20, 1-146.

- 1912. The plankton production in the north European waters in the spring of 1912. Bull. Plankt. 1912, 142. 
Gross, F., 1937. On the life histories of some marine plankton diatoms. Phil. Trans. R. Soc. (B) 228, $1-47$.

Hargraves, P. E., 1972. Studies on marine plankton diatoms. I. Chaetoceros diadema (Ehr.) Gran: life cycle, structural morphology, and regional distribution. Phycologia 11, 247-257.

Hendey, N. I., Cushing, D. H. \& Ripley, G. W., 1954. III. - Electron microscope studies of diatoms. J1 R. microsc. Soc. 74, 22-34.

Hormes, R. W., 1967. Auxospore formation in two marine clones of the diatom genus Coscinodiscus. Am. J. Bot. 52, 163-168.

HusteDt, F., 1930. Die Kieselalgen. T. 1. In: Rabenhorst's Kryptogamenflora. Akad. Verlagsges., Leipzig, 7, 1-920.

IKARI, J., 1921. On the formation of auxospores and resting spores of Chaetoceros teres CleVE. Bot. Mag., Tokyo 35, 222-227.

- 1926. On some Chaetoceros of Japan I. Bot. Mag., Tokyo 40, 517-534.

Tyengar, M. O. P. \& Subrahmanyan, R., 1944. On the structure and development of the spines or setae of some centric diatoms. Proc. natn. Acad. Sci. India (B) 14, 114-124.

LAUTERBORN, R., 1896. Untersuchungen über Bau, Kernteilung und Bewegung der Diatomeen. Engelmann, Leipzig, $165 \mathrm{pp}$.

LEwIN, J. \& NorRIS, R. E., 1970. Surf-zone diatoms of the coasts of Washington and New Zealand (Caetoceros armatum T. West \& Asterionella spp.). Phycologia 9, 143-149.

Lohmann, H., 1920. Die Bevölkerung des Ozeans mit Plankton nach den Ergebnissen der Zentrifugenfänge während der Ausreise der "Deutschland" 1911. Zugleich ein Beitrag zur Biologie des Atlantischen Ozeans. Arch. Biontol. 4 (3), 1-470.

Mangin, M. L., 1908. Observations sur les Diatomées. Annls Sci. nat. (Sér 9: Bot.) 8, 177-219.

- 1912. Phytoplancton de la croisière du René dans l'Atlantique. Annls Inst. oceánogr., Monaco 4, 1-66.

Manton, I. \& Stosch, H. A. von, 1966. Observations on the fine structure of the marine centric diatom Litbodesmium undulatum. J1 R. microsc. Soc. 85, 119-134.

- Kowallik, K. \& Stosch, H. A. von, 1969a. Observations on the fine structure and development of the spindle at mitosis and meiosis in a marine centric diatom (Lithodesmium undulatum). I. Preliminary survey of mitosis in spermatogonia. J. Microscopy 89, 295-320.

- - - 1969b. Observations on the fine structure and development of the spindle at mitosis and meiosis in a marine centric diatom (Lithodesmium undulatum). II. The early meiotic stages in male gametogenesis. J. Cell Sci. 5, 271-298.

- -1970 a. Observations on the fine structure and development of the spindle at mitosis and meiosis in a marine centric diatom (Lithodesmium undulatum). III. The later stages of meiosis I in male gametogenesis. J. Cell Sci. 6, 131-157.

- _ 1970b. Observations on the fine structure and development of the spindle at mitosis and meiosis in a marine centric diatom (Litbodesmium undulatum). IV. The second meiotic division and conclusion. J. Cell Sci. 7, 407-443.

Meunier, A., 1910. Microplankton des Mers de Barents et de Kara. Duc d'Orleans: Campagne Arcrique de 1907. Bulens, Bruxelles, 325 pp.

- 1913. Microplankton de la Mer Flamande. Part I. Le Genre "Chaetoceros» EHr. Mém. Mus. r. Hist. nat. Belg. 7 (2), 1-55.

Mrchatlova, N. F., 1962. On the germination of resting spores of Chaetoceros lauderi Ralfs. Dokl. Akad. Nauk SSSR 143, 741-742.

Oey, J. L. \& SChNepf, E., 1970. Über die Auslösung der Valvenbildung bei der Diatomee Cyclotella cryptica. Versuche mit Colchicin, Actinomycin D und Fluordesoxyuridin (FUDR). Arch. Mikrobiol. 71, 199-213.

Pavillard, J., 1921. Sur la reproduction du Chaetoceros Eibenii Meunier. C. r. hebd. Séanc. Acad. Sci., Paris 172, 469-471.

Persidsky, B. M., 1929. The development of auxospores in the group of the centricae (Bacillariaceae). (Selbstverl.), Moskau, 16 pp.

- 1935. The sexual process in Melosira varians. Beih. bot. Zbl, 53 (A), 122-132.

ReIMANN, B., 1969. Bildung und Zusammenhang der Bacillariophyceen-Schalen. Nova Hedwigia $2,349-373$. 
Schiller, J., 1909. Ein neuer Fall von Microsporenbildung bei Chaetoceros Lorenzianum GRun. Ber. dt. bot. Ges. 27, 351-361.

Sснüтt, E., 1888. Uber die Diatomeengattung Chaetoceros. Bot. Ztg. 46, 161-170; 177-184.

Stosch, H. A. von, 1951. Entwicklungsgeschichtliche Untersuchungen an zentrischen Diatomeen I. Die Auxosporenbildung von Melosira varians. Arch. Mikrobiol. 16, 101-135.

- 1952. Die Verwendung von Chloralhydrat oder Phenol zur Aufhellung und von PhenolBalsam als Einschlußmittel für Essigkarminpräparate. Züchter 22, 269-272.

- 1954. Die Oogamie von Biddulphia mobiliensis und die bisher bekannten Auxosporenbildungen bei den Centrales. Rapp. Comm. 8. Congr. Int. Bot. Sect. 17, 58-68.

- 1956. Entwicklungsgeschichtliche Untersuchungen an zentrischen Diatomeen II. Geschlechtszellenreifung, Befruchtung und Auxosporenbildung einiger grundbewohnender Biddulphicaceen der Nordsee. Arch. Mikrobiol. 23, 327-365.

- 1958a. Einige Bemerkungen zur Phylogenie der Diatomeen. Naturwissenschaften 45, 141.

- 1958b. Entwicklungsgeschichtliche Untersuchungen an zentrischen Diatomeen. III. Die Spermatogenese von Melosira moniliformis AgardH. Arch. Mikrobiol. 31, 274-282.

- 1958c. Kann die oogame Araphidee Rhabdonema adriaticum als Bindeglied zwischen den beiden großen Diatomeengruppen angesehen werden? Ber. dt. bot. Ges. 71, 241-249.

- 1962. Uber das Perizonium der Diatomeen. Vortr. GesGeb. Bot. N.F. 1, 43-52.

- 1965. Manipulierung der Zellgröße von Diatomeen im Experiment. Phycologia 5, 21-44.

- 1970. Methoden zur Präparation kleiner oder zarter Kieselelemente für die Elektronenund Lichtmikroskopie, insbesondere von Diatomeen und bei geringen Materialmengen. Z. wiss. Mikrosk. 70, 29-32.

- \& Drebes, G., 1964. Entwicklungsgeschichtliche Untersuchungen an zentrischen Diatomeen. IV. Die Planktondiatomee Stephanopyxis turris - ihre Behandlung und Entwicklungsgeschichte. Helgoländer wiss. Meeresunters. 11, 209-257.

— \& Kowallik, K., 1969. Der von Geitler aufgestellte Satz über die Notwendigkeit einer Mitose für jede Schalenbildung von Diatomeen. Beobachtungen über die Reichweite und Überlegungen zu seiner zellmechanischen Bedeutung. Ost. bot. Z. 116, 454-474.

SubRAHMANYAN, R., 1946. On the occurrence of microspores in some centric diatoms of the Madras Coast. J. Indian bot. Soc. 25, 61-66.

Yendo, K. \& Ikari, J., 1918. Auxospore-formation of Chaetoceros debile Cleve. Bot. Mag., Tokyo 32, 145-149.

Anschrift des erstgenannten Autors: Prof. Dr. H. A. v. STоsсH

Botanisches Institut

Universität Marburg

$355 \mathrm{Marburg} / \mathrm{Lahn}$

Lahnberge

Bundesrepublik Deutschland 